Maraíssa Silva Franco

\title{
Utilização de técnicas compatíveis com o conceito de química verde na determinação de micropoluentes orgânicos em matrizes ambientais
}

Tese apresentada no Instituto de Química de São Carlos da Universidade de São Paulo, como parte dos requisitos para o título de Doutor em Química.

Área de concentração: Química Analítica e Inorgânica

Orientador: Prof. Dr. Fernando Mauro Lanças

\section{Exemplar revisado}

O exemplar original encontra-se em acervo reservado na Biblioteca do IQSC-USP 



\section{Agradecimentos}

Ao Professor Fernando Mauro Lanças, por ter me recebido em seu grupo de pesquisa e confiado no meu trabalho, me orientando ao longo desses anos e, sem dúvida, contribuindo para meu crescimento profissional.

A minha mãe, Lenice, e minha irmã, Maressa, que sempre estiveram ao meu lado, apoiando minhas decisões, me fazendo seguir em frente e acreditando sempre nos meus ideais.

Ao Rodrigo, que sonhou junto a mim todos esses anos, acreditando no meu potencial e me ajudando a superar as dificuldades. Com certeza, perfeito namorado e melhor companheiro de trabalho.

Aos amigos do CROMA, que me ofereceram não só conhecimento cientifico, mais também amizade e companheirismo, dos quais eu jamais me esquecerei.

Ao professor Álvaro que, sempre com entusiasmo, colaborou com o desenvolvimento do trabalho, discutindo dados e aperfeiçoando ideias.

Ao Dalton, por estar sempre disposto a colaborar com a pesquisa, desenvolvendo junto comigo parte desse trabalho.

À Odete, que traz consigo a alma do laboratório, sempre com uma palavra amiga e a mão estendida para nos ajudar.

Ao Alcimar, Elaine e Guilherme que se fizeram sempre presentes, me auxiliando e contribuindo para o desenvolvimento do trabalho.

À professora Eny, pela amizade e carinho dedicados a mim e ao Rodrigo.

Aos funcionários das oficinas mecânica e elétrica pelo suporte técnico prestado, sempre dispostos a solucionarem nossos problemas.

Aos funcionários da Associação Internacional de Cromatografia, NST e Protheus pela pronta disposição a colaborar.

Aos amigos Adriel, André Barbie, Antônio, Augusto, Bruno, Carol Port, Carol Rodrigues, Daniele, Felipe, Flávia, Giovana, Lucas, Meire, Ricardo Baiano, Sergio, Priscilla e Ulisses que, por apenas um período ou por todo o doutorado, dividiram momentos de preocupação, descontração e alegria comigo, proporcionando sempre dias melhores. Obrigada pela amizade. 
Aos tios, primos e amigas Campestre que sempre, com ternura e carinho, olharam por mim e minha família.

E finalmente a Deus, por ter proporcionado que meu caminho se cruzasse com o de todas essas pessoas, e tantas outras dispostas a me ajudar. Obrigada por sempre me orientar. 


\section{Lista de Figuras}

Figura 1: Classificação de tecnologias de remediação de solos e sedimentos contaminados por PCBs 22

Figura 2: Diagrama de fases genérico

Figura 3: Número de publicações referentes a sulfonamidas e lodo de esgotos durante os últimos 10

anos.

Figura 4: Esquema representativo de uma fibra de SPME em uma extração por headspace................33

Figura 5: Modos de extração propostos para SPME (a) direto, (b) headspace e (c) modo direto protegido por membrana.

Figura 6: Etapas envolvidas no procedimento de SPE (1) condicionamento do cartucho, (2) amostra, (3)

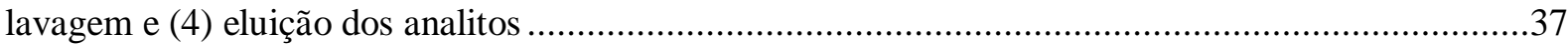

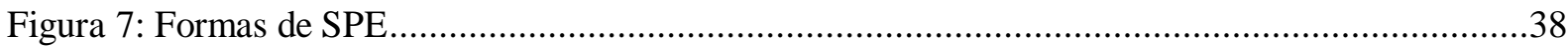

Figura 8: Configuração das válvulas nas etapas de (A) carregamento da amostra e (B) eluição dos

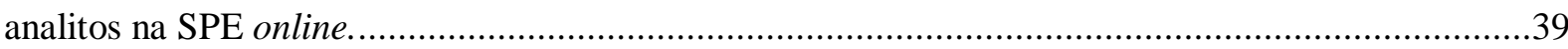

Figura 9: Estrutura de sorbentes a base de sílica .............................................................................

Figura 10: Esquema representativo de um planejamento composto central........................................48

Figura 11: Sistema "lab-made" desenvolvido para extração com fluído supercrítico. (1) cilindro de $\mathrm{N}_{2}$ (2) cilindro de $\mathrm{CO}_{2}$; (3) vaso de pressurização; (4) válvula on/off; (5) agitador para banho de água; (6) Banho de água; (7) cela de extração; (8) válvula on/off; (9) válvula micrométrica; (10) tubo coletor; (11) gerador de fluxo de ar quente.

Figura 12: Modificação no embolo utilizado para pressurização do $\mathrm{CO}_{2}$ por $\mathrm{N}_{2}$. A direita se encontra o êmbolo modificado, e a esquerda o êmbolo anteriormente utilizado.

Figura 13: Cromatograma da separação cromatográfica por GC e detecção por MS no modo SIM do (1) benzeno, (2) tolueno, (3) etilbenzeno, (4) $m$,p-xileno, (5) $o$-xileno e (6) padrão interno ...............62 Figura 14: Gráfico de Pareto referente ás variáveis dependentes (a) benzeno, (b) tolueno, etilbenzeno, (d) $m$,p-xileno e (e) $o$-xileno, com 95\% de confiança

Figura 15: Superfícies de resposta correlacionando as variáveis temperatura e quantidade de amostra, em um tempo de extração de 45 minutos para as variáveis dependentes, em relação a suas áreas cromatográficas absolutas de: (a) benzeno, (b) tolueno, (c) etilbenzeno, (d) m,p-xilenos e (e) o-xilenos.

Figura 16: Cromatograma referente à extração de um vial limpo e vazio por $H S$-SPME, demonstrando a presença de tolueno no ar.

Figura 17: Gráfico de Pareto referente ao planejamento fatorial fracionário, $2^{4-1}$, para as várias benzeno, etilbenzeno, m,p-xileno e o-xileno. 
Figura 18: Gráficos de Pareto referente ao planejamento fatorial $2^{2}$, avaliando o efeito das variáveis pressão e temperatura, bem como o efeito da interação entre elas. ....................................................72

Figura 19: Programa do gradiente da fase móvel utilizado para separação das sulfonamidas. ..............81 Figura 20: Avaliação do efeito da extração da sulfonamidas pelo método QuEChERS utilizando solventes de diferentes polaridades.

Figura 21: Diagramas de Pareto para todas as sulfonamidas estudadas, obtidos pela realização do planejamento $2^{4-1}$

Figura 22: Gráficos de superfície obtidos com auxílio do planejamento composto central, utilizados para determinar a melhor condição de extração.

Figura 23: Resultados referentes aos diferentes tipos de sorbentes utilizados na

d-SPE.

Figura 24: Esquema representativo das colunas capilares $(500 \mu \mathrm{m} \times 6,0 \mathrm{~cm})$ utilizadas na etapa de SPE (clean-up e concentração dos analitos) 106

Figura 25: Representação esquemática das válvulas de 6 e 10 pórticos utilizadas para o desenvolvimento da SPE online com duas colunas acopladas em série, com configuração de eluição no modo backflush.

Figura 26: Representação esquemátcica das válvulas de 6 e 10 pórticos utilizadas para o desenvolvimento da SPE online com duas colunas acopladas em série, com configuração de eluição no modo forward flush.

Figura 27: Representação gráfica das configuração das válvulas de 6 e 10 pórticos utilizadas para o estudo da interação das SA com a fase aniônica OASIS, na ausência da coluna analítica. 111

Figura 28: Cromatogramas de íons extraídos (EIC) obtidos com o estudo na coluna de extração (Oasis MAX) para os compostos de m/z (a) 251 (b) 279 (c) 271 (d) 265 (e) 254 (f) 256 (g) 311 (h) 285 e (i) 215.

Figura 29: Representação gráfica das configuração das válvulas de 6 e 10 pórticos utilizadas para o estudo da interação das SA com a fase polimérica Strata-X, na ausência da coluna analítica.

Figura 30: Cromatogramas (EIC) obtidos com o estudo na coluna de clean-up (Strata-X) para os compostos de m/z (a) 251 (b) 279 (c) 271 (d) 265 (e) 254 (f) 256 (g) 311 (h) 285 e (i) 215. 114 Figura 31: Cromatogramas obtidos utilizando fases trocadoras de íons forte ( ) e fraca ( ) para as sulfonamidas de $\mathrm{m} / z$ (a) 256 , (b) 251 e (c) 215 115 Figura 32: Área absoluta dos picos cromatográficos referentes as SAs estudadas em diferentes tempos de carregamento da amostra para SPE online. 116

Figura 33: Medida do fator de assimetria de um pico cromatográfico. 118 Figura 34: Cromatograma referente a eluição da sulfatiazol $(\mathrm{m} / \mathrm{z}, 254)$ no modo forward flush e backflush.

Figura 35: Representação gráfica da válvulas de 10 pórticos utilizadas para o desenvolvimento da SPE online com duas colunas acopladas em série e focalização do analitos no início da coluna analítica. 121 
Figura 36: Resultados comparativos entre os dois sistemas utilizados para remoção da fase móvel alcalinizada residual na tubulação do sistema, referentes a área dos picos cromatográficos. 122 Figura 37: Resultados comparativos entre os dois sistemas utilizados para remoção da fase móvel alcalinizada residual na tubulação do sistema, referentes à altura dos picos cromatográficos. 122 Figura 38: Gráfico correlacionando as diferentes porcentagens de ACN alcalinizada utilizada na etapa de carregamento da amostra e as respectivas áreas absolutas de cada analito estudado. 124 Figura 39: Cromatograma referente ao estudo de carry-over utilizando as duas colunas em série, com carregamento da amostra realizado com $50 \%$ ACN/ $\mathrm{H}_{2} \mathrm{O}$ alcalinizada 125 Figura 40: Gráfico de barras referente ao estudo comparativo entre as análises realizadas na presença e ausência da coluna de clean-up em série com uma coluna de extração do tipo trocadora aniônica....126 Figura 41: Cromatogramas comparativos entre as extrações realizadas com ( ) e sem ( ) a coluna de Strata-X para os compostos com $\mathrm{m} / \mathrm{z}$ (a) 256 e (b) 265 


\section{Lista de Tabelas}

Tabela 1- Valores orientadores para presença de benzeno, tolueno, etilbenzeno e xilenos em solo seco.

Tabela 2- Comparação entre diferenças nas propriedades físicas do $\mathrm{CO}_{2}$ supercrítico com solventes líquidos tradicionais

Tabela 3: Comparação entre as diferentes formas de classificação da cromatografia líquida.....

Tabela 4: Tabela representativa de um planejamento fatorial fracionário $2^{4-11}$.

Tabela 5- Íons utilizados para monitoramento no modo de aquisição SIM.

Tabela 6: Valores codificados e os respectivos valores reais para cada variável no planejamento composto central.

Tabela 7: Matriz do planejamento composto central, com os resultados obtidos para as variáveis-resposta expressas em área absoluta.

Tabela 8: Valores estimados para condição ótima de extração, mantendo-se fixo o tempo em 45 minutos.

Tabela 9: Valores obtidos na validação do método de HS-SPME para determinação de BTEX em solo por GC-MS

Tabela 10: Resultados referente ao planejamento fatorial fracionário $2^{4-1}$ para os analitos benzeno, etilbenzeno, $m, p$-xileno e $o$-xileno, expresso em eficiência de extração.

Tabela 11: Planejamento fatorial $2^{2}$ avaliando o efeito da pressão e temperatura, obtido em duplicata.71

Tabela 12: Estrutura química, massa molar e pka de todas as sulfonamidas estudadas.

Tabela 13: Valores estudados no planejamento fatorial fracionário $2^{4-1}$ utilizado para otimização do QuEChERS.

Tabela 14: Resultados, expressos em área absoluta, obtidos com o planejamento fatorial fracionário. 86 Tabela 15: Valores reais e codificados utilizados para a elaboração do planejamento composto central

Tabela 16: Resultados obtidos para planejamento composto central, considerando como variável resposta a área absoluta dos picos cromatográficos.

Tabela 17: Valores de $\mathrm{R}^{2}$ e da soma dos resíduos para todas as $\mathrm{SAs}$ estudadas, utilizando diferentes tipos de ponderação.

Tabela 18: Figuras de mérito utilizadas para validação do método QuEChERS na extração das sulfonamidas em lodo de esgoto.

Tabela 19: Estudo sobre exatidão e precisão interdias necessários para validação do método QuEChERS. 
Tabela 20: Valores obtidos com os ensaios de recuperação, efeito matriz e eficiência do método QuEChERS .98

Tabela 21: Fases poliméricas empregadas na etapa de clean-up da amostra e extração dos analitos..104 Tabela 22: Dados referentes a eluição das SAs estudadas no modo forward flush e backflush ..........118 Tabela 23: Desvios padrões relativos (DPR\%) obtidos para as diferentes porcentagens de acetonitrila alcalinizada utilizada na etapa de carregamento da amostra. 


\section{Lista de Abreviaturas}

POP - poluentes orgânicos persistentes

BTEX - benzeno, tolueno, etilbenzeno e xilenos

CETESB - Companhia de tecnologia de saneamento ambiental

PAHs - hidrocarbonetos policíclicos aromáticos

ETE - estação de tratamento de esgoto

CONAMA - Conselho nacional do meio ambiente

$\mathrm{SA}$ - sulfonamidas

PABA - ácido Para aminobenzóico

SPME - solid phase micro extraction

HS-SPME - headspace solid phase micro extraction

SPE - solid phase extraction

SFE - supercritical fluid extraction

QuEChERS - quick, easy, cheap, effective rugged and safe.

d-SPE - dispersive Solid phase extraction

PSA - primary Secundary Amine

LLE - liquid liquid extraction

SCX - strong cation exchanger

SAX - strong anion exchanger

HRGC - high resolution gas chromatography

LC - liquid chromatography

HPLC - high pressure liquid chromatography

UPLC - ultra performance liquid chromatography

cLC - capillary liquid chromatography

CV - coeficiente de variação 
LIQ - limite inferior de quantificação

LD - limite de detecção

SBSE - sorptive bar solid extraction

ANOVA - análise da variância

EPA - environmental protection agency

SIM -selected ion monitoring

$\mathrm{SE}$ - solução estoque

SI - solução intermediária

ACN - acetonitrila

ACT - acetato de etila

PSA - primary-secundary amine

$\mathrm{ME}$ - matrix effect

$\mathrm{RE}$ - recuperação

$\mathrm{EF}$ - eficiência do método

EIC - extracted ion chromatography

Tc - temperatura critica

Pc - pressão critica 


\section{Resumo}

Contaminantes orgânicos há tempos são normalmente encontrados em baixíssimas concentrações no meio ambiente. Compostos orgânicos monoaromáticos, derivados dos subprodutos do petróleo, frequentemente são encontrados próximos a postos de combustíveis, onde há constantes vazamentos nos tanques de armazenamento. Poluentes emergentes, como exemplo os fármacos, também são temas constantes de pesquisas, devido à baixa taxa de degradação dos mesmos, mesmo após submetidos a sistemas de tratamento convencionais. Assim, a busca por técnicas de remediação, que visem a completa remoção de poluentes em baixas concentrações e metodologias analíticas que permitam o isolamento e detecção de tais compostos se torna essencial. Esse trabalho tem como uma de suas finalidades otimizar e aplicar um sistema de remoção de compostos orgânicos monoaromáticos presentes em solo, utilizando $\mathrm{CO}_{2}$ no estado supercrítico. A SPME-GC-MS foi otimizada e validada para a etapa de extração, com separação e quantificação por GC-MS dos contaminantes remanescentes após o solo ser submetido ao processo de remediação. Outro etapa do projeto, está relacionada com a determinação de sulfonamidas em lodo de esgoto. Para isso, um método rápido, fácil, barato e robusto de extração foi otimizado e validado, obtendo bons limites de quantificação (10-25 ng $\mathrm{g}^{-1}$ ) e detecção (4-9 $\mathrm{ng} \mathrm{g}^{-1}$ ), com precisão e exatidão satisfatórios, de acordo com os valores estabelecidos pela ANVISA. Ainda com o propósito de determinar sulfonamidas em lodo de esgoto, um método LC online foi desenvolvido. A finalidade é promover o clean-up da matriz e extração dos analitos em um sistema de extração em fase sólida capilar online. Para isso, fez uso de duas colunas capilares $(530 \mu \mathrm{m} \times 6,0 \mathrm{~cm})$ dispostas em série, inseridas em um sistema cromatográfico capilar acoplado a detecção por espectrometria de massas. A primeira coluna teve como finalidade a retenção de interferentes presentes na amostra utilizando para isso, uma fase polimérica Strata-X. Já a segunda coluna, extraiu as sulfonamidas de interesse utilizando, para isso, uma fase polimérica aniônica Oasis Max. O extrato inserido no sistema de extração em fase sólida online era composto por 100 \% solvente orgânico (acetonitrila); utilizando diferentes porcentagens de acetonitrila na etapa de carregamento, foi possível realizar clean-up adequado da amostra. A eluição dos analitos foi feita utilizando-se fase móvel acidificada. Com esse sistema, melhorou-se em até $30 \%$ a extração de alguns compostos. Todos os métodos de preparo de amostra utilizados no trabalhos seguem a tendência atual sugerida pelo conceito do green chemistry. 


\section{Abstract}

The determination of organic contaminants in environmental matrices has long been a challenge for the scientific community, due to the very low concentrations they are present. Monoaromatic organic compounds derived from petroleum sub-products are still a concern, because they are often found in environmental sites near gas stations, where there are constant leaks in storage tanks. Emerging pollutants, which include personal care products and pharmaceuticals, are also constant subject of research due to their low degradation rate, even after conventional treatment systems. Moreover, the research for remediation techniques aimed at complete removal of pollutants at low concentrations, as weel as new analytical methodologies for isolation and detection of such compounds are, both, essential. This work aims to optimize and apply a system to remove monoaromatic organic compounds present in soil, using $\mathrm{CO}_{2}$ in the supercritical state. As an analytical tool, SPME was optimized and validated with separation and quantification by GC-MS of selected contaminants remaining after the remediation process. Another research work developed is related to the determination of sulfonamides in sewage sludge. Firstly a methodology based on QuEChERS extraction method was optimized and validated, obtaining good results as limits of quantification, LOQ (10-25 $\left.\mathrm{ng} \mathrm{g}^{-1}\right)$ and detection, LOD (4-9 $\left.\mathrm{ng} \mathrm{g}^{-1}\right)$ with satisfactory accuracy and precision, according to the values established by ANVISA. Still working to determine sulfonamides in sewage sludge, a new online sample preparation method was developed. The purpose of this method is to promote the matrix clean-up and concentration analytes in a capillary SPE system. It was used two capillary columns $(500 \mu \mathrm{m} \times 6.0 \mathrm{~cm})$ arranged in series in a capillary chromatographic system coupled to mass spectrometry. The first column was intended to retain interferences present in the sample, using a Strata-X polymer phase. The second column extracted sulfonamides of interest, making use of an anionic polymer phase (Oasis MAX). The extract inserted in the online SPE system was composed of $100 \%$ organic solvent (acetonitrile); using different percentages of $\mathrm{ACN}$ with appropriately $\mathrm{pH}$ at the loading stage, it was possible to achieve a satisfatory sample clean-up. The elution of the analytes was performed using an acidified mobile phase. This system improved by up to $30 \%$ extraction yield of some compounds. All sample preparation methods used in the works follow the current trend suggested by the green chemistry concept. 


\section{Sumário}

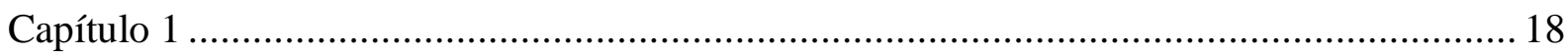

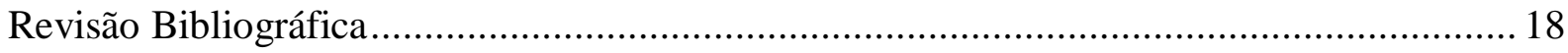

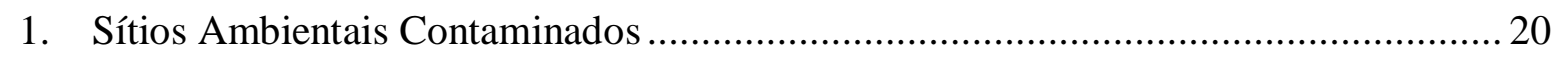

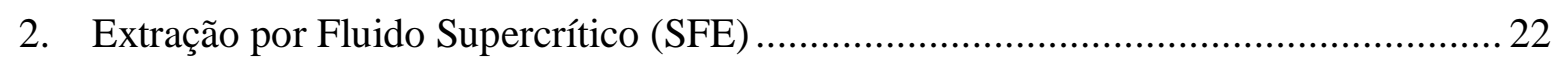

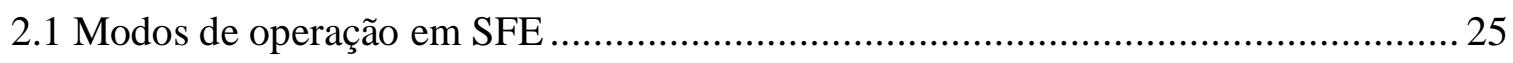

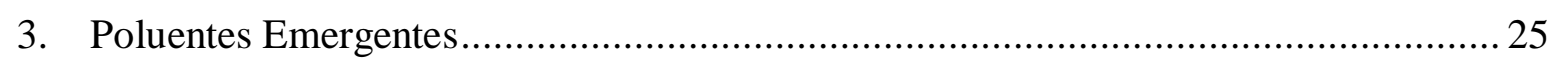

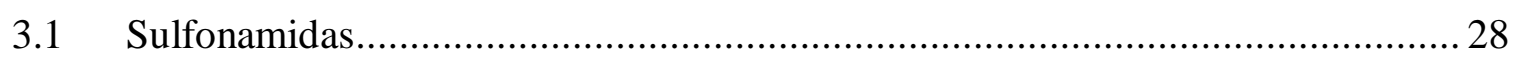

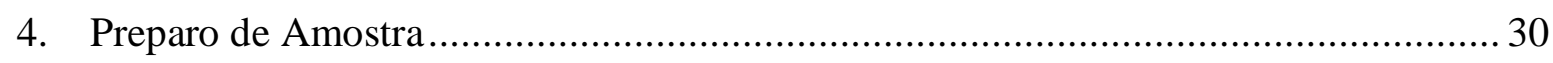

4.1 Microextração em Fase Sólida (SPME - Solid Phase Micro Extraction) .................. 32

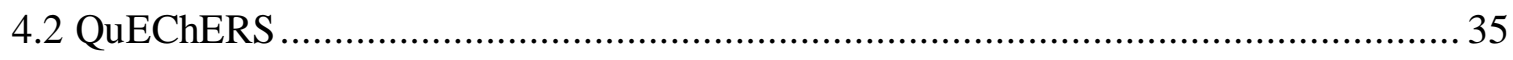

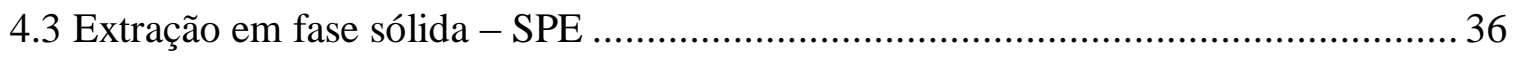

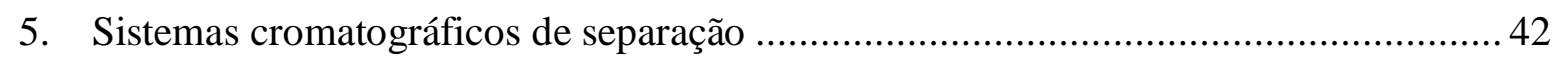

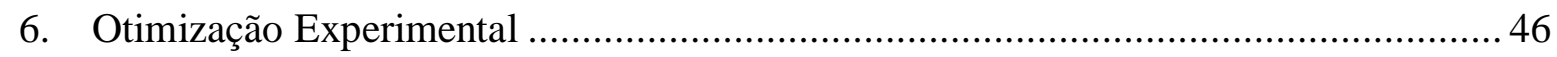

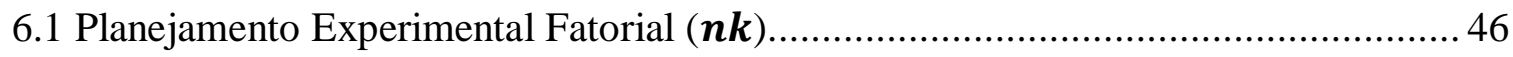

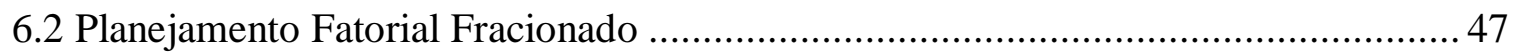

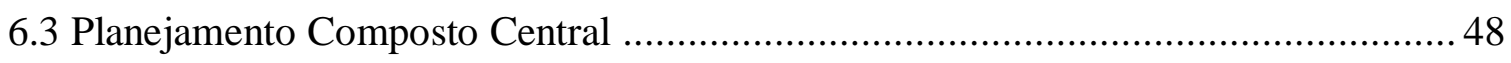

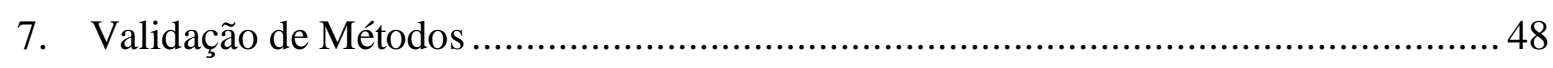

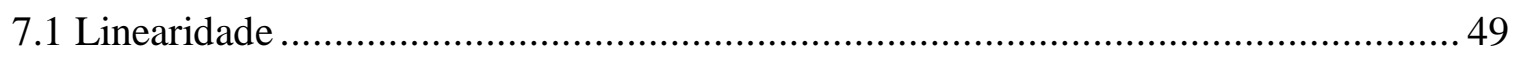

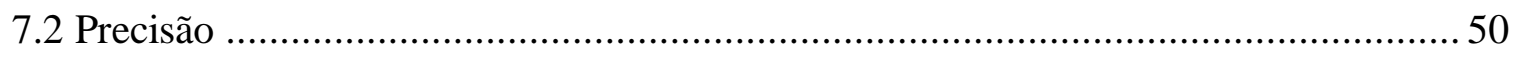

7.3 Sensibilidade ou Limite de Detecção (LD) …..................................................... 51

7.4 Limite de Quantificação ............................................................................... 51

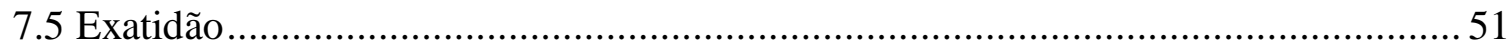

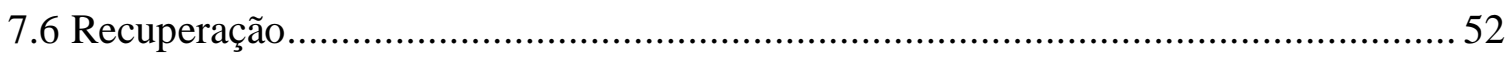

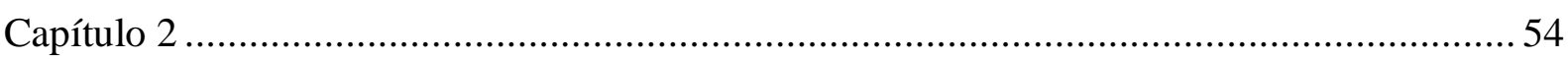

Remediação de solos contaminados por derivados de petróleo utilizando extração com $\mathrm{CO}_{2}$

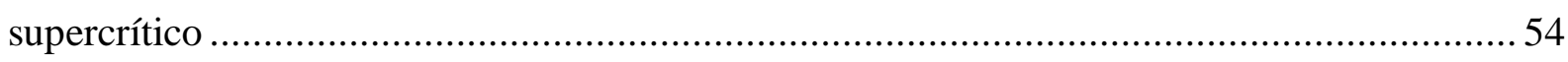

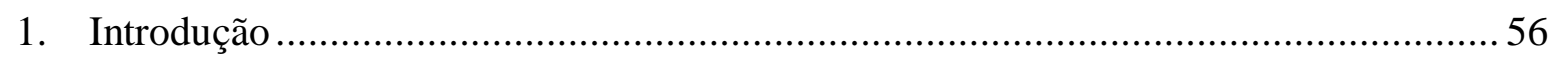




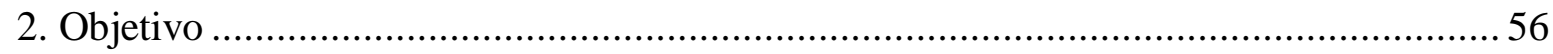

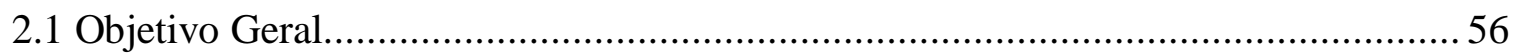

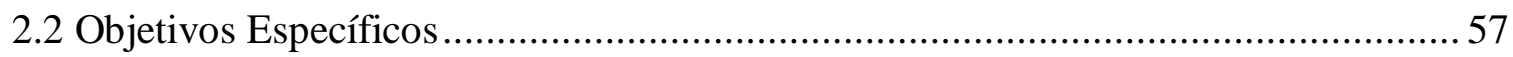

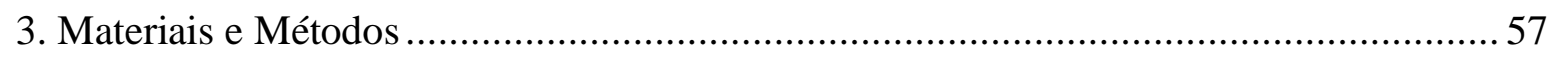

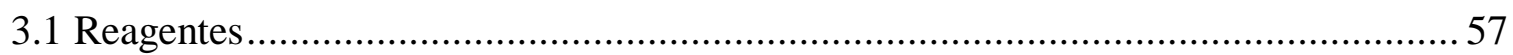

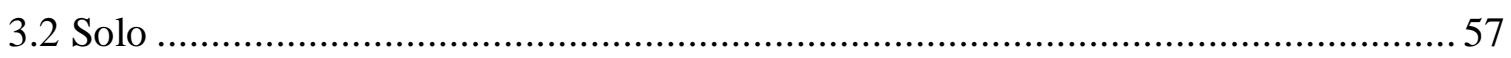

3.3 Microextração em fase sólida (SPME - Solid Phase Micro Extraction).................... 58

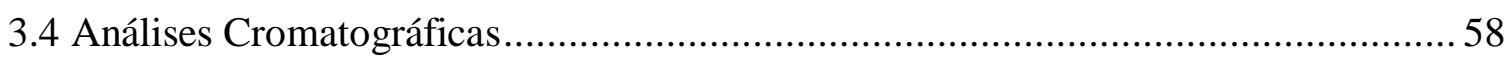

3.5 Extração com Fluido Supercrítico (SFE - Supercritical Fluid Extraction) ............... 59

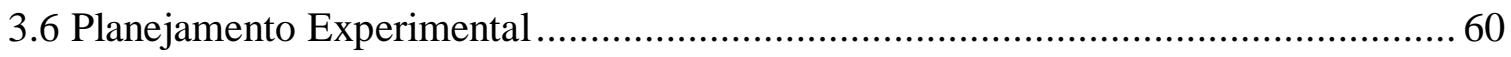

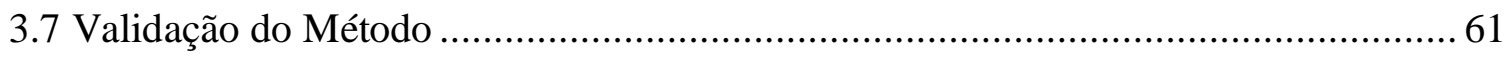

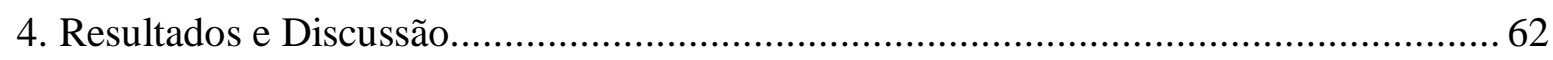

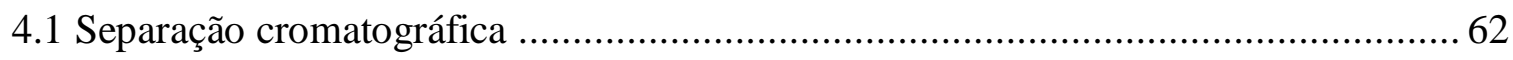

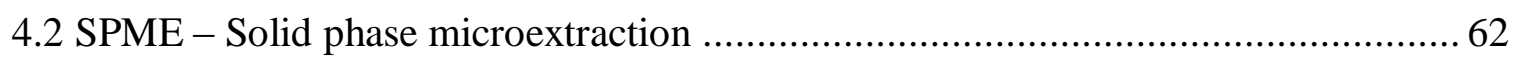

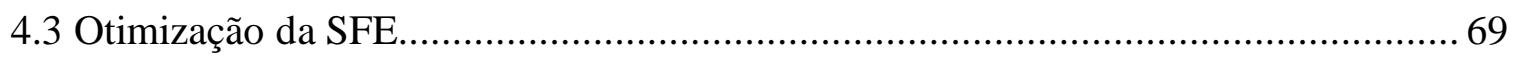

4.4 Aplicação do método de remediação e avaliação da eficiência por HS-SPME/GC-MS

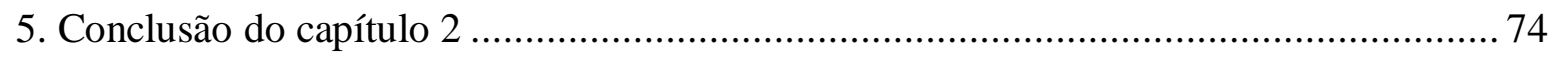

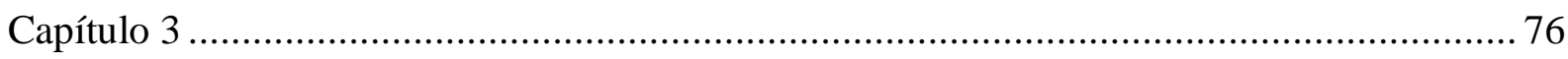

Desenvolvimento, otimização e validação de um método para determinação de sulfonamidas em lodo de esgoto por QuEChERS e LC-ESI-TOF ......................................................... 76

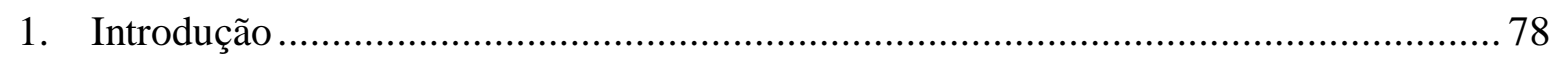

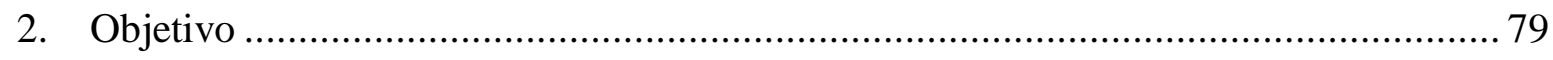

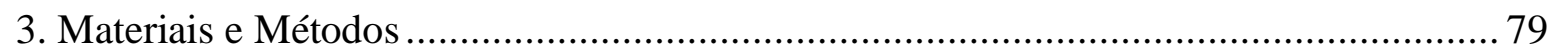

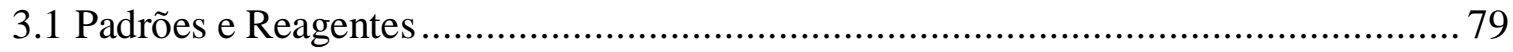

3.2 Separação e detecção analítica...................................................................... 81

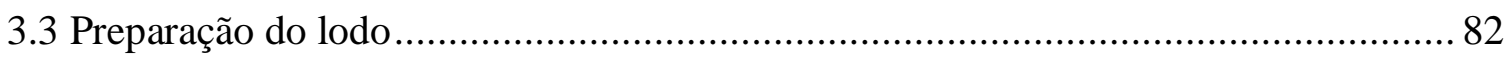

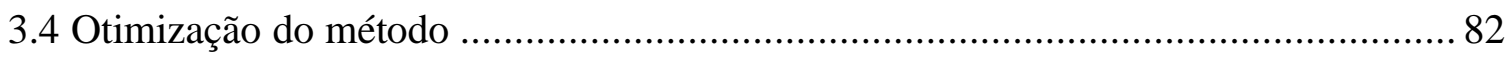

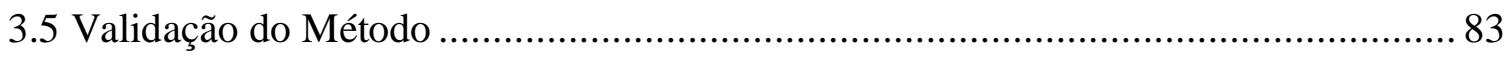

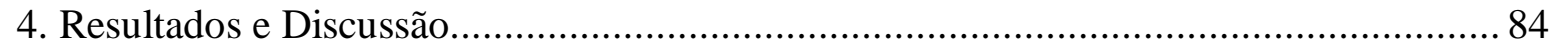

4.1 Otimização do método QuEChERS de extração ................................................. 84 


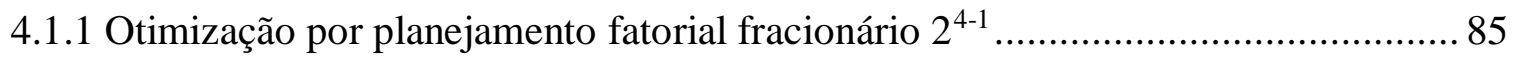

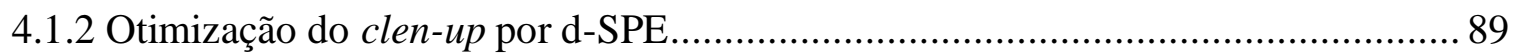

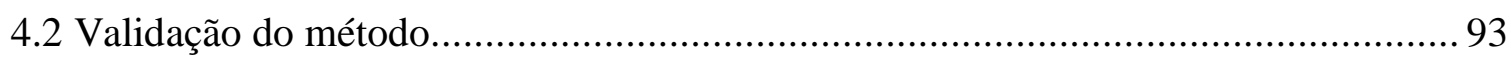

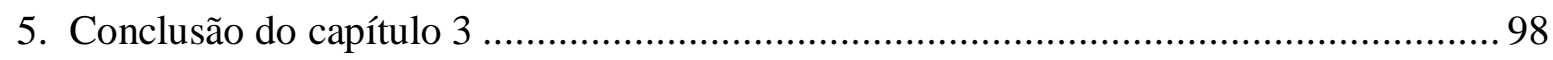

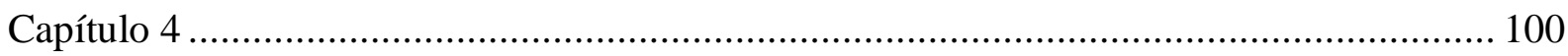

Desenvolvimento de um sistema online para extração e clean-up de sulfonamidas provenientes

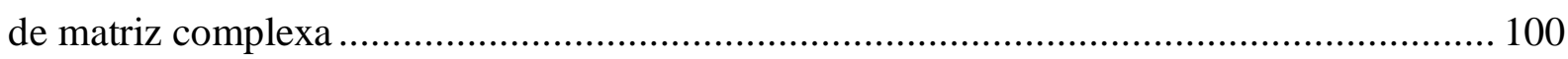

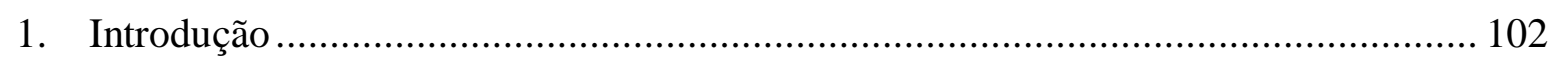

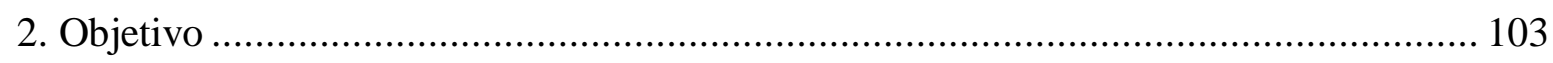

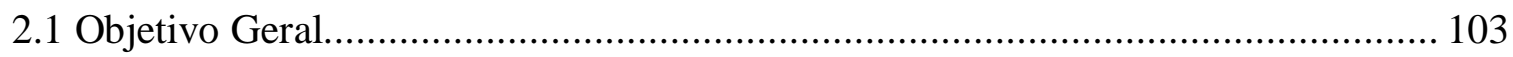

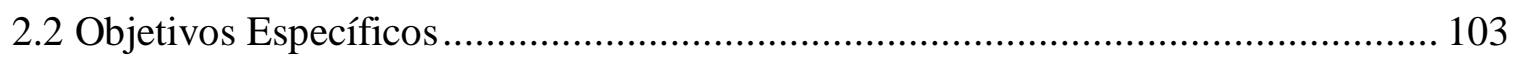

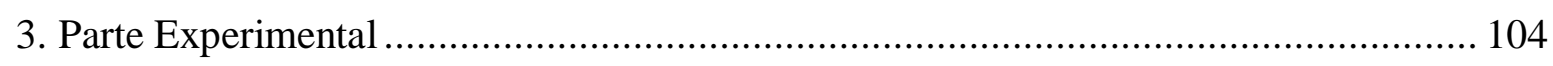

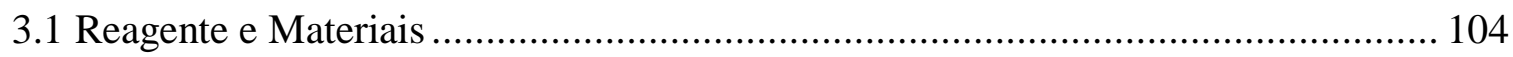

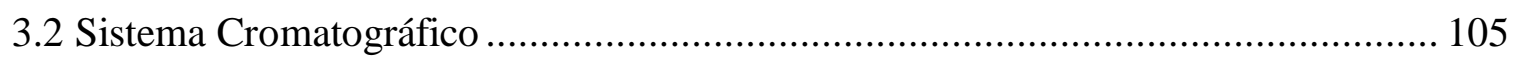

3.3 Condições de detecção por espectrometria de massas .......................................... 106

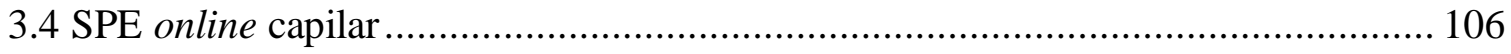

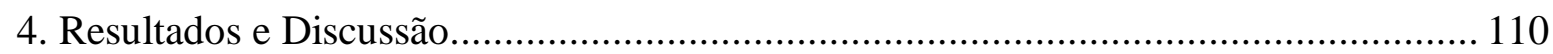

4.1 Desenvolvimento do sistema SPE capilar online ................................................ 110

4.2 Seleção do tipo de fase extratora aniônica ........................................................ 115

4.3 Avaliação do tempo de carregamento da amostra ............................................... 115

4.4 Seleção do modo de operação do sistema column swtiching ................................. 116

4.5 Sistema de remoção da amônia residual ............................................................... 119

4.6 Testes de diferentes porcentagens de ACN utilizada na etapa de carregamento da

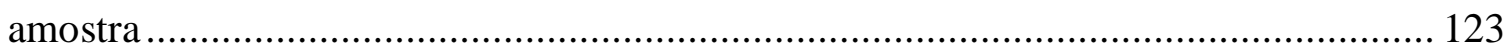

4.7 Comparação entre resultados obtidos com e sem a presença da coluna Strata-X .... 125

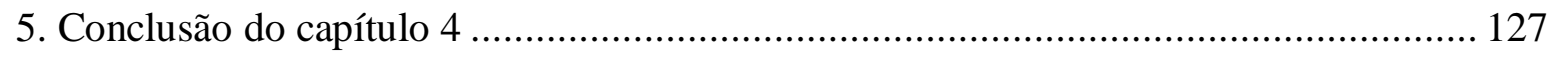

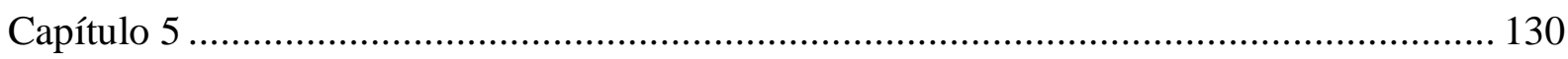

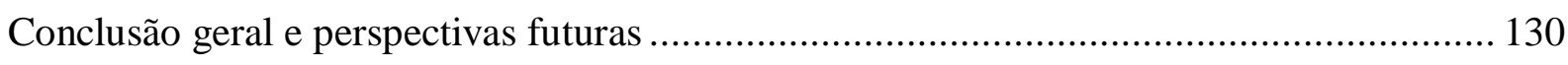

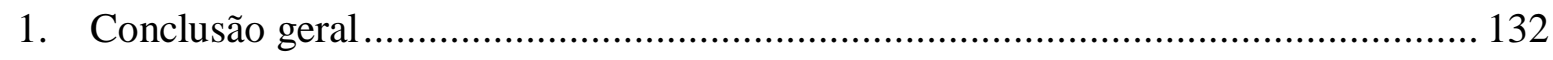

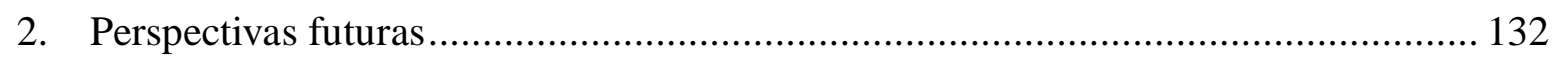

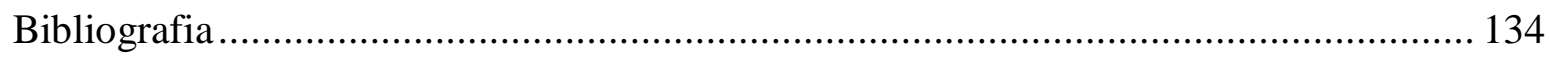




\section{Prefácio}

Estudos relacionados à cromatografia abrangem desde a coleta da amostra até o tratamento dos dados obtidos após separação e detecção analítica, visto que cada uma dessas etapas influencia diretamente na qualidade dos resultados obtidos.

A etapa de preparo de amostras é crucial para o bom desenvolvimento do método analítico, pois é nela que ocorre o clean-up da amostra, ou seja, remoção dos interferentes presentes e, também, o isolamento e concentração dos analitos de interesse. Após essa etapa, a escolha da melhor ferramenta de separação e detecção é essencial, considerando-se sempre as propriedade químicas dos compostos a serem analisados.

Dentro desse contexto, o grupo de cromatografia do Instituto de Química de São Carlos (CROMA) vem desenvolvendo inúmeros trabalhos visando a melhoria e criação de metodologias que, além de atender aos objetivos citados (clean-up da amostra e concentração dos analitos) possam atender também aos conceitos atuais da denominada química verde (green chemistry), ou seja, métodos que gerem menor impacto ao meio ambiente.

Sendo assim, o presente trabalho tem como proposito principal desenvolver e aplicar metodologias analíticas que proporcionem menor tempo de análise, menor consumo de solvente orgânico e menor manipulação da amostra pelo analista, criando para isso, métodos online de preparo de amostras.

Para fins didáticos, essa tese foi dividida em capítulos facilitando a compreensão das estratégias e metodologias utilizados, bem como dos resultados obtidos.

O Capitulo 1 apresenta, de forma resumida, os fundamentos teóricos e práticos disponíveis na literatura utilizados no decorrer desse trabalho, incluindo as técnicas cromatográficas mais utilizadas como cromatografia em fase gasosa e liquida, bem como as vertentes atuais em relação a essas técnicas. Problemas relacionados a contaminação ambiental, por diversos tipos de contaminantes também são listados, e tanto as formas de remediação e análise são relatas. Assim, esse capítulo apresenta um breve resumo sobre técnicas somo SFE, SPME, QuEChERS, SPE e SPE online. 
O Capítulo 2 se refere a otimização e aplicação da SFE, utilizando um sistema desenvolvido no CROMA para a remediação de solos contaminados com compostos orgânicos monoaromáticos os quais são, frequentemente, encontrados em derivados do petróleo. Para verificar a eficiência da técnica SFE empregada para esse propósito, utilizou-se a SPME como ferramenta analítica, a qual foi devidamente otimizada e validada.

O Capítulo 3 aborda a otimização e validação do método QuEChERS para extração de sulfonamidas presentes em lodo de esgoto. Trata-se de um assunto atual, considerando-se a ineficácia dos sistemas de tratamento biológicos normalmente utilizados. Quando não degradados adequadamente, esses compostos podem ficar adsorvidos no lodo que, dependendo do tipo de descarte, pode perfeitamente reintroduzir esses antibióticos no meio ambiente.

O capítulo 4 aponta a importância do desenvolvimento de métodos de preparo de amostra online, principalmente para a extração de analitos presentes em extratos constituídos por $100 \%$ de solvente orgânico. Trata-se de um sistema versátil que permite tanto o clean-up da amostra quanto o isolamento do analito de interesse, de forma totalmente automatizada, utilizando duas colunas capilares acopladas em série e conectadas a um sistema de cLC-MS.

Por fim, o capítulo 5 apresenta a conclusão geral sobre o trabalho, bem como as perspectivas futuras relacionadas ao tema. 


\section{Capítulo 1}

\section{Revisão Bibliográfica}





\section{Sítios Ambientais Contaminados}

A poluição ambiental é tema constante de pesquisas, seja para determinação de poluentes em água, ar ou solo. Porém a contaminação do solo vem ganhando destaque, devido às várias "portas" de entrada dos poluentes nesse ambiente. Seja por vazamentos, disposição de lodos de esgoto ou até mesmo pela deposição atmosférica, os contaminantes orgânicos penetram no solo e, embora alguma parte destes seja perdida por volatilização, biodegradação ou lixiviação, outra parte pode ficar fortemente adsorvidos na matéria orgânica ou inorgânica presentes no solo, mesmo que em baixas concentrações.

Os compostos solúveis em água, de alta mobilidade ou facilmente degradáveis, ficam menos tempo no solo, podendo ser totalmente eliminados. Já os compostos de estrutura molecular recalcitrante podem ficar adsorvidos e manter uma baixa concentração por muito tempo. Quanto maior o tempo de contato entre os contaminantes e o solo, menor a disponibilidade química e biológica destes. Além da matéria orgânica e compostos minerais, componentes inorgânicos e a atividade microbiológica participam destes processos de adsorção. ${ }^{1}$

Entre os vários tipos de poluentes, os BTEX (benzeno, tolueno, etilbenzeno e isômeros de xileno) já foram bastante estudados na contaminação de solo., ${ }^{2,3,4}$ No entanto, ainda são um problema a ser resolvido.

Trata-se de hidrocarbonetos aromáticos derivados do petróleo, que podem gerar metabólitos carcinogênicos no organismo humano, como no caso do benzeno, ou apresentar efeitos nocivos ao sistema nervoso central, como caso do tolueno e xilenos, razões que explicam a preocupação com estes poluentes.

Em 2008, a CETESB - Companhia Ambiental do Estado de São Paulo, órgão fiscalizador e licenciador de atividades consideradas potencialmente poluidoras, realizou um levantamento que revelou cerca de 2.524 áreas contaminadas neste estado, sendo que $78 \%$ deste valor correspondem à contaminação causada por postos de gasolina, seguido de $13 \%$ causados por atividades industriais. ${ }^{5}$

A CETESB utiliza os padrões de qualidade citados na Lista Holandesa, a qual apresenta 3 limites de valores para diversos poluentes: o valor de referência indica o nível de qualidade dos solos que possa considerá-los limpos; o valor de intervenção indica o nível de qualidade que apresenta riscos para a população e meio ambiente, necessitando de medidas de 
remediação; já o valor de prevenção apresenta um nível intermediário entre os dois primeiros valores, indicando que houve uma modificação nas propriedades funcionais do solo. ${ }^{5}$

Estes valores são estabelecidos para uma série de compostos poluentes como, por exemplo, metais, pesticidas, fenóis. Na Tabela 1, podem-se observar os valores de referência, prevenção e intervenção para os BTEX em 3 tipos de áreas diferentes: agrícola, residencial e industrial.

Tabela 1: Valores orientadores para presença de benzeno, tolueno, etilbenzeno e xilenos em solo seco.

\begin{tabular}{|c|c|c|c|c|c|}
\hline & \multirow{2}{*}{$\begin{array}{c}\text { Referência } \\
\text { de } \\
\text { qualidade }\end{array}$} & \multirow{2}{*}{$\begin{array}{c}\text { Prevenção } \\
\mu^{\prime} k^{-1}\end{array}$} & \multicolumn{3}{|c|}{ Intervenção } \\
\hline & & & $\begin{array}{c}\text { Agrícola } \\
\mu_{\text {gkg }}^{-1}\end{array}$ & $\begin{array}{c}\text { Residencial } \\
\mu_{\text {gkg }}\end{array}$ & $\begin{array}{c}\text { Industrial } \\
\mu_{\mathrm{gkg}}\end{array}$ \\
\hline Benzeno & n.a. & 30 & 60 & 80 & 150 \\
\hline Tolueno & n.a. & 140 & 30000 & 30000 & 75000 \\
\hline Etilbenzeno & n.a. & 6200 & 35000 & 40000 & 95000 \\
\hline $\begin{array}{l}\text { Xilenos } \\
(\mathbf{o , m}, \mathbf{p})\end{array}$ & n.a. & 130 & 25000 & 30000 & 70000 \\
\hline
\end{tabular}

No caso dos solos, as descontaminações são geralmente complexas, podendo ocorrer tanto in-situ como ex-situ (Figura 1), Gomes e colaboradores (2013) ${ }^{6}$ efetuaram uma revisão dos métodos de remediação de solos e sedimentos contaminados por PCBs (bifenilas policloradas).

No entanto, ainda há uma preocupação em se desenvolver novas tecnologias para a remediação de solo, como Kempa e colaboradores $(2013)^{7}$ fizeram, ao desenvolver um sistema para a descontaminação de uma área industrial contaminada com Hidrocarbonetos Aromáticos Policíclicos (PAHs), hidrocarbonetos derivados de petróleo, mercúrio, cianeto entre outros, utilizando vapor de água in-situ, obtendo resultados satisfatórios para este procedimento. 
Figura 1: Classificação de tecnologias de remediação de solos e sedimentos contaminados por PCBs

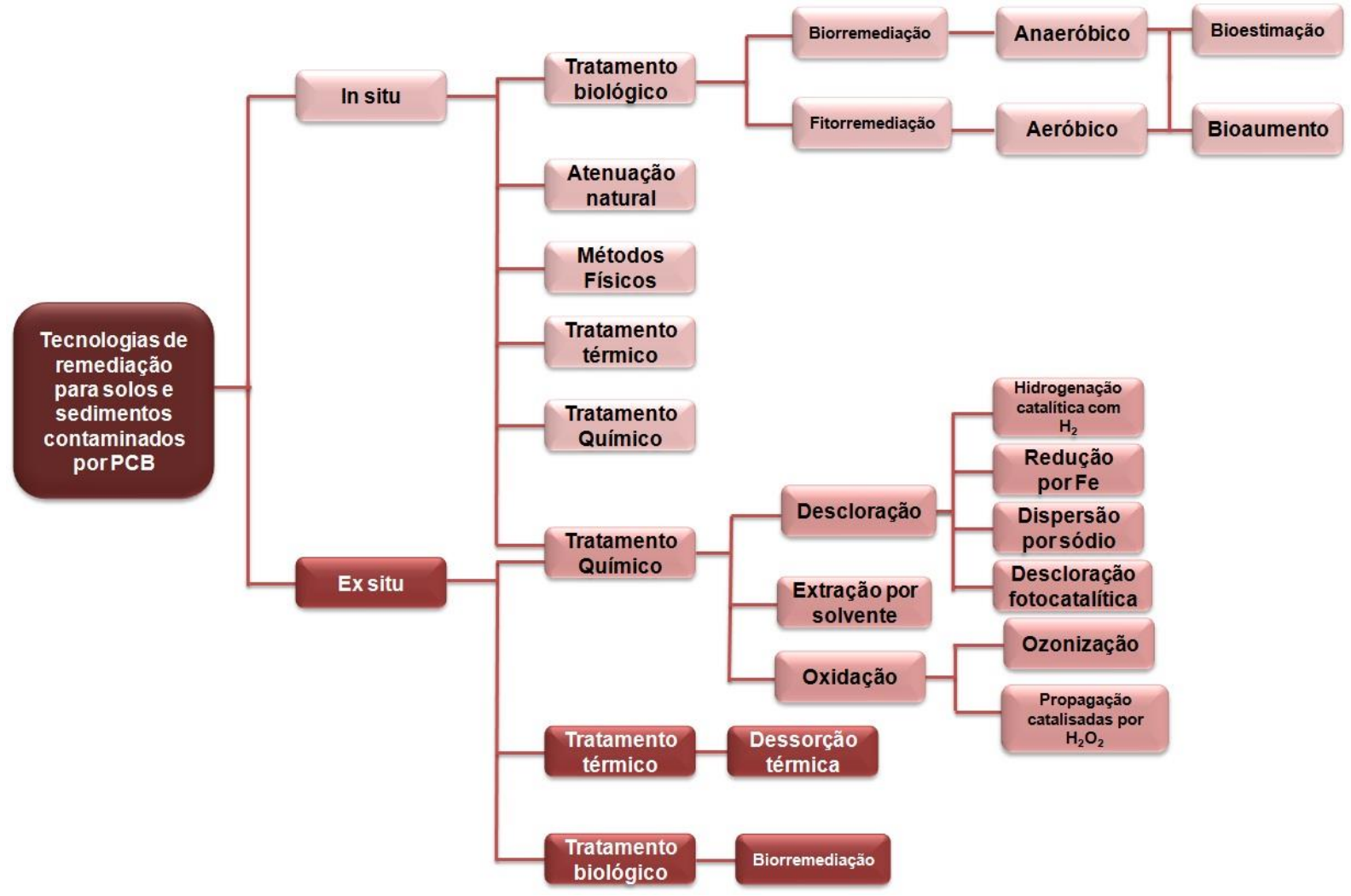

Adaptada de: GOMES, H. I.; DIAS-FERREIRA, C.; RIBEIRO, A. B. Overview of in situ and ex situ remediation technologies for PCB-contaminated soils and sediments and obstacles for full-scale application. Science of The Total Environment, v. 445-446, n. 15, p. 237-260, 2013.

A utilização de fluidos supercríticos em processos de extração abrange várias vertentes dentro da química analítica como por exemplo, extração de óleos essenciais de plantas, aplicação em produtos alimentícios e também, na área ambiental, para análises de inúmeras classes de contaminantes. ${ }^{8,9,10}$

Dentro desse contexto, surgiu o interesse em aplicar a SFE como meio de remover poluentes de solo, visto que o grupo de cromatografia do Instituto de Química de São Carlos (CROMA) há tempos converge esforços para o desenvolvimento tanto da instrumentação quanto para a aplicação de novas metodologias utilizando fluidos no estado supercrítico ${ }^{11-15} \mathrm{e}$ também devido a aplicabilidade e eficiência já reportada referente a essa técnica. ${ }^{16,17,18}$

\section{Extração por Fluido Supercrítico (SFE)}

No diagrama de fases de uma substância pura, obtido ao se variar pressão e temperatura simultaneamente, têm-se três linhas que descrevem o processo de sublimação, evaporação e 
liquefação. As linhas definem as regiões correspondentes ao estado gasoso, líquido e sólido, e entre elas, as fases correspondentes encontram-se em equilíbrio. A pressão de vapor inicia-se no ponto triplo (onde as 3 linhas se encontram) e termina no ponto crítico, como observado na Figura 2.

Figura 2: Diagrama de fases genérico

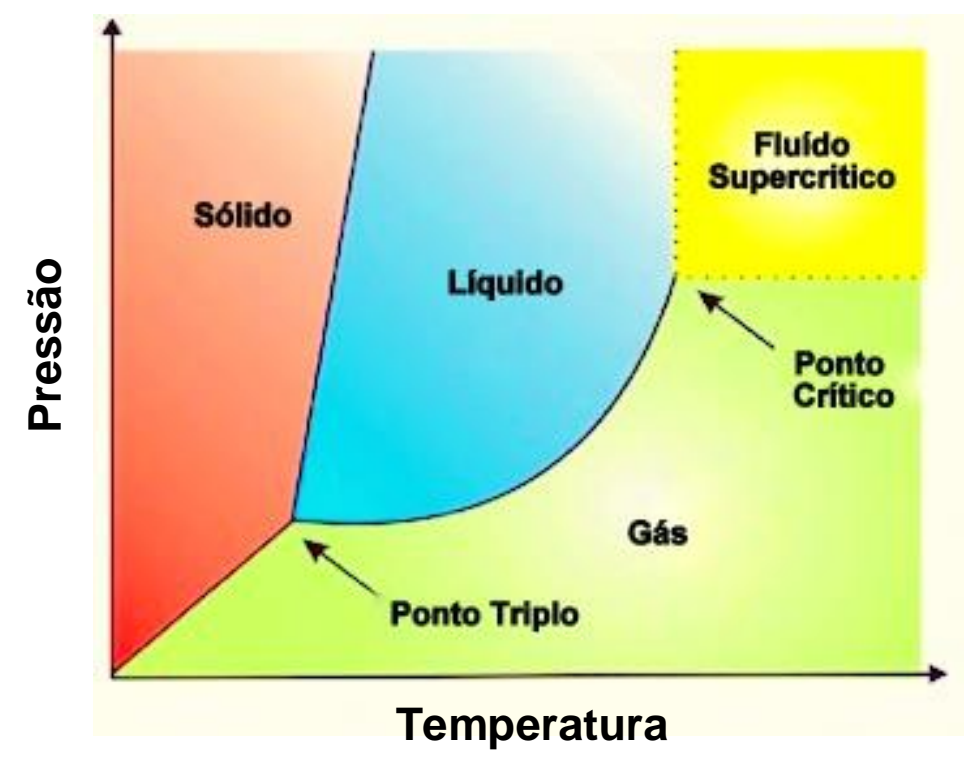

A temperatura crítica de uma substância é definida como a temperatura mais alta na qual um gás pode ser convertido à líquido pelo aumento da pressão; já a pressão crítica corresponde ao valor mais alto de pressão, na qual um líquido pode ser convertido a gás pelo aumento da temperatura. Nestas condições, as substâncias não se comportam nem como gás nem como líquido e, sim, adquirem propriedades físicas de ambos estados, sendo denominadas de fluidos no estado supercrítico ou, simplesmente, fluidos supercríticos.

Um fluido no estado supercrítico possui densidade característica de um líquido, proporcionando melhor poder de solvatação. Propriedades como difusividade e viscosidade também são alteradas com a variação da pressão e temperatura, adquirindo características aproximadas de um gás. Aliadas a valores extremamente baixos para tensão superficial (aproximadamente zero), os fluidos no estado supercrítico possuem melhor penetração nas amostras que um solvente na fase líquida. ${ }^{19}$

Entre os vários fluidos utilizados em $\mathrm{SFE}, \mathrm{O} \mathrm{CO}_{2}$ é, indubitavelmente, o mais empregado, devido a características como: ${ }^{20}$ 
- Gás não inflamável,

- Não tóxico

- Condições de pressão e temperatura críticas amenas $\left(72,9\right.$ bar e $31{ }^{\circ} \mathrm{C}$, respectivamente)

- Disponível comercialmente em elevado grau de pureza.

$\mathrm{Na}$ Tabela 2, pode-se observar uma comparação realizada entre o $\mathrm{CO}_{2}$ supercrítico e dois dos mais tradicionais solventes orgânicos, o $n$-hexano e metanol.

As características do $\mathrm{CO}_{2}$ supercrítico podem ser alteradas com o uso de solventes polares, denominados de modificadores, que possibilitam a ampliação do espectro de aplicação.

Tabela 2: Comparação entre diferenças nas propriedades físicas do $\mathrm{CO}_{2}$ supercrítico com solventes líquidos tradicionais

\begin{tabular}{lccc}
\hline & CO$_{2}$ & $\boldsymbol{n}$-Hexano & Metanol \\
\hline Densidade $\left(\mathrm{g} \mathrm{mL}^{-1}\right)$ & 0,746 & 0,660 & 0,791 \\
Viscosidade $\left(\mathrm{m}^{2} \mathrm{~s}^{-1} \times 10^{7}\right)$ & 1,00 & 4,45 & 6,91 \\
$\begin{array}{l}\text { Difusividade do ácido benzóico } \\
\left(\mathrm{m}^{2} \mathrm{~s}^{-1} \times 10^{9}\right)\end{array}$ & 6,0 & 4,0 & 1,8 \\
\hline
\end{tabular}

Fonte: TAYLOR, L.T. Properties of supercritical fluids. In: Supercritical fluid extraction. Canada: John Wiley, 1996. v. 1, p 7-27. ${ }^{19}$

Estas substâncias estão no estado líquido à temperatura ambiente e têm sido muito utilizadas para alterar as propriedades de solvatação do $\mathrm{CO}_{2}$ supercrítico. Vários solventes podem ser usados como modificadores; no entanto, o metanol geralmente apresenta os melhores resultados, como observado por Koinecke, Kreuzig e Bahadir (1997), ${ }^{21}$ que ao testarem a eficiência da extração de pesticidas em solo utilizando $\mathrm{CO}_{2}$ supercrítico modificado a $5 \%$ por $n$-hexano, acetona e metanol, obtiveram melhores resultados com metanol, o qual proporcionou recuperações na faixa de 93 a $104 \%$.

A $T_{c}$ e $P_{c}$ da mistura $\mathrm{CO}_{2}$-modificador situam-se entre os valores das duas substâncias puras, de acordo com as equação 1 e 2 :

$$
T_{c}=X_{C O_{2}} T_{C\left(\mathrm{CO}_{2}\right)}+X_{M} T_{C(M)}
$$




$$
P_{C}=X_{\mathrm{CO}_{2}} P_{C\left(\mathrm{CO}_{2}\right)}+X_{M} P_{C(M)}
$$

onde, $\mathrm{X}_{\mathrm{CO}_{2}}$ e $\mathrm{X}_{\mathrm{m}}$ correspondem respectivamente as frações molares de $\mathrm{CO}_{2}$ e do solvente utilizado como modificador.

\subsection{Modos de operação em SFE}

A extração por fluido supercrítico pode ocorrer no modo estático, dinâmico ou ainda uma combinação de ambos.

$\mathrm{Na}$ extração estática, uma quantidade fixa de fluido supercrítico interage com a matriz devido à alta permeabilidade, removendo os analitos presentes. Esse tipo de extração é comumente usada quando modificadores são adicionados à cela de extração, antes da pressurização. No entanto, extrações exaustivas são dificilmente obtidas, caso uma quantidade insuficiente de fluido supercrítico seja adicionada à cela.

Normalmente a extração estática é seguida por um período de extração dinâmica, na qual um fluxo de fluido supercrítico é continuamente passado pela cela extratora. Um dos problemas obtidos por essa técnica ocorre quando o fluido contém impurezas e, ao se passar elevadas quantidades desse, estas impurezas podem ser concentradas na etapa de aprisionamento dos analitos e interferirem nas análises posteriores.

\section{Poluentes Emergentes}

Durante muito tempo, os POPs (Poluentes Orgânicos Persistentes), compostos largamente utilizados após a segunda guerra mundial, foram alvos de muitos trabalhos devido aos efeitos adversos que estes podem causar tanto a saúde humana, vida animal e ao meio ambiente em geral. Dentro desse grupo de compostos, encontram-se alguns pesticidas, bifenilas policloradas, dioxinas e furanos, que devido ao uso indiscriminado podem ser encontrados no meio ambiente em dias atuais.

No entanto, uma nova classe de poluentes, denominados de poluentes emergentes, vem ganhando atenção da comunidade cientifica, a qual inclui, fármacos (medicamentos destinados a prevenção e tratamento humano e animal) e os produtos de cuidados pessoais, que incluem cremes dentais, protetores solares, disruptores endócrinos, entre outros. 
Estes compostos são, geralmente, encontrados no meio ambiente em baixas concentrações, e a preocupação em relação a eles se deve ao fato que muitos são desenvolvidos para exercerem efeitos biológicos (no caso dos fármacos), que podem ser negativos a fauna e flora. Devido ao fato de serem continuamente lançados ao meio ambiente são cumulativos e de difícil remoção por métodos de degradação convencionais. ${ }^{22}$

Dentro desse contexto, os fármacos recebem atenção especial por se tratar de uma classe variada de compostos que são, frequentemente, encontrados no meio ambiente.

Este fato se deve ao alto consumo, sendo estimado que em 2015 o Brasil alcance a sexta posição no ranking mundial, tratando-se, portanto, de um mercado altamente lucrativo, movimentando a economia nacional em aproximadamente 110 bilhões de reais, segundo fontes da IMS Health. ${ }^{23}$ Aliado ao alto consumo mundial encontra-se a persistência dos mesmos no meio ambiente, já que na maioria das vezes, são resistentes a degradação química, física e biológica.

Os caminhos que os fármacos percorrem até chegarem ao meio ambiente são os mais diversos possíveis. Compreendem desde a excreção, ao serem administrados em humanos ou animais (eliminados tanto em sua estrutura química intacta quanto em produtos de biotransformação), a descartes irregulares de resíduos hospitalares, de indústrias farmacêuticas e até mesmo, resíduos gerados em farmácias de manipulação.

O consumo humano doméstico também pode ser considerado como fonte de contaminação, visto que ainda há casos de descarte inadequado de remédios com o prazo de validade expirado diretamente na rede de esgoto convencional, alcançando assim as Estações de Tratamento de Esgoto (ETE), quando essas se fazem presente. ${ }^{24}$

As ETEs têm como principal objetivo a remoção de material particulado, matéria orgânica dissolvida e alguns nutrientes presentes nos esgotos. Para isso, se faz uso de processos unitários baseados, basicamente, em sistemas de filtração e coagulação e, posteriormente, os sistemas biológicos de tratamento são adicionados. Estes são os responsáveis por degradar a matéria orgânica presente no esgoto que, na maioria das vezes, são ineficientes para degradação dos fármacos, fazendo com que os mesmos sejam lançados ao meio ambiente.

Os sistemas de tratamento biológicos podem variar em eficiência de acordo com os parâmetros de operação da estação como, por exemplo, temperatura, tempo de retenção hidráulico, diluição do esgoto bruto, configuração da planta de tratamento e, até mesmo, em 
relação às características do lodo utilizado, visto que normalmente, são empregados nas plantas de tratamentos biológicos lodos contendo microorganismos da biota local. ${ }^{25-28}$

Vieno e seus colaboradores $(2007)^{29}$ avaliaram a influência das variáveis supracitadas na eficiência de remoção de antiepiléticos, antibióticos e betabloqueadores em um sistema de tratamento biológico. Foi observado que a classe dos antiepiléticos (carbamazepina) não sofreu degradação, e que a eficiência de remoção da maioria dos betabloqueadores variou muito ao comparar o período de seca com o chuvoso. Isso ocorreu devido à diminuição do tempo de retenção hidráulico, necessário para tratar o excesso de água causado pelas chuvas. Já para os antibióticos, a maioria dos compostos avaliados teve satisfatória remoção, acima de $80 \%$ de eficiência.

Sistemas biológicos de tratamento por lodos ativados são bastante comuns. Baseia-se na oxidação da matéria orgânica presente no esgoto/efluente industrial pela ação de bactérias aeróbias, assimiladas como "alimento" e fonte de energia pelas bactérias, que necessitam de oxigênio para sobreviver. Esse processo ocorre em duas etapas distintas: primeiramente, ocorre no tanque de aeração a mistura entre o efluente e o lodo, onde a aeração é extremamente necessária para manter as condições vitais das bactérias. É nessa etapa que ocorrem os processos que dão início a oxidação dos compostos biotransformáveis. Na etapa seguinte, há a separação entre biomassa e efluente, por meio do processo de decantação. Caso o efluente esteja dentro das especificações determinadas pelos órgãos ambientais, este pode ser devolvido ao meio ambiente, e o lodo retornar a estação de tratamento ou seguir para um destino apropriado.

A disposição final do lodo de esgoto requer conhecimentos prévios sobre as características do lodo gerado para, assim, garantir o destino mais adequado. Trata-se de uma etapa problemática, visto que pode alcançar elevados custos e, por isso, muitas vezes é negligenciada.

Os destinos mais comuns são a incineração, reuso industrial (fabricação de tijolos, por exemplo), conversão em óleo combustível, disposição em aterro sanitário e a aplicação na atividade agrícola e de reflorestamento.

Devido à elevada concentração de matéria orgânica, macronutrientes (nitrogênio, fósforo) e micronutrientes (zinco, cobre, ferro, manganês e molibdênio) essenciais para as plantas, a biomassa resultante do processo biológico se torna um atrativo fertilizante agrícola, sendo a aplicação em lavouras muitas vezes seu destino final. ${ }^{30}$ Além de oferecer melhorias em relação aos nutrientes, a aplicação do lodo de esgoto auxilia na retenção de água em solos 
arenosos, melhorando a permeabilidade e infiltração em solos argilosos e mantendo, por um determinado tempo, uma boa estrutura e estabilidade dos agregados na superfície.

O lodo processado, após o uso nas estações, recebe o nome de biosólido que, em muitos países, passam por avaliação de risco, segundo as regulamentações específicas. No Brasil, a Resolução CONAMA 375 de 29 de agosto de 2006 “define critérios e procedimentos, para o uso agrícola de lodos de esgoto gerados em estações de tratamento de esgoto sanitário e seus produtos derivados, e dá outras providências. Essa resolução visa garantir a segurança Ambiental e Humana, obrigando a caracterização do lodo quanto ao potencial agronômico, substâncias orgânicas e inorgânicas potencialmente tóxicas presentes, indicadores bacteriológicos, agentes patogênicos e quanto à estabilidade. ${ }^{31}$

No entanto, a presença de outros compostos, como PFC, disruptores endócrinos, produtos de cuidado pessoal e fármacos, estão sendo constantemente notificados em alguns países. $^{32,33}$

Yang e Wu $(2012)^{34}$ detectaram a presença de diversos fármacos ao analisarem o biosólido gerado por 4 diferentes estações de tratamento da Califórnia. Em uma das estações, foi possível detectar e quantificar compostos como ácido acetilsalicílico, bisfenol A, carbamazepina, diclofenaco, estrona, gemfibrozil, ibuprofeno, cetoprofeno, naproxeno, octofenol, paracetamol, triclosan, entre outros. A concentração desses compostos variou entre 23, $2 \mathrm{ng} \mathrm{g}^{-1}$ a $1703 \mathrm{ng} \mathrm{g}^{-1}$, sendo mais abundantemente encontrados nos 4 lodos analisados o triclosan e octofenol, com concentração média de 1416 e $1293 \mathrm{ng} \mathrm{g}^{-1}$, respectivamente.

A presença desses compostos em níveis de concentração elevados é alarmante pois, além da problemática da re-utilização dos biosólidos como fertilizantes agrícolas, atestou a ineficiência de remoção dessas classes pelos sistemas de tratamento atualmente utilizados.

Dentro dos denominados contaminantes emergentes, uma classe que vem recebendo bastante atenção dos pesquisadores são os antibióticos, mais especificamente as sulfonamidas (SA), devido à ampla utilização tanto na medicina humana como animal.

\subsection{Sulfonamidas}

No ano de 1935 foi introduzido no mercado farmacológico um novo conceito para o tratamento quimioterápico antimicrobiano, com a utilização da sulfacrisoidina. Trata-se de um bacteriostático com estrutura química similar à do ácido Para-AminoBenzóico (PABA). ${ }^{35}$ 
O mecanismo de ação das sulfonamidas está na competição pelo sítio ativo da enzima diidropteroato sintetase, a qual catalisa a conversão do PABA a ácido diidropteróico, precursor da síntese do ácido tetrahidrofólico. Este, por sua vez, é essencial para produção de purinas e ácidos nucléicos. As sulfonamidas também inibem a permeabilidade da parede celular para o ácido glutâmico, que também é um componente essencial para a síntese do ácido fólico. Dessa forma, cepas bacterianas que produzem ácido fólico a partir do PABA são sensíveis a presença das sulfonamidas.

A maioria das sulfonamidas pode ser classificada como compostos polares, de características anfóteras, já que o nitrogênio ligado diretamente ao anel benzênico é protonado em pH ácidos (2-3), enquanto o que compõe o grupamento amida desprotona-se entre 4,5-11.36

Contudo, a ligação de substituintes no grupo amino da sulfanilamida produz sulfonamidas com características químicas, físicas e farmacológicas diferentes proporcionando, assim, um amplo espectro de aplicação. Por exemplo, a sulfametoxazol e sulfacetamida são mais comumente utilizadas no tratamento humano, enquanto que sulfatiazol, sulfadiazina, sulfamerazina, sulfametazina e sulfadimetoxina são empregados no tratamento e prevenção da saúde animal. ${ }^{35}$

Vários trabalhos relatam a presença das sulfonamidas no meio ambiente, sendo que a pesquisa em lodos de esgoto vem crescendo anualmente, como é possível observar na Figura 3, ao se realizar uma busca na base de dados SCOPUS por "sulfonamides and sludge" referente aos últimos 10 anos.

Pamreddy e colaboradores (2013) identificaram 4 sulfonamidas (sulfametazina, sulfatiazol, sulfametoxazol e sulfapiridina) em lodos de esgoto retirados de diferentes plantas de tratamento da Espanha. Todas as sulfas foram quantificadas em níveis de concentração variando de 13,1 a $249 \mathrm{ng} \mathrm{g}^{-1}$, sendo a sulfatiazol a mais frequentemente encontrada. ${ }^{37}$ 
Figura 3: Número de publicações referentes a sulfonamidas e lodo de esgotos durante os últimos 10 anos.

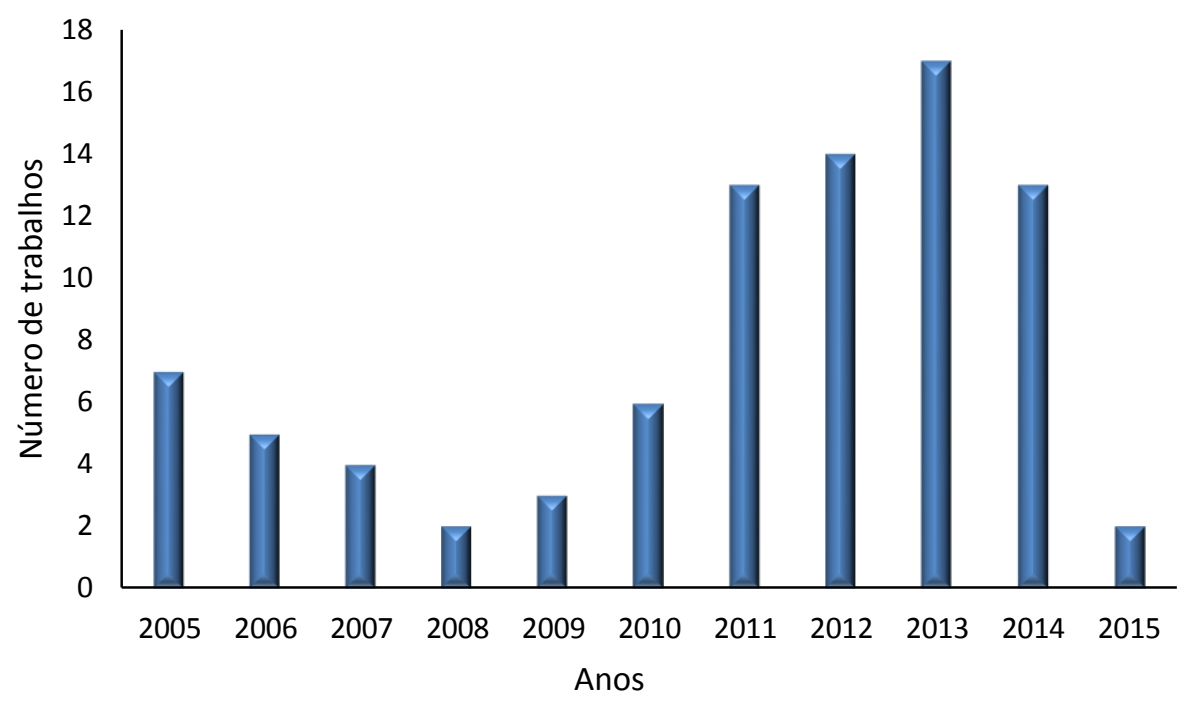

Gobel et al. (2005) também obteve resultados semelhantes, encontrando sulfonamidas nos lodos de esgoto das estações de tratamento da Alemanha, atingindo valores de $197 \mu \mathrm{g} \mathrm{kg}^{-1}$ para a sulfapiridina, já no lodo proveniente da estação de tratamento da Suíça, a máxima concentração foi atribuída a sulfametoxazole, a $73 \mu \mathrm{g} \mathrm{kg}^{-1}$. 38

Os efeitos causados pelas sulfonamidas para fauna, flora e seres humanos ainda é tema de muitos estudos, mas é sabido que raízes e caules de algumas plantas podem acumular tais compostos, podendo atingir níveis de concentrações que variam de 13 a $2000 \mathrm{mg} \mathrm{kg}^{-1} .{ }^{39}$ No entanto, uma das maiores preocupações se concentra no aumento da população de bactérias super-resistentes. Com a realização de testes realizados com alguns tipos de bactérias expostas a antibióticos, foi possível observar que houve um aumento de 5 vezes na resistência. ${ }^{40}$

A determinação de tais compostos em matrizes complexas, como o caso das matrizes ambientais, especialmente lodo de esgoto, só se tornou possível após o aprimoramento das ferramentas analíticas, tanto na etapa de preparo de amostra, como na posterior separação e detecção dos compostos.

\section{Preparo de Amostra}

A etapa denominada de preparo de amostra corresponde a todo processo envolvendo a manipulação da amostra antes da determinação instrumental dos analitos. Geralmente, corresponde à fase de processamento da amostra, extração e isolamento do analito de interesse 
e adição de outros compostos que permitam a melhor detectabilidade dos mesmos, como por exemplo, agentes derivatizantes.

Pode-se dizer que essa etapa exerce profunda influência nos resultados obtidos após o desenvolvimento de toda metodologia analítica, sendo responsável por cerca de $80 \%$ do tempo total de desenvolvimento. ${ }^{41}$

Os métodos tradicionais de preparo de amostras líquidas, quase nunca são adaptáveis para extração dos compostos em matrizes sólidas/semi-sólidas; no máximo são aplicados na etapa de purificação do extrato final obtido, seja com a remoção de compostos intrínsecos da matriz (matéria orgânica, proteínas, lipídeos, etc.) ou eliminação de interferentes que possam prejudicar a determinação instrumental.

Soxhlet foi, por muito tempo, a técnica de extração mais utilizada para amostras sólidas e semi-sólidas, na qual um solvente orgânico (hexano, por exemplo) percola pela amostra por meio de refluxo em um sistema adequado. Essa técnica, embora eficiente, apresenta como problemática os elevados tempos de extração e uso de grandes volumes de solventes orgânicos, tornando-a de elevado custo, tanto pela aquisição desses solventes, quanto pelo descarte dos mesmos.

No dias atuais, muitas são as buscas por técnicas que reduzam a quantidade de solvente orgânico e minimizem a manipulação da amostra evitando, assim, erros experimentais e diminuindo o tempo total de extração. Espera-se, também, que os métodos de preparo de amostra sejam robustos, evitando que pequenas alterações nas condições experimentais alterem significativamente o resultado.

Dentro desse contexto, surgem as técnicas miniaturizadas, como por exemplo, a extração em fase sólida (SPME, Solid Phase Microextraction). Em 1993, Zhang e Pawliszyn ${ }^{42}$ propuseram a extração de BTEX e PAHs de água, utilizando um sistema HS-SPME, sendo portanto, viável para a extração de composto voláteis. Outra forma de extração utilizando a SPME seria com imersão direta da fibra na amostra, o que, se tratando de amostras sólidas ou liquidas muito complexas, não seria possível devido à degradação da fibra. 


\subsection{Microextração em Fase Sólida (SPME - Solid Phase Micro Extraction)}

Em 1990, Arthur e Pawliszyn introduziram um novo método de preparo de amostra, denominada Microextração em Fase Sólida (SPME, Solid Phase Micro Extraction), como alternativa miniaturizada a extração em fase sólida (SPE, Solid Phase Extraction).

Embora a SPE já utilize volumes reduzidos de solventes orgânicos, quando comparada à extração líquido-líquido, a SPME consome menos solvente ainda. Dependendo da propriedade dos analitos utilizados, pode ser classificada como uma técnica de extração "solventless" (sem uso de solventes), devido a possibilidade de dessorção térmica. Além dessa vantagem, a SPME não requer instrumentação sofisticada, é facilmente automatizada e permite a reutilização das fibras extratoras.

Em sua configuração original, uma fibra de sílica fundida é recoberta com uma fase extratora, que pode ser um líquido, sólido ou ainda uma mistura dos dois. Um dispositivo, denominado holder, protege a fibra recoberta com a fase e controla a exposição dessa durante o processo de extração e de dessorção, conforme apresentado na Figura 4.

No passado, a análise de compostos voláteis por headspace era realizada por sistemas como purge-and-trap, ou ao se tratar de amostras concentradas, a amostragem era feita com seringas do tipo gastigh. Essas técnicas possuem como desvantagem a falta de seletividade aos compostos presentes na fase gasosa ou, ainda, a inserção de vapor de água dentro da coluna, diminuindo a vida útil desta.

Em 1993, Zhang e Pawliszyn propuseram a extração de BTEX e PAHs em amostras de água, utilizando um sistema HS-SPME, eliminando os problemas das antigas técnicas de extração por headspace e possibilitando a análise de compostos menos voláteis. 
Figura 4: Esquema representativo de uma fibra de SPME em uma extração por headspace

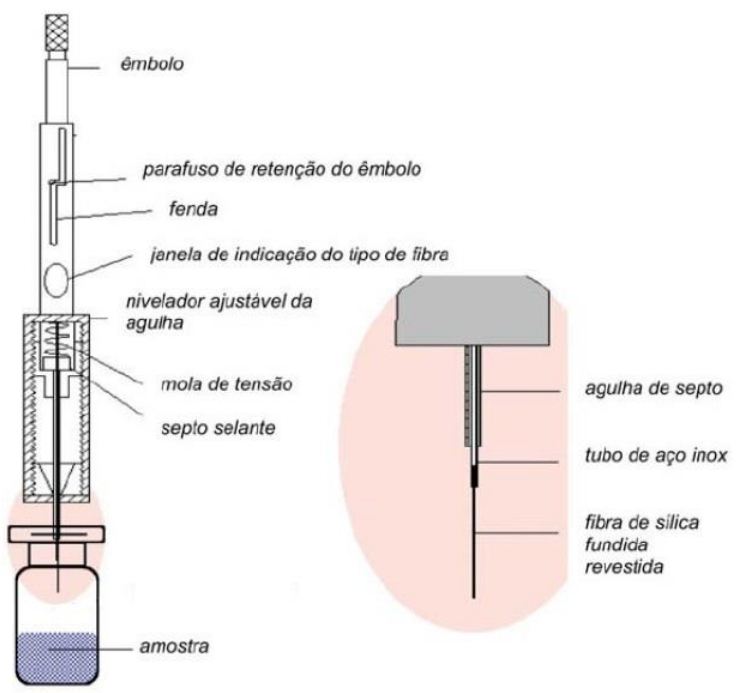

Fonte: Adaptado de ALMEIDA, C.; ROSÁRIO, P.; SERÔDIO, P.; NOGUEIRA, J.M.F. Novas perspectivas na preparação de amostras para análise cromatográfica. Química, v. 95, p. 69-77, 2009. ${ }^{43}$

Para este sistema, a SPME é baseada no equilíbrio de partição do analito entre as três fases: líquida (amostra homogênea), gasosa (headspace) e polimérica (fase extratora). A massa total do analito deverá permanecer constante durante o processo de extração, de acordo com a equação 3:

$$
C_{0} V_{2}=C_{1} V_{1}+C_{2} V_{2}+C_{3} V_{3}
$$

na qual $C_{0}$ é a concentração inicial do analito na fase gasosa, $C_{1}, C_{2} e C_{3}$ são as concentrações no equilíbrio na fase polimérica, aquosa e headspace, respectivamente. Da mesma maneira $V_{l}$, $V_{2} e V_{3}$ se referem ao volume das mesmas.

Ao definir $K_{1}$ como sendo o coeficiente para $C_{1} / C_{3}$ e $K_{2}$ como coeficiente $C_{3} / C_{2}$, tem se que a quantidade de analito absorvida pela fase polimérica, $n=C_{l} V_{l}$, pode ser definida pela equação 4:

$$
n=\frac{C_{0} V_{1} V_{2} K}{K V_{1}+K_{2} V_{3}+V_{2}}
$$

onde $K$ é o coeficiente de partição entre a fibra e a água $\left(C_{1} / C_{2}\right)$.

Para a maioria dos analitos, $K_{2}$ é muito pequeno (por exemplo, para benzeno o $K_{2}$ é 0,26 e a quantidade absorvida pela fibra no modo headspace não será afetada se o volume do headspace for muito inferior ao volume da fase aquosa. Dessa forma, o limite de detecção para 
o headspace será muito próximo ao obtido pelo modo direto de extração, na qual $n$ é expresso pela equação 5 .

$$
n=\frac{C_{0} V_{1} V_{2} K}{\left(K V_{1}+V_{2}\right)}
$$

Durante a extração no modo direto, a fibra é exposta diretamente à amostra líquida. No entanto, para analitos que possuem um alto coeficiente de partição K, o tempo de extração pode ser relativamente alto devido à camada estática de água formada em torno da fibra.

Na extração utilizando modo headspace, a difusão dos analitos na fase gasosa é em torno de 4 ordens de magnitude maior que na fase líquida diminuindo, assim, o problema causado no modo direto de extração. Além disso, a extração no headspace objetiva também proteger a fibra de interferentes de elevada massa molecular ou baixa volatilidade presentes na amostra (materiais húmicos, por exemplo), possibilitando a amostragem em amostras mais complexas, como solo, sedimentos e lodos. ${ }^{42}$

Há ainda a extração direta protegida por membrana, em que a fibra é circundada por uma membrana que tem por finalidade proteger a fibra quando exposta em amostras líquidas mais sujas. ${ }^{44}$ A Figura 5 apresenta as principais diferenças entre os 3 modos de extração citados.

Figura 5: Modos de extração propostos para SPME (a) direto, (b) headspace e (c) modo direto protegido por membrana.

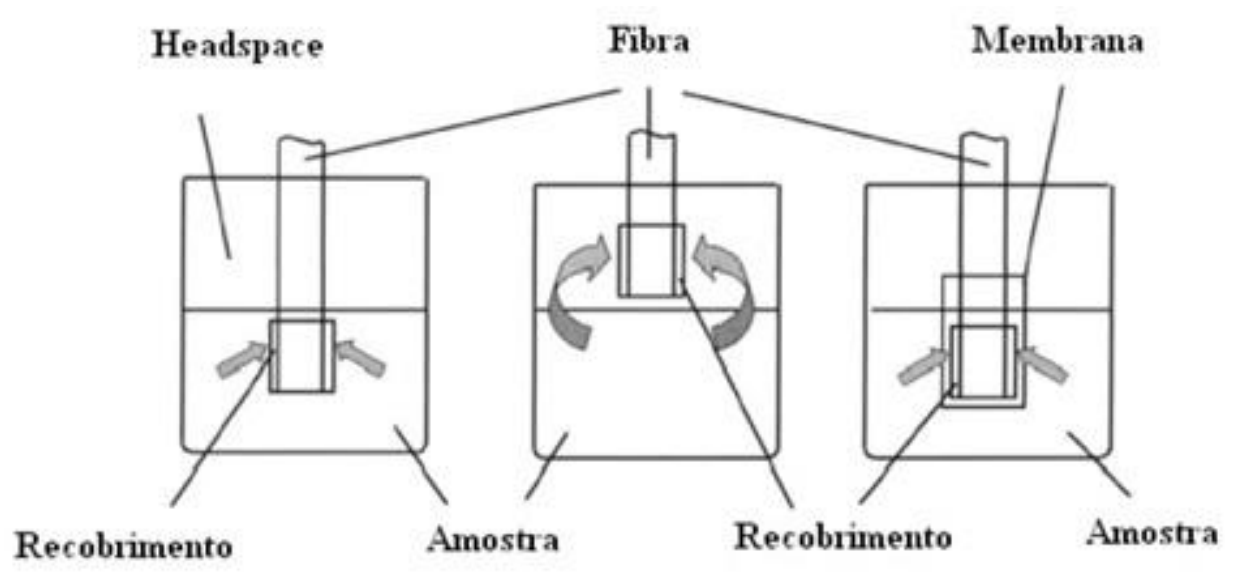

Fonte: Adaptado de ALMEIDA, C.; ROSÁRIO, P.; SERÔDIO, P.; NOGUEIRA,

J.M.F. Novas perspectivas na preparação de amostras para análise cromatográfica.

Química, v. 95, p. 69-77, 2009. ${ }^{43}$ 


\subsection{QuEChERS}

Em 2003, um novo procedimento de extração, denominado QuEChERS, foi desenvolvido por Anastassiades e colaboradores (2003). Trata-se de um acrônimo para Quick, Easy, Chip, Effective e Robust, inicialmente aplicado para análise de pesticidas presentes em frutas e vegetais. ${ }^{45}$

Esse procedimento consiste, basicamente, na extração dos analitos de interesse com acetonitrila na presença de sais $\left(\mathrm{MgSO}_{4} \mathrm{e} \mathrm{NaCl}\right)$. Como a amostra é previamente hidratada, essa etapa induz a separação das fases líquidas, promovendo a partição dos compostos de interesse para a fase extratora (fase orgânica) enquanto que a maior parte dos interferentes permanece na fase aquosa (efeito salting out). Após a centrifugação, a fase orgânica é retirada e submetida a uma etapa de SPE dispersiva (d-SPE) utilizando PSA, visando o clean-up da amostra, ou seja, remoção de possíveis interferentes.

Sendo assim, pode-se resumir o QuEChERS como uma adaptação dos conceitos já estabelecidos das técnicas LLE e d-SPE. Esse procedimento apresenta as características essenciais para ser considerado adequado para o preparo de amostra, gerando uma quantidade mínima de resíduo de solvente orgânico e possibilitando o preparo simultâneo de várias amostras, somente com a utilização de materiais de uso rotineiro de laboratório. Assim, se torna uma opção viável visto que os custos são diminuídos por não utilizar grandes quantidades de solvente e de fase sólida para a d-SPE.

Por ser um procedimento desenvolvido originalmente para a análise de pesticidas em frutas e vegetais, muitos trabalhos foram realizados dentro desse contexto. ${ }^{46,47,48}$ No entanto, o QuEChERS é extremamente flexível, permitindo modificações quanto às características do solvente orgânico, sorbente utilizado na d-SPE e combinações de sais, o que resulta na aplicação para extração de uma variedade de compostos presentes nas mais diversas matrizes. Assim, vem crescendo o número de trabalhos publicados com adaptações doQuEChERS aplicado a matrizes ambientais, principalmente, as sólidas e semi-sólidas.

Padilla-Sánchez e colaboradores (2010) desenvolveram uma metodologia analítica para a determinação de compostos fenólicos (clorofenóis, nitrofenóis, alquilfenois e cresóis) em solos utilizados para agricultura. O QuEChERS foi escolhido para o preparo de amostras, com o qual foi possível alcançar bons limites de quantificação $\left(<10 \mu \mathrm{g} \mathrm{kg}^{-1}\right.$ ), com precisão inter dias, expressa em RSD, variando entre $7-24 \% .{ }^{49}$ 
Peysson e Voulet (2013) adaptaram o QuEChERS para a extração multiresíduo de fármacos e hormônios presentes em lodo de esgoto. Em relação ao procedimento original proposto por Anastassiades, outras substâncias foram adicionadas a fim de se obter melhores resultados como, por exemplo, adição de solução de EDTA para melhorar a recuperação de algumas classes de analitos e diminuir o efeito matriz. O método foi desenvolvido para análise de mais de 116 compostos, sendo que foi possível quantificar, nas amostras reais, 35 fármacos, em concentrações em torno de $\mathrm{ng} \mathrm{g}^{-1}$. $^{0}$

\subsection{Extração em fase sólida - SPE}

A extração em fase sólida, indubitavelmente, é uma das técnicas de preparo de amostras mais utilizada ao longo dos últimos anos. A forma atual da SPE data de 1977, quando foram introduzidos no mercado cartuchos a base de sílica produzidos pela Waters Corporation. O termo atualmente utilizado, Solid Phase Extraction (SPE), foi então criado, em 1982, por colaboradores da empresa J.T. Baker Chemical Company.

O modelo de SPE mais utilizado é encontrado com a fase extratora empacotada em cartuchos ou seringas, constituídos de polietileno ou polipropileno. A fase extratora fica aprisionada entre dois discos porosos (frits), que permitem a passagem da amostra líquida sem perda de fase sólida. Pode-se variar a quantidade e tipo de fase extratora utilizada, que dependerá do objetivo final do procedimento. Uma grande quantidade de amostra pode ser percolada por este cartucho aumentando, assim, o fator de concentração. Porém, uma das desvantagens desse método é a elevada quantidade de fase sólida utilizada.

Ao se comparar as vantagens da SPE com a técnica clássica LLE, também muito utilizada nas décadas 70 - 80, evidenciam-se a redução no tempo de extração, menor potencial de formação de emulsão, baixo consumo de solvente orgânico e assim, a menor exposição do analista a solventes tóxicos, além de ser facilmente automatizada.

\subsubsection{Modos de utilização de SPE}

A realização da SPE ocorre basicamente em 4 etapas: (a) condicionamento, na qual um solvente apropriado é utilizado para a ativação da superfície da fase extratora utilizada; este solvente é então retirado ao se passar um outro solvente que seja similar ao utilizado para dissolver a amostra, (b) carregamento, quando a amostra é percolada através da fase extratora 
ocorrendo a retenção dos analitos, (c) lavagem, os interferentes retidos indesejadamente na fase extratora são removidos, (d) eluição, os analitos são eluídos da fase extratora com auxílio de um solvente adequado.

Quando realizado manualmente, o procedimento é denominado SPE off-line (fora de linha), representada na Figura 6.

No entanto, toda a etapa realizada pelo analista pode ser substituída por sistemas robotizados, caracterizando assim, a SPE at-line na qual o extrato final da SPE é injetado diretamente no cromatógrafo.

O modo de SPE in-line apresenta duas colunas acopladas diretamente em linha; a primeira destinada à extração e a segunda à separação analítica. Não há nenhum dispositivo entre as duas, fazendo com que todo eluente da primeira coluna seja direcionado para a segunda. Essa característica pode ser um problema, visto que interferentes presentes também são direcionados à coluna analítica.

Ao se realizar o procedimento descrito com auxílio do próprio cromatógrafo, o procedimento é denominado SPE online. Essa modalidade requer um arranjo bidimensional no qual se faz uso de uma pré-coluna, utilizada para a extração dos analitos, interligada a coluna analítica por meio de uma válvula de comutação.

Figura 6: Etapas envolvidas no procedimento de SPE (1) condicionamento do cartucho, (2) amostra, (3) lavagem e (4) eluição dos analitos
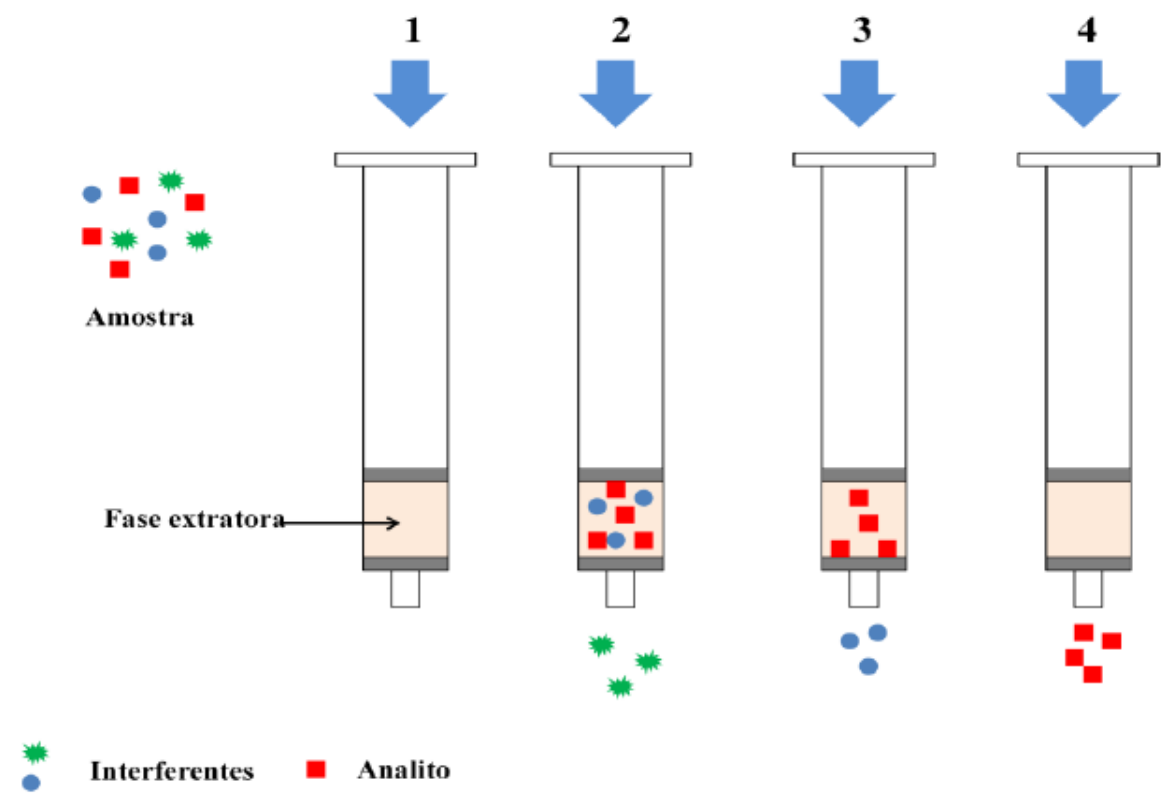
Portanto, é importante que os termos off-line, at-line, in-line e online sejam empregados adequadamente, visto que cada um apresenta um modo de integração com o cromatógrafo diferenciado. A Figura 7 ilustra a definição de cada modo.

Figura 7: Formas de SPE

\section{Preparo de amostra}

\section{Sistema de separação e detecção}

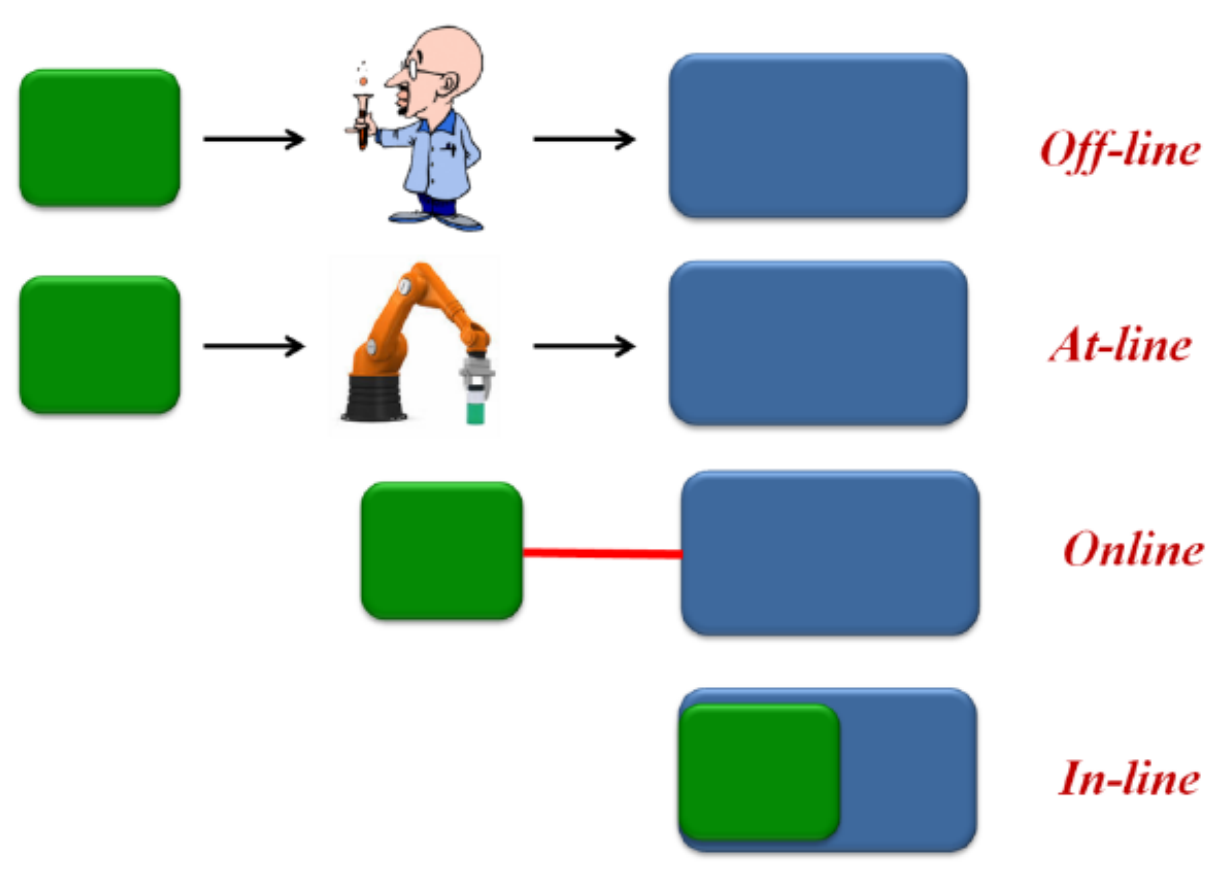

No sistema online, a amostra é carregada para a coluna de extração com auxílio de uma bomba adicional, utilizada para fazer o carregamento. Nesse modo, geralmente, se faz uso de válvulas de comutação, geralmente de 6 pórticos, permitindo que os compostos não retidos na coluna de extração sejam direcionados para o descarte, enquanto os analitos de interesse ficam aprisionados na mesma. Durante esse processo, a fase móvel utilizada para a separação cromatográfica, fica continuamente condicionando a coluna analítica. Com um giro de válvula, permite-se a eluição dos analitos, os quais são direcionados para a etapa de separação analítica (Figura 8). O modo online oferece assim, maior fator de enriquecimento da amostra, menor interferência do analista e menor tempo de análise. 
Figura 8: Configuração das válvulas nas etapas de (A) carregamento da amostra e (B) eluição dos analitos na SPE online.

A

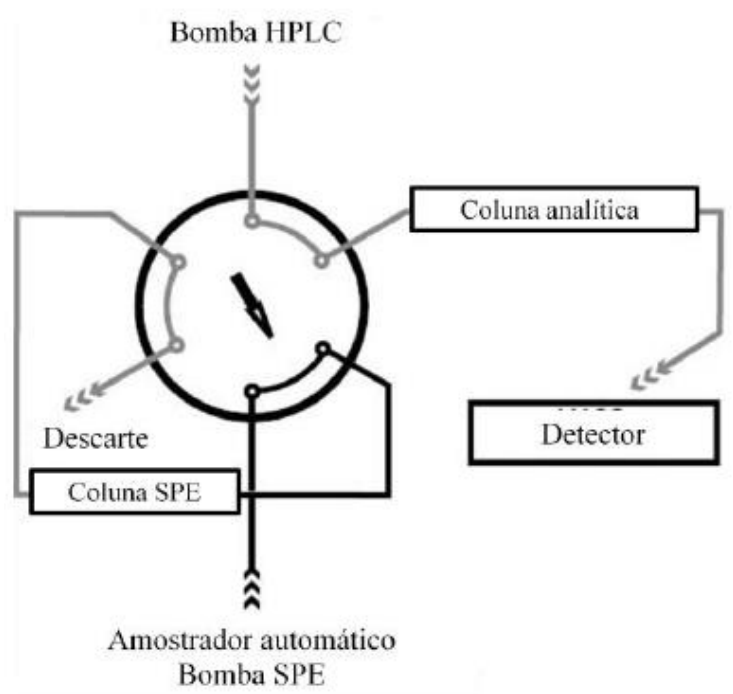

B

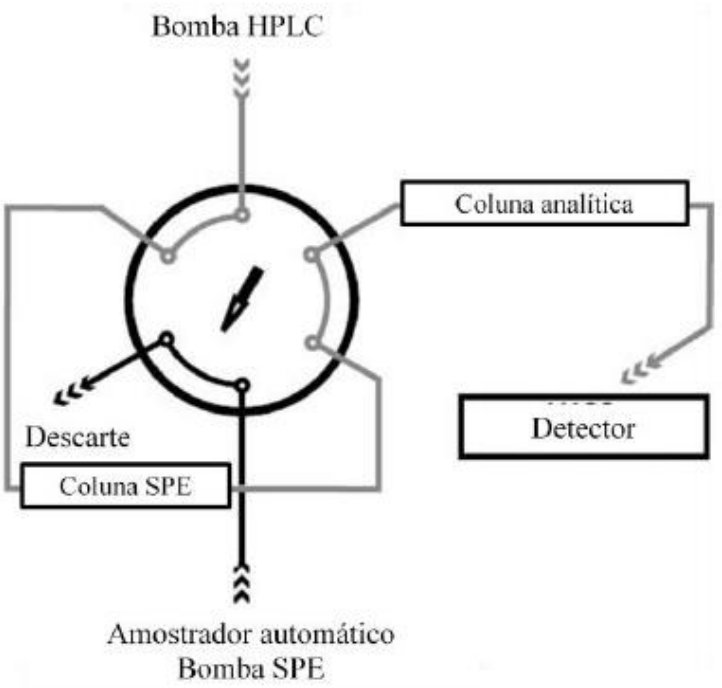

O termo column switching (comutação de colunas) muitas vezes é utilizado para referenciar o modo de extração em fase sólida online, visto que há a presença de válvula de comutação entre as colunas. No entanto, o termo pode também ser utilizado ao se acoplar colunas com outras finalidades, como por exemplo, proteger o detector e coluna analítica de interferentes e aumentar resolução e seletividade cromatográfica.

\subsubsection{Fases e modos de separação em SPE}

Em SPE a fase extratora desempenha um papel fundamental para a obtenção de bons resultados, visto que a escolha adequada da fase irá controlar parâmetros tais como seletividade, afinidade e capacidade de amostra. A determinação do tipo de fase a ser utilizada em uma determinada análise, depende fortemente das características dos analitos que se deseja isolar levando em consideração, também, as características da matriz.

Muitos são os sorbentes utilizados em SPE, sendo a sílica e as fases derivadas dela as mais tradicionais. Na superfície da sílica, encontram-se grupos silanóis livres $(\mathrm{Si}-\mathrm{OH})$ que, por adsorção, interagem com o analito (polar) no processo de extração. A adsorção em superfícies sólidas depende de uma série de fatores, tais como a distância de separação dos sítios ativos em relação ao tamanho dos solutos, da natureza da superfície sólida, da competição das moléculas pelos sítios ativos, do arranjo espacial das moléculas sorvidas no sólido, dentre outras. No 
entanto, interações fortes entre o analito e a superfície da sílica são comuns, ocasionando extrações lentas, ou até mesmo, a adsorção irreversível dos analitos.

Sendo assim, nos dias atuais, a sílica tem sido bastante empregada como material de partida para síntese de novas fases, denominadas de fases quimicamente ligadas (bonded phases). Nesse processo, os grupos ativos da sílica (silanóis) são substituídos por diferentes grupos funcionais, como CN, C8 e C18, ampliando, assim, o espectro de aplicação.

O mecanismo que rege a interação dos analitos com a fase extratora quimicamente ligada com grupos apolares é a partição, ou seja, processo que envolve a distribuição dos solutos entre a fase móvel e a fase extratora, altamente dependente da solubilidade dos analitos em ambas as fases. Porém, alguns problemas podem ser encontrados com esses tipos de sorbentes, visto que os grupos silanóis remanescentes podem adsorver facilmente água, prejudicando a extração. Outro problema também relevante está relacionado a estabilidade das mesmas, que se restringe a uma faixa de $\mathrm{pH} 3-8$. O processo denominado endcapping tem como finalidade diminuir a presença dos grupos silanóis remanescentes, aumentando a qualidade dos sorbentes à base de sílica.

As fases trocadoras de íons também são bastante comuns em SPE, caracterizadas pela interação iônica entre o analito e fase extratora. Tanto compostos de caráter ácido como compostos básicos podem ser isolados com as fases de troca iônica.

Os compostos básicos são, normalmente, retidos por fases constituídas de trocadores fortes de cátions ( $\mathrm{SCX}$, do inglês Strong Cation Exchanger) como, por exemplo, $\mathrm{SO}_{3}^{-}$ adicionado a estrutura da sílica, enquanto que para os compostos ácidos são utilizadas fases com grupos trocadores fortes de ânions (SAX, do inglês Strong Anion Exchanger), do tipo $N^{+}\left(\mathrm{CH}_{3}\right)_{3}$. É possível encontrar também, trocadores de íons mais fracos evitando-se, assim, fortes interações entre o analito e o íon de carga oposta (contra-íon), o que pode acarretar elevados tempos de extração. A Figura 9 apresenta alguns exemplos de estrutura dos sorbentes a base de sílica.

Obviamente, o pH do meio é um dos fatores mais importantes na utilização de sorbentes envolvendo fases trocadoras de íons. A ionização de um determinado composto depende do valor do seu pKa. Para compostos de caráter ácido, o pH deve ser aumentado em valores que excedam em 2 unidades o pKa do composto, garantindo a ionização do mesmo. Estando o analito na forma ionizada, ocorrerá a retenção ao se utilizar uma fase aniônica, da qual só será 
eluído ao se utilizar uma solução com $\mathrm{pH}$ duas unidades mais baixas que o valor do $\mathrm{pKa}$. $\mathrm{O}$ mesmo raciocínio é utilizado para compostos de caráter básico.

Há ainda como mecanismo de separação a exclusão por tamanho que, por meio de processos físicos de separação pode eliminar compostos indesejáveis presentes na amostra. As fases utilizadas possuem poros com tamanhos controlados, permitindo a retenção de moléculas pequenas e a eliminação de moléculas maiores. Um exemplo é a Sephadex®, polímero formado por unidades de glicose e epicloridirina.

É possível encontrar, ainda, fases extratoras que possuem tanto caráter hidrofílico quanto lipofílico, obtidas pela polimerização do divinilbenzeno (lipofílico) com nvinilpirrolidona (hidrofílico), que apresentam bons resultados tanto para compostos polares quanto para apolares. ${ }^{51}$

Figura 9: Estrutura de sorbentes a base de sílica
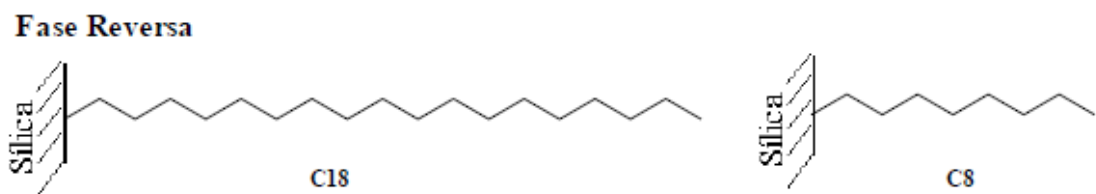

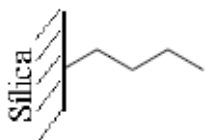

$\mathrm{C} 4$

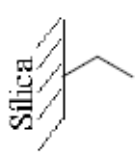

$\mathrm{C} 2$

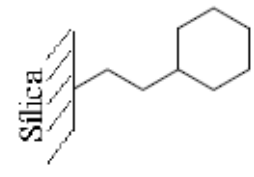

Ciclohe xil<smiles>C1=CC(CCc2ccccc2)CCC1</smiles>

Fenil

Fase Normal

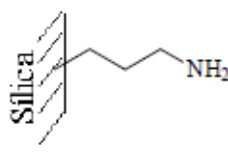

Amino<smiles>CCC12C=CC=CC(CCCC#N)(C=C1)C2</smiles>

Ciano<smiles>OC(O)COCCCC12C=CCC(CC1)C2</smiles>

Diol

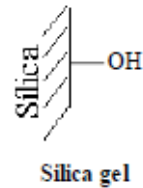

Troca Iônica

Catiônicos<smiles>CCC12C=CC=CC(CCCS(=O)(=O)[O-])(C=C1)C2</smiles>

Ácido propil sulfônico $\left(\mathrm{SO}_{3} \mathrm{H}\right)$

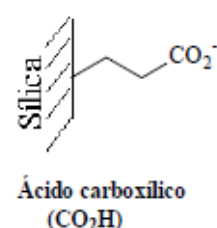

$\left(\mathrm{CO}_{2} \mathrm{H}\right)$

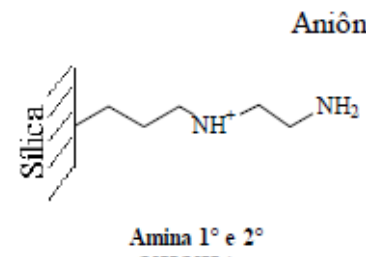

$\left(\mathrm{NH} / \mathrm{NH}_{2}\right)$

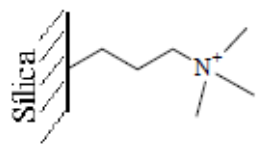

Amina quaternária

$\left(\mathrm{N}^{+}\right)$

Fonte: NAZARIO, CARLOS EDUARDO DOMINGUES. Desenvolvimento e caracterização de materiais baseados em sílica com aplicabilidade em extração em fase sólida e cromatografia líquida de alta eficiência. 2013. 225f. Tese (Doutorado em Química Analítica e Inorgânica) - Instituto de Química de São Carlos, Universidade de São Paulo, São Carlos, 2013. ${ }^{52}$ 
A busca por fases extratoras que sejam mais seletivas proporcionaram o desenvolvimento de fases mistas (mixed-mode polymeric sorbents), que possuem as características básicas das fases poliméricas (retenção por mecanismos de partição) juntamente com a presença de grupos ionizáveis permitindo, também, a retenção por ligações iônicas. Dessa forma, os componentes da matriz (interferentes) e os analitos são eluídos separadamente nas etapas de lavagem e eluição, respectivamente, por soluções com pH adequado para cada procedimento. ${ }^{53}$ As fases mistas podem ser classificadas tanto como catiônicas como aniônicas, dependendo do grupo iônico ligado ao polímero.

O desenvolvimento e aprimoramento dos métodos utilizados para preparo de amostra permitem a obtenção de extratos com uma menor quantidade de interferentes facilitando, assim, a identificação do composto alvo. Porém, com a complexidade das matrizes de interesse atual como, por exemplo, fluidos biológicos e matrizes ambientais, se faz necessário o uso de ferramentas analíticas poderosas, como os sistemas de separação por cromatografia e posterior detecção por espectrometria de massas garantindo, dessa forma, a identificação e quantificação do composto de interesse.

\section{Sistemas cromatográficos de separação}

A cromatografia é uma poderosa técnica de separação analítica conhecida, oficialmente, desde 1903 com os experimentos de Mikhael Tswett. A separação ocorre devido à distribuição dos analitos entre duas fases: uma fase estacionária e uma fase móvel. ${ }^{54}$

Entre as diversas formas de se caracterizar os métodos cromatográficos, a distinção entre a natureza física da fase móvel empregada no processo de separação é mais usual, podendo-se citar três grupos distintos: cromatografia gasosa, quando a fase móvel for um gás; cromatografia liquida, quando a mesma for um líquido e cromatográfica com fluido supercrítico, ao se utilizar um fluido em estado supercrítico para a separação analítica.

A cromatografia gasosa é amplamente utilizada para a separação de componentes voláteis/semivoláteis, visto que, a introdução dos analitos ocorre por meio da volatilização dos mesmos dentro do compartimento denominado injetor, que deve estar devidamente aquecido para garantir a rápida e completa vaporização dos analitos. Assim, com o auxílio do gás de arraste, a amostra é levada para a coluna analítica onde, sob condições de temperatura ajustadas, ocorrerá a separação analítica. O tipo de gás utilizado independe do tipo de analito analisado, sendo a escolha determinada pelo tipo de detector que será empregado. 
Embora a HRGC (High Resolution Gas Chromatography) apresente bons resultados referentes à eficiência cromatográfica e a velocidade de separação, inconvenientes quanto às características dos analitos são ressaltados. Como supracitado, é necessário que ocorra a volatilização dos analitos para que a separação possa ocorrer, e que nas condições de separação, os compostos sejam termicamente estáveis. Dessa forma, o espectro de aplicação da HRGC é vastamente diminuído, visto que uma grande parcela dos compostos orgânicos não pode ser satisfatoriamente separada sem prévia modificação da amostra (como, por exemplo, derivatização), fato que amplia a aplicação da HRGC, porém adiciona mais uma etapa no preparo de amostra, aumentando-se assim, as fontes de erro.

A cromatografia liquida (LC) compensa os problemas apresentados pela gasosa, não se limitando a compostos voláteis e semivoláteis. Assim, a LC se torna apropriada para análise de macromoléculas, compostos iônicos, produtos naturais instáveis, e também moléculas pequenas como os fármacos, os quais são de grande interesse atualmente.

A separação em cromatografia liquida ocorre a partir da interação especifica dos analitos entre a fase móvel e estacionária gerando, assim, uma variável adicional a ser otimizada e controlada a fim de obter melhores resultados. A escolha dessas variáveis depende exclusivamente das características dos analitos; assim, a HPLC (High performance liquid chromatography) pode assumir denominações diferentes em relação à polaridade tanto da fase móvel quanto da estacionária, que devem ser selecionadas de acordo com o objetivo da análise. Nos dias atuais, a HPLC em fase reversa (RP - do inglês Reversed Phase) é a mais empregada, principalmente por ser compatível com a maioria dos compostos de interesse. ${ }^{54}$

Nesse modo de operação, a fase estacionária geralmente consiste de partículas de sílica utilizadas como suporte para ligação da fase adequada. Cadeias alquílicas são normalmente utilizadas como fase ligada nesse tipo de suporte, principalmente a C18 (cadeia octadecil ligada à superfície da sílica); porém, cadeias alquílicas menores podem também ser empregadas, modificando assim, a polaridade da fase. A eluição dos compostos ocorre com a utilização de uma fase móvel mais polar quando comparada a fase estacionária, normalmente composta por água ou tampão aquoso, misturado a solventes orgânicos (metanol, acetonitrila e outros). O mecanismo que rege esse tipo de separação é a partição, na qual os analitos menos polares são mais retidos pela fase alquílica quimicamente ligada.

Os avanços em LC, por muito tempo, foram motivados pelo desenvolvimento constante de novas partículas a serem empregadas como fase estacionária melhorando, assim, a 
seletividade, eficiência e estabilidade das colunas até então utilizadas. No entanto, após a consolidação dessa etapa, pesquisas foram direcionadas à necessidade de desenvolver análises mais rápidas sem prejudicar a eficiência cromatográfica.

A diminuição no tamanho médio das partículas utilizadas como fase estacionária se tornou objeto de pesquisas a fim de se diminuir o tempo total de análise sem perda de eficiência. De acordo com a equação de van Deemter (Equação 6), originalmente desenvolvida para GC e posteriormente estendida para LC, pode-se observar a relação existente entre eficiência (expressa pela altura de um prato $-H$ ) e o tamanho da partícula $(d p)^{54}$

$$
H=A+\frac{B}{\mu}+C \mu
$$

onde o termo A é responsável pelo alargamento dos picos devido a diferentes caminhos seguidos pela molécula, o termo B pela difusão turbulenta e o termo C pela transferência de massa entre a fase móvel e a fase estacionária.

Os termos A e C são influenciados pelo tamanho da partícula, ou seja, partículas menores favorecem a diminuição da altura do prato teórico $(H)$, que, para uma coluna de mesmo comprimento, acarretará no aumento do número de pratos e, consequentemente, o aumento da eficiência da coluna.

Assim, o uso de partículas menores que 2,0 $\mu \mathrm{m}$, aliado ao desenvolvimento de sistemas cromatográficos que suportem as elevadas pressões requeridas (15000 psi) para se obter o máximo de desempenho, foi possível diminuir o tempo das análises em até 20 vezes, quando comparado aos sistemas convencionais. ${ }^{55}$

O uso de tais partículas, associada à elevada vazão da fase móvel, originou o termo UPLC (cromatografia liquida em pressões ultra elevadas), foi utilizado pela Waters Corporation $®$ em 2004, capaz de operar em pressões acima de $100 \mathrm{Mpa}^{56}$

Outra vertente em relação aos avanços relacionados à LC se refere à miniaturização do sistema, caracterizada pela diminuição do consumo de solvente e por obter melhoras consideráveis no desempenho analítico.

No entanto, a nomenclatura referente à miniaturização da LC possui algumas divergências como, por exemplo, a classificação por vazão da fase móvel feita por Chervet et 
al. (1996) $)^{57}$ e a de Saito et al. (2004) ${ }^{58}$ por subdivisão entre as colunas com diâmetro interno inferior a $1,0 \mathrm{~mm}$ (Tabela 3$)$.

Tabela 3: Comparação entre as diferentes formas de classificação da cromatografia líquida

\begin{tabular}{ccc}
\hline Classificação & Saito (d.i.) & Chervet (vazão) \\
\hline HPLC convencional & $2,0-5,0 \mathrm{~mm}$ & $0,5-2,0 \mathrm{~mL} \mathrm{~min}{ }^{-1}$ \\
HPLC microbore & $<2,0 \mathrm{~mm}$ & $100-500 \mu \mathrm{L} \mathrm{min}{ }^{-1}$ \\
Micro-HPLC & $0,5 \mathrm{a} 1 \mathrm{~mm}$ & $10-100 \mu \mathrm{L} \mathrm{min}^{-1}$ \\
HPLC capilar & 0,1 a $0,5 \mathrm{~mm}$ & $1,0-10 \mu \mathrm{L} \mathrm{min}{ }^{-1}$ \\
Nano-HPLC & 0,01 a $0,1 \mathrm{~mm}$ & $10-1000 \mathrm{~nL} \mathrm{~min}^{-1}$ \\
\hline
\end{tabular}

Embora haja discrepâncias na forma de se nomear a miniaturização da LC, todos pesquisadores citados concordam que colunas com diâmetro interno inferior a 1,0 mm, não podem ser consideradas como HPLC convencional. Desse modo, este trabalho se referirá como cromatografia liquida capilar (cLC) a todos os sistemas que operarem utilizando colunas com d.i. $<1,0 \mathrm{~mm}$.

As vantagens da cLC não se restringem somente a miniaturização do sistema mas, sim às vantagens inerentes a ela como, por exemplo, a economia no uso de solventes orgânicos, menor consumo de fase estacionária, quantidades diminutas de amostras, possibilidade do uso de programação de temperatura e o aumento na sensibilidade dos métodos ao se fazer uso de detectores sensíveis a massa. ${ }^{59}$

Embora as vantagens listadas para a miniaturização da LC sejam atrativas, alguns empecilhos foram encontrados para a implementação da técnica como, por exemplo, adequação dos sistemas instrumentais devido à necessidade de se reduzir o tamanho da válvula de injeção, cela de detecção e qualquer outro volume extra coluna a fim de se minimizar o efeito de espalhamento da banda cromatográfica. ${ }^{60}$

Porém, espera-se que com o desenvolvimento mecânico e eletrônico, essa técnica possa alcançar a aceitação dos laboratórios de rotina visto que no meio acadêmico já está bastante consolidada. 


\section{Otimização Experimental}

Ao iniciar o desenvolvimento de um método, é de extrema importância que se otimize os fatores que irão afetar o resultado final; para isso, é necessário ter um conhecimento prévio do método para que se faça a escolha correta de quais parâmetros avaliar.

Muitas podem ser as variáveis que afetam a resposta e, assim, a otimização se torna uma etapa crucial para se obter melhores resultados. A otimização univariada, assim denominada por analisar o efeito individual de cada variável sobre a resposta, já foi largamente utilizada nos últimos anos. No entanto, tal otimização pode induzir ao erro visto que não há meios para se avaliar o efeito causado pela interação das variáveis estudadas. ${ }^{61}$

Uma alternativa viável para contornar esse problema está na utilização da ferramenta quimiométrica "planejamento de experimentos", que consiste na análise multivariada dos dados, fornecendo informações tanto do efeito individual de cada variável independente como dos efeitos gerados pela interação entre elas.

\subsection{Planejamento Experimental Fatorial $\left(n^{k}\right)$}

Para executar um planejamento fatorial, deve-se estipular, primeiramente, quantas variáveis independentes $(k)$ serão avaliadas no sistema e em quais níveis essas serão estudadas (n), ou seja, quais os valores para cada variável. O efeito gerado para cada variável é observado quando há mudança no nível da variável; então, para que isso aconteça é necessário $n \geq 2$. Assim, o planejamento fatorial mais simples existente é o $2^{2}$, em que 4 ensaios serão realizados.

É importante salientar que desvios atípicos podem ser associados aos ensaios, e como forma de contornar esse problema é extremamente importante que o planejamento experimental seja realizado de forma aleatória evitando-se que o efeito dos erros sistemáticos possa ser atribuído a resposta.

Embora a realização do planejamento experimental fatorial seja uma excelente alternativa para a avaliação dos efeitos individuais e conjugados das variáveis independentes, o elevado número de variáveis estudadas pode prejudicar a prática dessa técnica, devido ao excessivo número de ensaios requeridos. Normalmente, valores para $k \geq 4$, correspondendo a 16 ensaios, podem se tornar um problema de acordo com as características do tipo de ensaios 
necessários. Essa decisão deve ser cautelosamente tomada, considerando-se custo, tempo e disponibilidade de cada estudo. ${ }^{62}$

\subsection{Planejamento Fatorial Fracionado}

Ao se trabalhar em um sistema que possui um número elevado de variáveis que possam interferir na resposta desejada, o uso da ferramenta planejamento de experimentos fatorial pode se tornar um problema, visto que, quanto mais variáveis independentes, maior o número de experimentos realizados, maior número de interações de ordem elevada e maior a probabilidade de uma ou mais variáveis não serem significativas para a obtenção da resposta.

No entanto, ao se inicializar um estudo com muitas variáveis não é possível estimar qual delas exercerá menor efeito na variável resposta. Assim, o uso de planejamento de experimentos fracionário permite estudar todas variáveis importantes, utilizando o menor número de ensaios possíveis para, posteriormente, ajudar na identificação das variáveis que realmente irão exercer maior efeito no sistema, funcionando como um planejamento de triagem, normalmente, seguido por um planejamento mais completo.

O número de ensaios gerado nesse tipo de planejamento obedece à relação $2^{k-a}$, onde $a$ representa o tamanho da fração empregado (por exemplo, $1 / 2,1 / 4, \ldots, 1 / 16$ ), que influenciara diretamente no número de ensaios. Como exemplo, a Tabela 4 representa a configuração de um planejamento fatorial fracionário $2^{4-1}$, onde o quarto fator $\left(V_{4}\right)$ é determinado pela interação dos 3 primeiros fatores $\left(V_{1}, V_{2}\right.$ e $\left.V_{3}\right)$.

Tabela 4: Tabela representativa de um planejamento fatorial fracionário $2^{4-11}$.

\begin{tabular}{ccccc}
\hline \multirow{2}{*}{ Ensaios } & \multicolumn{5}{c}{ Variáveis } \\
\cline { 2 - 5 } & $\boldsymbol{V}_{\mathbf{1}}$ & $\boldsymbol{V}_{\mathbf{2}}$ & $\boldsymbol{V}_{\mathbf{3}}$ & $\boldsymbol{V}_{\mathbf{4}}$ \\
\hline 1 & - & - & - & - \\
2 & + & - & - & + \\
3 & - & + & - & + \\
4 & + & + & - & - \\
5 & - & - & + & + \\
6 & + & - & + & - \\
7 & - & + & + & - \\
8 & + & + & + & + \\
\hline
\end{tabular}




\subsection{Planejamento Composto Central}

O planejamento composto central é muito utilizado na etapa de determinação da melhor condição aplicada, sendo entre os planejamento de segunda ordem, o mais aplicado.

Os componentes mais importantes para a elaboração de um planejamento composto central são:

$\checkmark$ Pontos do vértice: são os pontos idênticos aos utilizados no planejamento fatorial completo de dois níveis, determinado pela expressão $2^{\text {n }}$, responsáveis pelos termos quadráticos.

$\checkmark$ Pontos estrela: pontos mais distantes do ponto central, determinado por $\alpha=\sqrt{k}$. Com eles é possível ampliar a área de estudo normalmente estipulada pelos níveis máximo e mínimos estipulados pelo planejamento fatorial.

$\checkmark$ Pontos centrais: geralmente os experimentos referentes a esse ponto são realizados em replicatas, que têm como finalidade verificar a variância da resposta prevista e fornecer uma medida do erro puro.

A Figura 10 apresenta um esquema gráfico de um planejamento composto central $2^{3}{ }^{63}$

Figura 10: Esquema representativo de um planejamento composto central

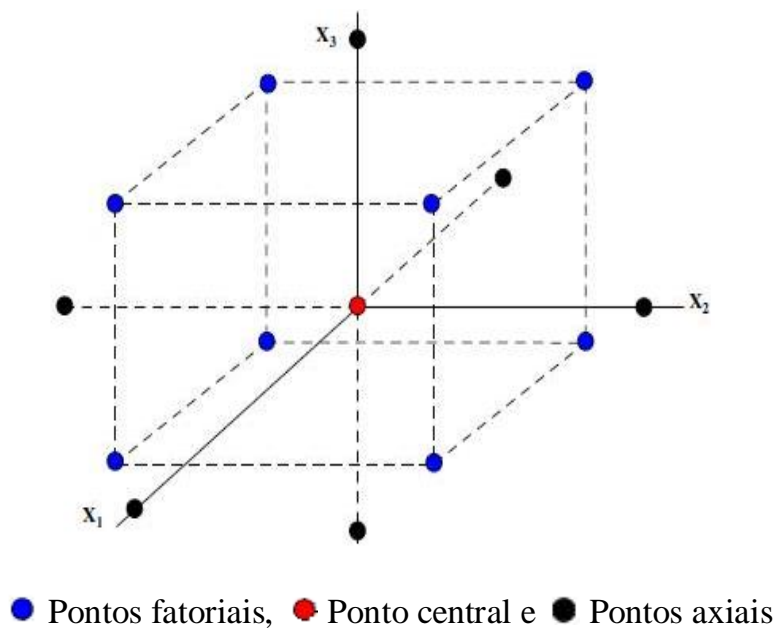

\section{Validação de Métodos}

A necessidade da apresentação de resultados analíticos confiáveis fez com que as medições químicas sejam submetidas uma avaliação denominada validação, promovendo assim a comparabilidade, rastreabilidade e credibilidade dos métodos analíticos atualmente propostos. 
As definições de validação variam de acordo com os guias utilizados; no entanto, todos visam atender ao mesmo objetivo. De acordo com a RE 899 de 2003 da ANVISA (Agência Nacional de Vigilância Sanitária), validar um método significa "garantir, por meio de estudos experimentais, que o método atenda às exigências das aplicações analíticas, assegurando a confiabilidade dos resultados. Para tanto, deve apresentar especificidade, linearidade, intervalo, precisão, sensibilidade, limite de quantificação, exatidão, adequados à análise". ${ }^{64}$

Assim, a validação do método visa controlar os fatores que podem levar a imprecisão ou inexatidão de um dado apresentado. Os parâmetros normalmente avaliados durante a validação de um método estão apresentados a seguir.

\subsection{Linearidade}

A necessidade de se obter resultados que sejam confiáveis quanto à quantificação do analito é uma das etapas mais importantes da validação. Garantir, em um dado intervalo de confiança, que a concentração medida corresponde fielmente à encontrada na amostra garante a qualidade do método. Para isso a curva de calibração, ou curva analítica, é elaborada, garantindo a linearidade do método, ou seja, que os resultados obtidos são diretamente proporcionais à concentração do analito nessa faixa. Na maioria das vezes, corresponde a uma reta obtida pela regressão linear dos dados, a partir da qual se obtém o coeficiente linear (a), angular (b) e o de correlação dos dados (R). Esse último normalmente é utilizado para expressar a qualidade da regressão, visto que, quanto mais seu valor se aproximar de 1 , menor será a dispersão do conjunto de dados em torno da curva, ou seja, menor a somatória dos resíduos.

Ao se elaborar a curva analítica, estima-se que a dispersão das medidas sejam independentes ao longo da curva, ou seja, dos níveis de concentração avaliados. Ao se obter esse comportamento, caracterizam-se os dados como homocedásticos.

No entanto, os dados podem apresentar variâncias diferentes para as diferentes concentrações utilizadas na elaboração da curva analítica, principalmente quando a faixa linear é muito extensa e desvios maiores são encontrados nas concentrações mais elevadas, o que demonstra a heterocedasticidade dos dados. ${ }^{65}$

Uma forma eficaz de observar esta característica é por meio da aplicação do teste-F. O $F$ experimental $\left(F_{E x p}\right)$ é determinado pela equação 7 : 


$$
F_{E x p}=\frac{S_{2}^{2}}{S_{1}^{2}}
$$

onde, $S_{1}^{2}$ se refere à variância obtida no menor nível e $S_{2}^{2}$ à variância no maior nível da curva analítica. $O$ valor obtido com essa razão é comparado ao valor tabelado $F_{T a b}=F_{(f 1, f 2)}$, sendo $f 1=f 2=(n-1)$ graus de liberdade $(n=$ número total de experimentos), com $99 \%$ de

confiança. A verificação da heterocedasticidade se dá ao encontrar $F_{E x p}>F_{T a b}$, obtido com limite de confiança de $99 \%$, ou seja, com resíduos dispersos de forma não aleatória ao longo do eixo $x .^{66}$

Como forma de correção do modelo, pode-se fazer o uso da calibração ponderada com auxílio de pesos ( $w$, do inglês weight least square) que atribuirá menor importância aos dados com elevada variância e maior importância para os dados com menor variância. Os pesos normalmente são valores empíricos $\left(1 / x, 1 / x^{2}, 1 / x^{0,5}, 1 / y, 1 / y^{0,5}, 1 / y^{2}\right)$ que quando utilizados atribuem novos valores para os coeficientes a e b, possibilitando a elaboração de novos modelos lineares. $\mathrm{O}$ melhor ajuste fornecerá a menor de percentagem de erro individual.

Para métodos analíticos sugere-se que a curva seja elabora em, no mínimo, 5 níveis de concentração distintos, enquanto para métodos bioanalíticos, a curva deve conter, no mínimo 6 níveis, com coeficiente de correlação de no mínimo 0,98 e 0,99 , respectivamente.

A região compreendida entre o nível de menor concentração e o nível de maior concentração é definida como intervalo ou faixa linear. Para quantificar corretamente os analitos deve-se considerar a interação dos mesmos com os componentes da matriz, por isso, é extremamente importante que a curva seja construída com os analitos extraídos da matriz.

\subsection{Precisão}

Parâmetro que avalia a confiabilidade de uma análise ao se repetir sequencialmente. A precisão pode ser expressa tanto pela estimativa do desvio padrão absoluto quanto pelo desvio padrão relativo (DPR\%), conhecido também por coeficiente de variação (CV\%). Os valores aceitáveis são geralmente de 15\%, exceto para o LIQ (Limite Inferior de Quantificação), no qual a variação permitida chega a $20 \%$. 


\subsection{Limite de Detecção (LD)}

Representa a menor concentração do analito que pode ser detectada em confiabilidade de precisão aceitável, em função do ruído do sistema. Para isso, a medição o nível mínimo é estimada na relação de 3 vezes o ruído da linha de base, de acordo com a equação 8:

$$
L D=3 \times \frac{S}{S}
$$

onde, $s$ se refere ao desvio padrão do intercepto com eixo Y e $S$ é a inclinação da curva de calibração (coeficiente angular).

Outra forma de determinar o limite de detecção é estipular a concentração ou massa do analito que gere um sinal três vezes maior que o ruído gerado empregando-se o branco como referência.

\subsection{Limite de Quantificação}

Trata-se do menor valor que pode ser determinado quantitativamente pelo método analítico obtido com exatidão adequada. A determinação é feita de acordo com a equação 9.

$$
L Q=10 \times \frac{S}{S}
$$

A outra maneira de se determinar o limite de quantificação é calculando-se a massa ou concentração do analito que gere um sinal 10 vezes maior que aquele gerado ao se empregar o branco como referência.

\subsection{Exatidão}

Determinada pela concordância dos dados obtidos experimentalmente com os valores de referência aceito como verdadeiros, determinada pela equação 10

$$
\text { Exatidão }=100 \times \frac{\text { Concentração média experimental }}{\text { Concentração téorica }}
$$


obtida em pelo menos 3 níveis distintos de concentração (concentração baixa, média e alta) em, pelo menos, triplicata dos ensaios analíticos. Valores baixos de exatidão podem ser ocasionados, na maioria das vezes, por erros sistemáticos que provocam tendências no resultados. Equipamentos não calibrados, interferentes na amostra, baixa recuperação na extração, entre outros exemplos, podem refletir negativamente nos valores de exatidão.

\subsection{Recuperação}

Figura de mérito que avalia a eficiência do método analítico em se isolar o analito da matriz estudada. Esse estudo é avaliado ao se adicionar o analito a matriz isenta de interferente e submetê-la ao processo de extração e comparar o sinal fornecido com aquele obtido por meio da análise realizada ao se adicionar o analito no extrato da matriz. 



\section{Capítulo 2}

Remediação de solos contaminados por derivados de petróleo utilizando extração com $\mathrm{CO}_{2}$ supercrítico 



\section{Introdução}

A preocupação com a poluição ambiental é tema constante de pesquisas desenvolvidas nos dias atuais. Compostos orgânicos monoaromáticos, como os BTEX (benzeno, tolueno, etilbenzeno e isômeros do xileno) são indicadores de possível contaminação ambiental, visto que frequentemente, são encontrados nos produtos derivados do petróleo, como por exemplo, gasolina. Quando esses compostos são encontrados em solos próximos a postos de combustíveis, suas presenças podem ser atribuídas às precárias condições de armazenamento nos tanques subterrâneos, ocasionando vazamentos.

Dessa forma, o estudo de técnicas de remediação se torna importante, principalmente, se for adequada para remoção dos contaminantes in-situ aumentando, assim, a eficiência do método e diminuindo custos operacionais.

A extração com fluido supercrítico (SFE) foi estudada nesse projeto com o propósito de remover compostos orgânicos monoaromáticos de solos contaminados usando, para isso, um sistema simples de extração operando na sua capacidade plena. Essa técnica é bastante atrativa, visto que o solvente mais utilizado, $\mathrm{CO}_{2}$, é ambientalmente correto e possui propriedades críticas amenas (temperatura e pressão).

Porém, a quantificação por SFE não é muito simples, principalmente quando se trata de compostos voláteis e em baixa concentração. Muitos trabalhos realizam o procedimento de extração com elevadas concentrações de contaminantes adicionados ao solo, revertendo em concentrações residuais também elevadas.

Esse trabalho visa a remediação de solos contaminados em baixa concentração do BTEX (máximo de 2,0 $\mu \mathrm{g} \mathrm{g}^{-1}$ ), utilizando a técnica SPME como método de preparo de amostra após a SFE, por essa ser eficiente e não utilizar solvente orgânico em nenhuma das etapas (novamente, ambientalmente correto).

\section{Objetivo}

\subsection{Objetivo Geral}

Este trabalho tem como objetivo principal desenvolver uma técnica de remediação de solos contaminados por derivados de petróleo presentes em combustíveis (BTEX), utilizando $\mathrm{CO}_{2}$ no estado supercrítico. 


\subsection{Objetivos Específicos}

$\checkmark$ Desenvolver e validar um método analítico que permita o acompanhamento da descontaminação do solo por $S F E$, utilizando para isso a extração por $H S$-SPME com separação e detecção por $G C-M S$.

$\checkmark$ Otimizar as condições da HS-SPME por planejamento de experimentos multivariados

$\checkmark$ Modificar o sistema de SFE já existente no laboratório do Grupo de Cromatografia IQSC - USP para a extração de interesse

$\checkmark$ Otimizar o tempo de extração total, razão do tempo de extração estático/dinâmico, pressão e temperatura para a SFE por planejamento de experimentos.

\section{Materiais e Métodos}

\subsection{Reagentes}

Os padrões analíticos das substâncias benzeno, tolueno, etilbenzeno e xilenos foram adquiridos de Alltech (StateCollege, USA), enquanto que o isopropilbenzeno, utilizado como padrão interno, foi adquirido de Supelco (Bellefonte, EUA).

As soluções estoque de BTEX foram preparadas em metanol a $500 \mathrm{mg} \mathrm{L}^{-1}$ e estocadas a $-20^{\circ} \mathrm{C}$. O isopropilbenzeno foi também preparado em metanol a $0,6 \mathrm{~g} \mathrm{~L}^{-1}$.

\subsection{Solo}

As amostras de solo isentas dos contaminantes de interesse foram retiradas entre 15 a $20 \mathrm{~cm}$ de profundidade no Campus I da USP - São Carlos (-22,004797 de longitude e $-47,898991$ de latitude) e caracterizadas pelo departamento de Geociências do mesmo instituto.

Trata-se de um solo caracterizado, de acordo com sua granulometria, em areia média a fina siltosa marrom avermelhada, com umidade em torno de $14 \%$ e matéria orgânica em torno de $10 \%$. As amostras foram peneiradas a $2 \mathrm{~mm}$ para manter a homogeneidade durante os ensaios analíticos.

Todas as amostras foram contaminadas com um volume fixo de solução padrão na concentração desejada e mantidas por 48 horas a $-20{ }^{\circ} \mathrm{C}$, como realizado no trabalho de Martendal e Carasek (2011), ${ }^{67}$ na análise de PAHs por SPME em solo. 


\subsection{Microextração em fase sólida (SPME - Solid Phase Micro Extraction)}

As fibras e holders foram adquiridas de Supelco (Bellefonte, EUA). Utilizaram-se para as análises de BTEX, fibras de PDMS $100 \mu \mathrm{m}$, condicionadas conforme recomendações do fabricante.

As extrações foram realizadas em vials de headspace, hermeticamente fechados, com capacidade para $22 \mathrm{~mL}$, com temperatura controlada por um banho termostático modelo Q214 M2 de Quimis (Diadema, Brasil). As fibras foram expostas no headspace após 5,0 minutos, permitindo, assim, que a amostra alcançasse a temperatura desejada. A dessorção térmica dos analitos foi realizada no injetor cromatográfico por 2,0 minutos no modo splitless.

\subsection{Análises Cromatográficas}

As análises cromatográficas foram realizadas nas condições descritas abaixo:

- $\quad$ Sistema GC-MS QP5050, Shimadzu, Japão

- Injetor: Modo Splitless (2,0 min)

- Temperatura do injetor: $250^{\circ} \mathrm{C}$

- Temperatura da interface: $300^{\circ} \mathrm{C}$

- Gás de arraste: Hélio

- Coluna Supelco SLB - 5MS (30 m x 0,25 mm x 0,25 $\mu \mathrm{m})$, com fluxo de 1,4 $\mathrm{mL} \mathrm{min}^{-1}$

- Temperatura da coluna: $40^{\circ} \mathrm{C}$ por $1 \mathrm{~min}, 12^{\circ} \mathrm{C} \mathrm{min}{ }^{-1}$ até $150{ }^{\circ} \mathrm{C}$

- Modo de aquisição: SIM, com íons monitorados de acordo com o proposto pelo EPA, 1996 (Tabela 5).

Tabela 5: Íons utilizados para monitoramento no modo de aquisição SIM

\begin{tabular}{cc}
\hline Compostos & Íons monitorados \\
\hline Benzeno & 77,78 \\
Tolueno & 91 \\
Etilbenzeno, Xilenos & $77,78,91$ \\
\hline
\end{tabular}




\subsection{Extração com Fluido Supercrítico (SFE - Supercritical Fluid Extraction)}

O sistema utilizado para SFE foi anteriormente desenvolvido por Sargenti e Lanças $(1994)^{68}$ como ilustrado na Figura 5.

Para o atual trabalho, foi necessária a modificação/substituição de alguns componentes pré-existentes (representados na Figura 11 pelos números 3,8 e 9). As novas válvulas foram adquiridas da Swagelok ${ }^{\circledR}$.

Figura 11: Sistema "lab-made" desenvolvido para extração com fluído supercrítico. (1) cilindro de $\mathrm{N}_{2}$ (2) cilindro de $\mathrm{CO}_{2}$; (3) vaso de pressurização; (4) válvula on/off; (5) agitador para banho de água; (6) Banho de água; (7) cela de extração; (8) válvula on/off; (9) válvula micrométrica; (10) tubo coletor; (11) gerador de fluxo de ar quente.

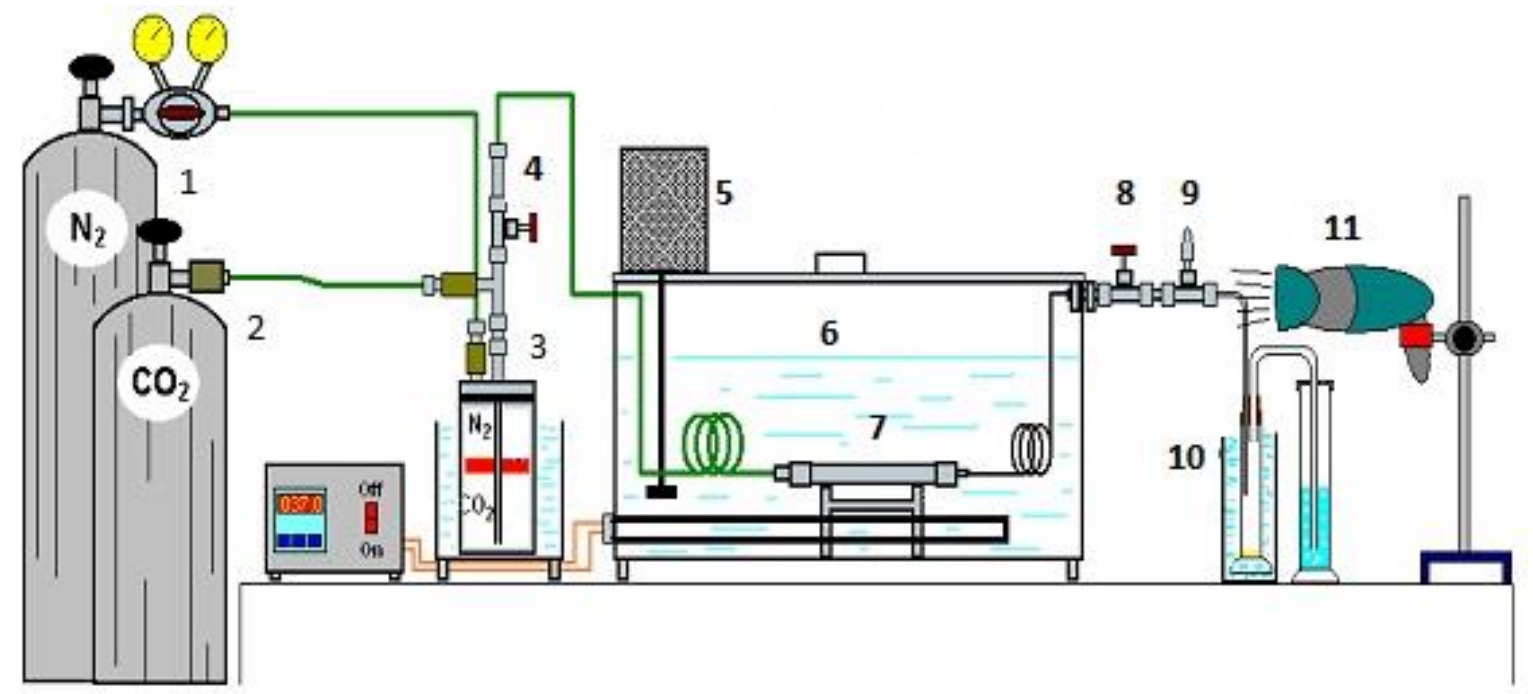

A válvula 8 (Figura 11) tem como finalidade abrir ou fechar o fluxo do fluido podendose, assim, realizar a extração no modo estático ou dinâmico. No entanto, esta válvula não tem o ajuste necessário para o controle do fluxo de gás sendo, portanto, necessária a instalação da válvula 9 , por se tratar de uma válvula micrométrica para o controle de fluxo.

O sistema de pressurização, item 3 da Figura 11, possuía como desvantagem a existência de um êmbolo de teflon, que se comprime com o resfriamento, favorecendo a mistura de gás $\mathrm{N}_{2}$ ao $\mathrm{CO}_{2}$, fato que compromete a pureza do $\mathrm{CO}_{2}$. Para tanto, um novo êmbolo foi elaborado mantendo-se o mesmo conceito de fabricação, mas com alguns ajustes que permitiriam que, ao se contrair, assumisse o diâmetro interno do vaso de compressão (Figura 12). 
Figura 12: Modificação no embolo utilizado para pressurização do $\mathrm{CO}_{2}$ por $\mathrm{N}_{2}$. A direita se encontra o êmbolo modificado, e a esquerda o êmbolo anteriormente utilizado.

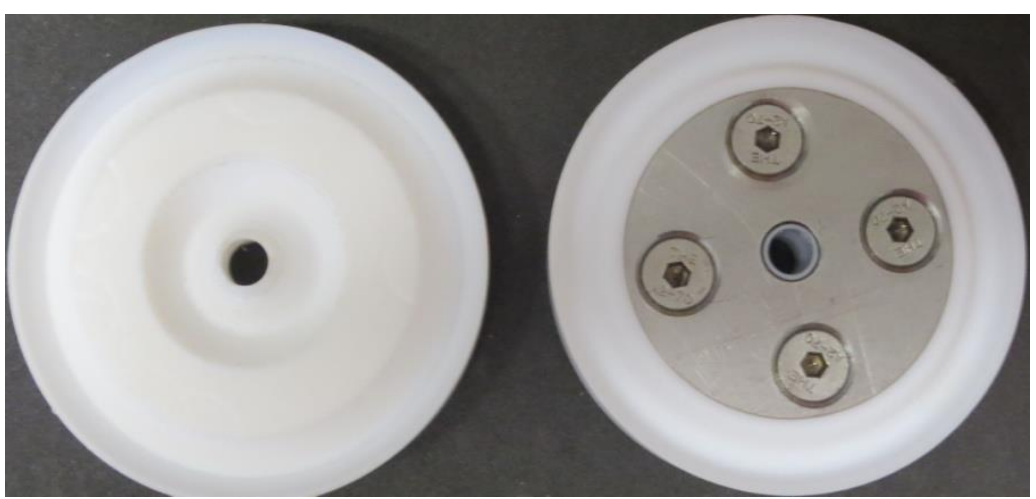

\subsection{Planejamento Experimental}

\subsubsection{Planejamentos Fatoriais}

Os experimentos realizados para a otimização da SPME e da SFE tiveram suas variáveis avaliadas de acordo com planejamento de experimentos. Tal ferramenta estatística permite avaliar os possíveis efeitos das variáveis isoladas, bem como o efeito das interações entre elas. $^{62}$

O passo mais importante para se realizar um planejamento de experimentos é estipular quais são as variáveis importantes para o processo e em quais níveis, ou seja, valores que estas serão avaliadas. Para a SPME, foi elaborado um planejamento fatorial $2^{3}$, gerado pelo software Statistica 6.0, no qual variáveis foram avaliadas em 2 níveis distintos: quantidade de amostra $(1,0$ e $2,0 \mathrm{~g})$, temperatura $\left(30\right.$ e $\left.70{ }^{\circ} \mathrm{C}\right)$ e tempo de extração (25 e 45 minutos), com triplicata no ponto central, resultando um total de 11 experimentos.

Já para a SFE, foram avaliadas 4 variáveis também em 2 níveis distintos, obedecendo a um planejamento fatorial fracionário $2^{4-1}$ : relação de tempo de extração estático/dinâmico (1/4 e $1 / 2$ do tempo total de extração), pressão (55 e 95 bar), temperatura $\left(25\right.$ e $\left.45^{\circ} \mathrm{C}\right)$ e tempo de extração total (10 e 30 minutos), com duplicata no ponto central, realizando um total de 10 experimentos. 


\subsubsection{Planejamento Composto Central}

Após a realização dos experimentos propostos pelos planejamentos fatoriais, os dados foram avaliados com auxílio do software Statistica 6.0 o qual, por meio da análise de variância ANOVA, indicou o melhor modelo e quais variáveis foram significativas para o processo, bem como as interações entre elas.

A partir de então, novos experimentos foram realizados para se estimar um ponto ótimo de extração, obedecendo a um planejamento composto central com o seguinte número de experimentos: $2^{\mathrm{n}}$ (pontos fatoriais) $+2 \mathrm{n}$ (pontos axiais) + réplicas no ponto central, onde $n$ se refere ao número de variáveis avaliadas no processo.

\subsection{Validação do Método}

Todo método desenvolvido no próprio laboratório ou adaptado de uma metodologia já normalizada (referente àquelas desenvolvidas por agências reguladoras ou por órgãos reconhecidos na sua área de atuação, como por exemplo, U. S. Environmental Protection Agency - EPA) deve ser normalizado de acordo com protocolos de validação, podendo ser nacionais ou internacionais, dependendo do objetivo principal da análise.

A análise de BTEX em solo por HS/SPME-GC/MS foi anteriormente avaliada em outros trabalhos, ${ }^{42}$ no entanto, como este trabalho visa desenvolver uma metodologia simplificada de análise, foi feito uma validação parcial avaliando as seguintes figuras de mérito: Limite de Quantificação (LQ), Limite de Detecção (LD), precisão intra-dia e linearidade.

Os limites de detecção e quantificação foram determinados como sendo a concentração que apresentou a intensidade do sinal 3 e 10 vezes superior à do ruído obtido, respectivamente.

A curva analítica foi obtida pela fortificação da matriz isenta em 6 níveis crescentes de concentração dos analitos, sendo feito em quintuplicata nos níveis baixos, médio e alto, e nos demais em duplicata. Plotou-se a razão de área obtida pela divisão da área do analito pela área padrão interno (isopropilbenzeno) versus a concentração adicionada à amostra. 


\section{Resultados e Discussão}

\subsection{Separação cromatográfica}

A Figura 13 apresenta um cromatograma adquirido no modo SIM (Selected Ion Monitoring), referente à extração por HS-SPME de um solo fortificado a $0,5 \mathrm{mg} \mathrm{L}^{-1}$ de BTEX, no qual pode-se observar que não há co-eluição dos analitos, exceto para os isômeros $m, p$ xileno, apresentando-se simétricos e sem caudas.

Figura 13: Cromatograma da separação cromatográfica por GC e detecção por MS no modo SIM do (1) benzeno, (2) tolueno, (3) etilbenzeno, (4) $m, p$-xileno, $o$-xileno e (6) padrão interno

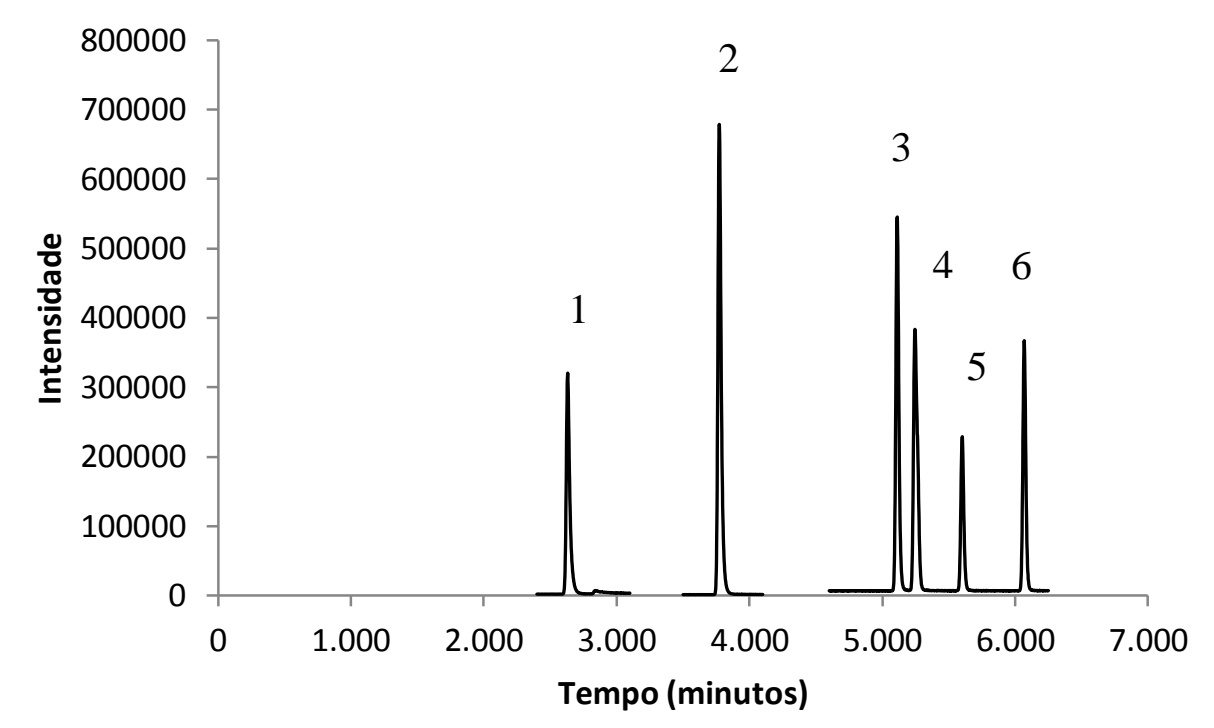

\subsection{SPME - Solid phase microextraction}

A fim de se avaliar o processo de remediação do solo por SFE, uma metodologia analítica foi desenvolvida e validada. Por se tratar de compostos voláteis em amostra complexa, a HS-SPME foi escolhida devido às características supracitadas.

De acordo com os experimentos realizados por meio do planejamento fatorial $2^{3}$, usando como variável resposta a área absoluta dos picos cromatográficos, foi possível estimar quais variáveis foram significativas para o processo de extração, como demonstrado pelos diagramas de Pareto (Figura 14). 
Figura 14: Gráfico de Pareto referente ás variáveis dependentes (a) benzeno, (b) tolueno, (c) etilbenzeno, (d) $m$, $p$-xileno e (e) $o$-xileno, com 95\% de confiança

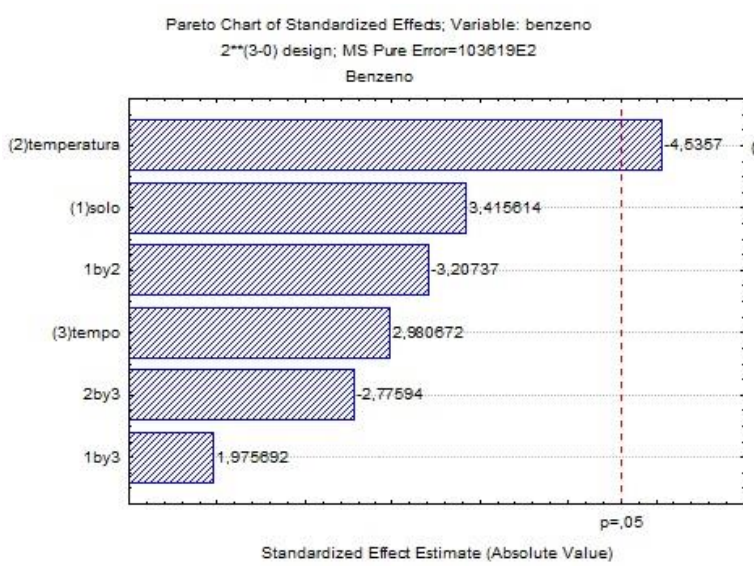

(a)

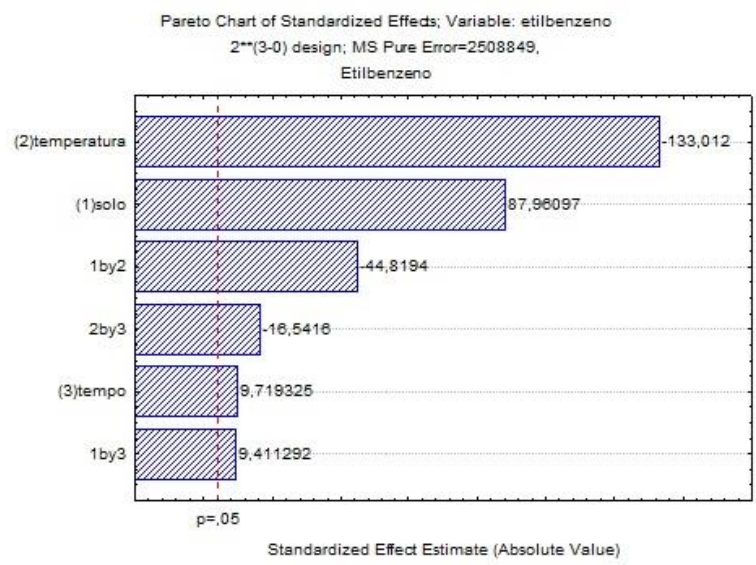

(c)

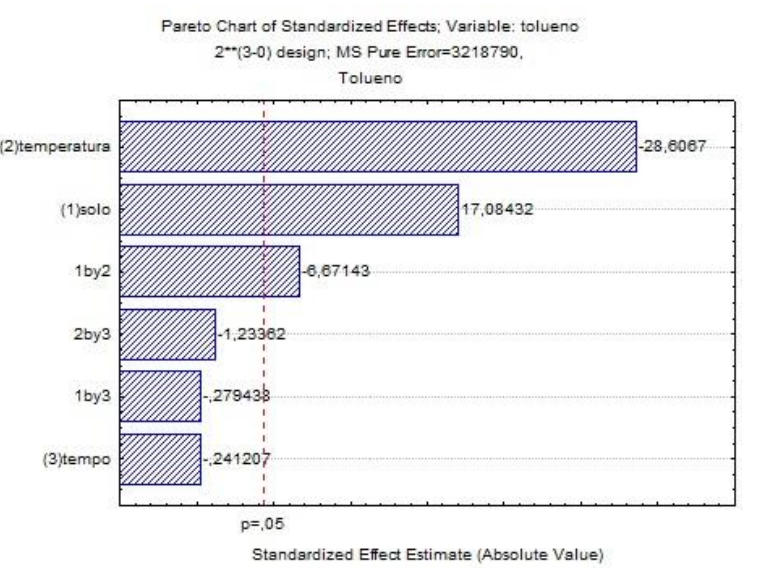

(b)

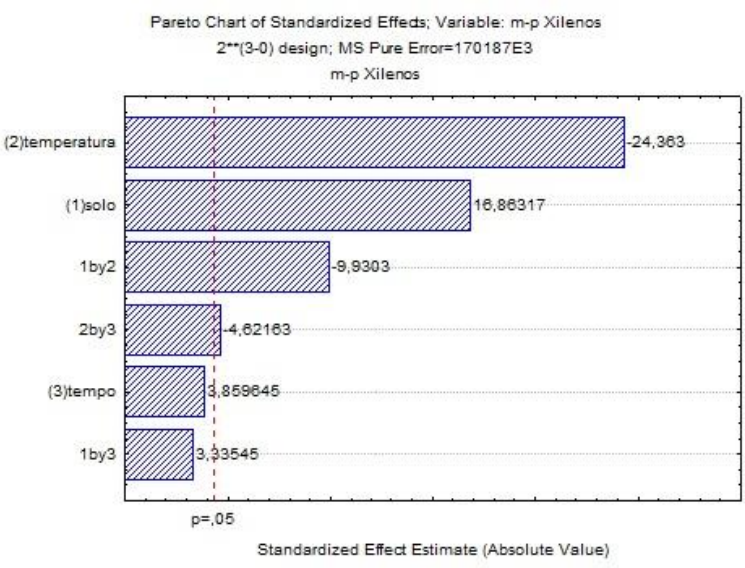

(d)

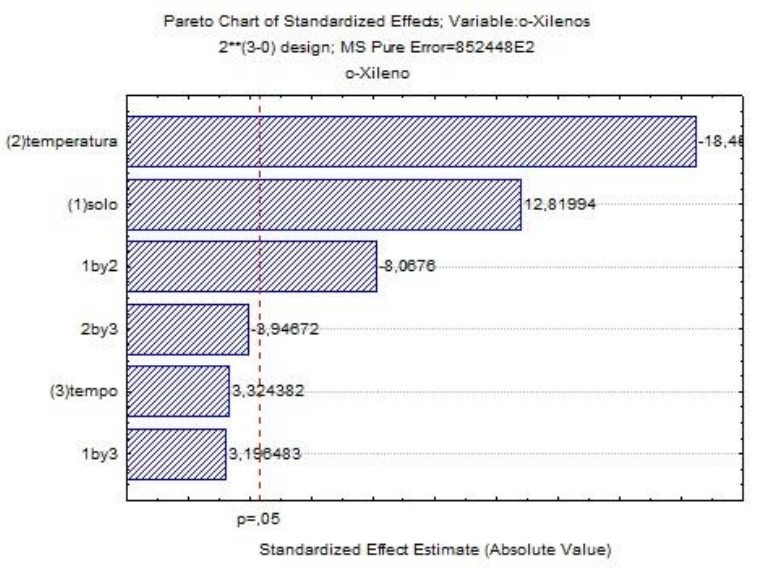

(e) 
Observa-se que as variáveis independentes temperatura e quantidade de amostra (solo) são significativas para todos os analitos. O efeito causado pela variável temperatura possui um sinal negativo, indicando que ao se diminuir a temperatura, aumenta-se a área adquirida. Já para a quantidade de amostra, observa-se um efeito positivo, ou seja, quanto mais amostra, melhor a resposta.

A variável independente tempo de extração, mostrou-se significativa somente para o analito etilbenzeno, ao passo que a interação dessa com a variável quantidade de amostra foi significativa para $o$-xilenos. No entanto, o efeito causado é muito pequeno e por tal motivo essa variável foi mantida constante, em seu maior nível (45 minutos) devido ao efeito positivo.

Para a elaboração do planejamento composto central, a quantidade de amostra e temperatura foram avaliadas em 5 níveis diferentes. Os valores codificados e os reais para cada variável podem ser observados na Tabela 6 , na qual os valores +1 e -1 são referentes aos níveis máximos e mínimos, respectivamente. Os valores $+1,41$ e $-1,41$ referem-se aos pontos axiais. O ponto 0 (zero) corresponde ao ponto central do planejamento.

Tabela 6: Valores codificados e os respectivos valores reais para cada variável no planejamento composto central

\begin{tabular}{cccccc}
\hline Variáveis & \multicolumn{5}{c}{ Variáveis Codificadas } \\
\cline { 2 - 6 } Originais & $\mathbf{- 1 , 4 1}$ & $\mathbf{- 1}$ & $\mathbf{0}$ & $\mathbf{+ 1}$ & $\mathbf{+ 1 , 4 1}$ \\
\hline Quant. amostra $(\mathrm{g})$ & 2,59 & 3,0 & 4,0 & 5,0 & 6,41 \\
Temp. $\left({ }^{\circ} \mathrm{C}\right)$ & 8,0 & 10,0 & 15,0 & 20,0 & 22,0 \\
\hline
\end{tabular}

Um total de 12 experimentos foi realizado utilizando também como variável dependente a área absoluta dos picos cromatográficos de cada analito. Os dados obtidos estão apresentados na Tabela 7.

Com esses resultados foi possível elaborar modelos matemáticos para todas variáveis respostas com $\mathrm{R}^{2}$ de aproximadamente 0,9 demonstrando, assim, que não há falta de ajuste no modelo proposto. Foi possível então, a elaboração de gráficos de superfícies de resposta, correlacionando as variáveis dependentes quantidades de amostra e temperatura, como observado na Figura 15. 
Tabela 7: Matriz do planejamento composto central, com os resultados obtidos para as variáveis-resposta expressas em área absoluta.

\begin{tabular}{|c|c|c|c|c|c|c|c|}
\hline \multirow{2}{*}{ Ensaios } & \multicolumn{2}{|c|}{$\begin{array}{c}\text { Variáveis } \\
\text { independentes }\end{array}$} & \multirow{2}{*}{ Benzeno } & \multirow{2}{*}{ Tolueno } & \multirow{2}{*}{$\begin{array}{c}\text { Etil- } \\
\text { benzeno }\end{array}$} & \multirow{2}{*}{$\begin{array}{c}m, p- \\
\text { xilenos }\end{array}$} & \multirow{2}{*}{$\begin{array}{c}o- \\
\text { xileno }\end{array}$} \\
\hline & $x_{1}$ & $x_{2}$ & & & & & \\
\hline 1 & $-1,0$ & $-1,0$ & 78024 & 94655 & 288994 & 455122 & 238692 \\
\hline 2 & $-1,0$ & 1,0 & 83552 & 103034 & 334877 & 543438 & 289650 \\
\hline 3 & 1,0 & $-1,0$ & 144583 & 152812 & 501361 & 608421 & 430274 \\
\hline 4 & 1,0 & 1,0 & 170670 & 132806 & 417478 & 679449 & 357523 \\
\hline 5 & $-1,41$ & 0,0 & 31798 & 93664 & 262147 & 390584 & 212210 \\
\hline 6 & 1,41 & 0,0 & 130849 & 121215 & 392949 & 632442 & 331367 \\
\hline 7 & 0,0 & $-1,41$ & 154096 & 114519 & 357132 & 572312 & 301439 \\
\hline 8 & 0,0 & 1,41 & 105235 & 100669 & 324941 & 527454 & 277979 \\
\hline $9(\mathrm{C})$ & 0,0 & 0,0 & 225662 & 295372 & 767931 & 1000283 & 555312 \\
\hline $10(\mathrm{C})$ & 0,0 & 0,0 & 185737 & 202507 & 611594 & 899232 & 456203 \\
\hline $11(\mathrm{C})$ & 0,0 & 0,0 & 226001 & 246803 & 762961 & 1121791 & 572080 \\
\hline
\end{tabular}

Obs.: $x_{1}$ se refere à variável independente quantidade de amostra e $x_{2}$ a temperatura

Observa-se pelos gráficos que o aumento da temperatura ocasiona uma diminuição das áreas absolutas dos picos. Este resultado é semelhante ao encontrado por Esquerro e colaboradores (2004), quando realizaram extrações sucessivas de BTEX em solo por HS-SPME à 30, 60 e $90^{\circ} \mathrm{C}$, obtendo os melhores resultados a temperaturas mais baixas. No entanto, este trabalho não utilizou análise multivariada para estipular o ponto ótimo, não avaliando, portanto, temperaturas inferiores a $30^{\circ} \mathrm{C}$. 
Figura 15: Superfícies de resposta correlacionando as variáveis temperatura e quantidade de amostra, em um tempo de extração de 45 minutos para as variáveis dependentes, em relação a suas áreas cromatográficas absolutas de: (a) benzeno, (b) tolueno, (c) etilbenzeno, (d) m,p-xilenos e (e) o-xilenos.

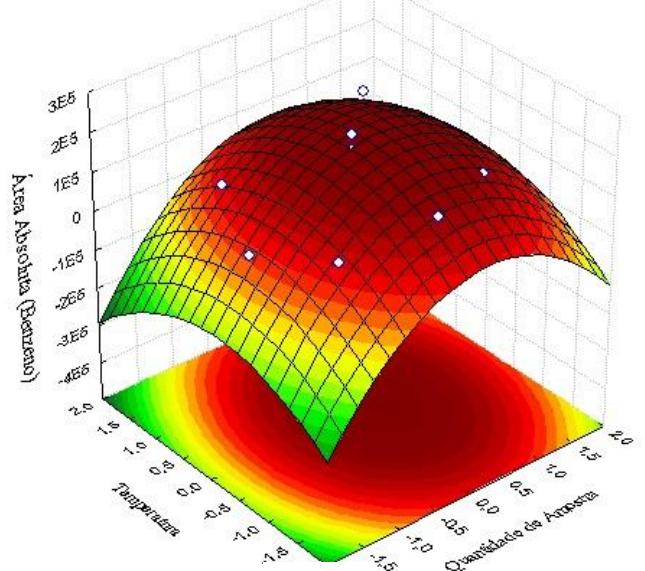

(a)

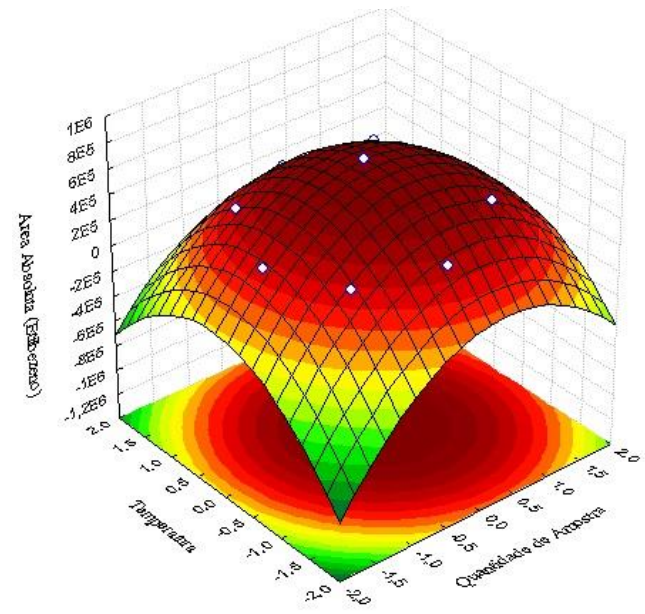

(c)

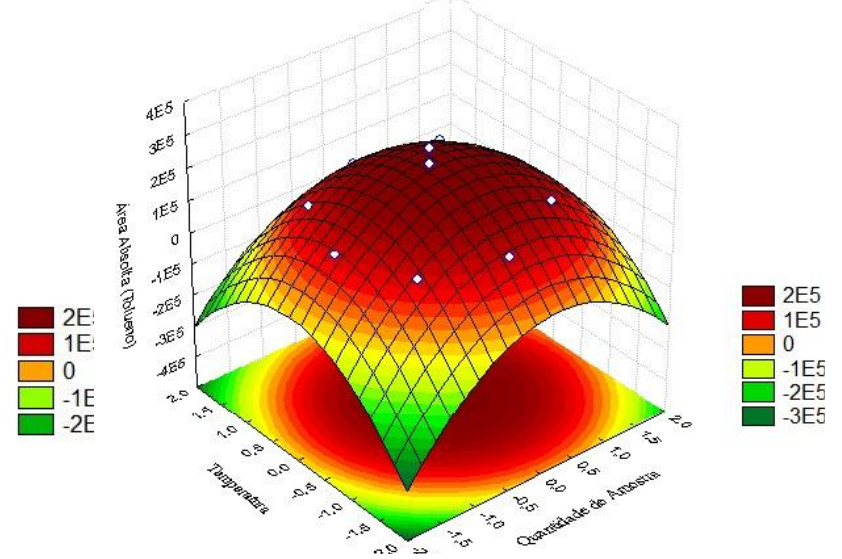

(b)
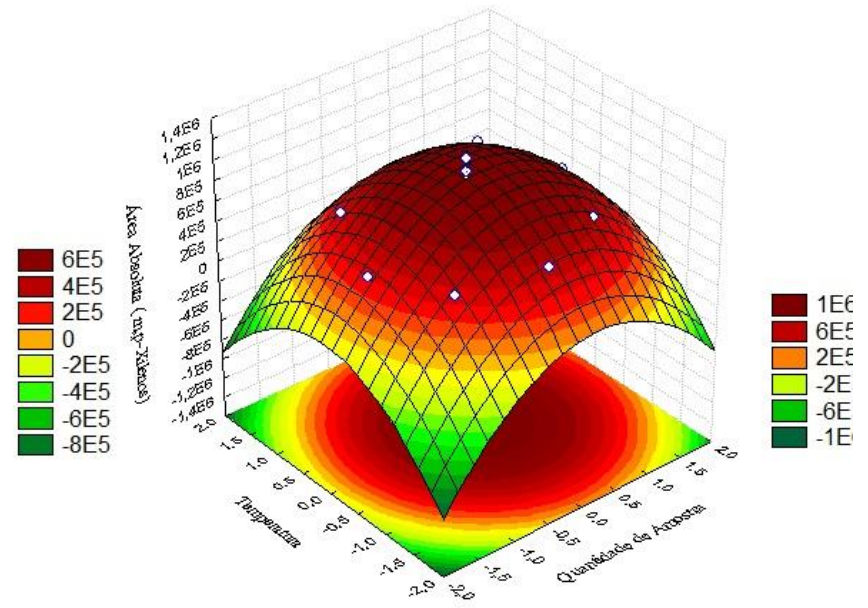

(d)

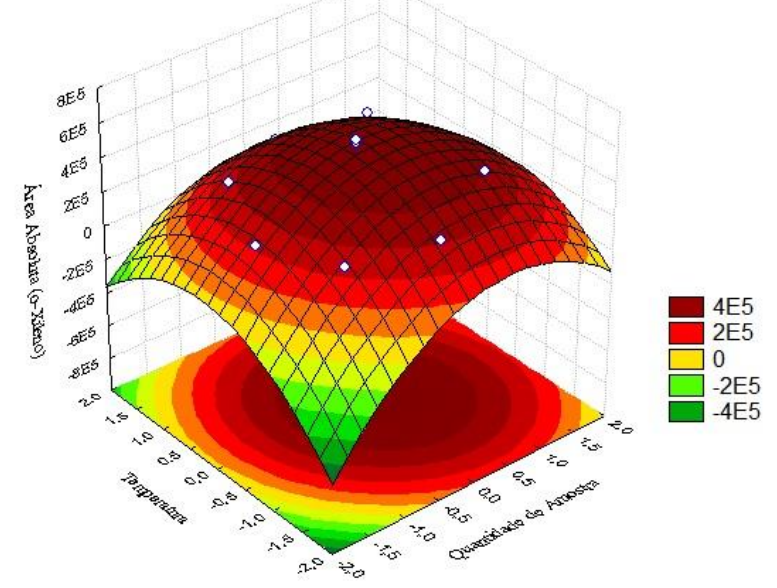

(e) 
Os seguintes valores então escolhidos para a condição ótima de extração, mantendo-se o tempo fixo em 45 minutos, estão expressos na Tabela8:

Tabela 8: Valores estimados para condição ótima de extração, mantendo-se fixo o tempo em 45 minutos.

\begin{tabular}{ccc}
\hline Variáveis & Valores codificados & Valores reais \\
\hline Quant. de amostra $(\mathrm{g})$ & $+0,58$ & 4,5 \\
Temperatura $\left({ }^{\circ} \mathrm{C}\right)$ & $-0,07$ & 15 \\
\hline
\end{tabular}

\subsubsection{Validação da SPME}

Com a melhor condição de extração estabelecida, deu-se início a validação do método.

Alguns empecilhos foram encontrados nessa etapa, visto que foi detectada uma contaminação por tolueno nas dependências físicas do nosso laboratório. Tal fato é facilmente explicado visto que se trata de um solvente de uso rotineiro em laboratório, e como a técnica de extração é sensível, a interferência é muito facilitada.

Pode-se observar facilmente este problema na Figura 16, cujo cromatograma foi obtido pela extração de um vial limpo e vazio, observando a elevada intensidade do pico referente ao tolueno, quando comparado aos outros compostos. Por tal motivo, excluiu-se o tolueno das análises e validou-se o método somente com os outros analitos.

Figura 16: Cromatograma referente à extração de um vial limpo e vazio por $H S$-SPME, demonstrando a presença de tolueno no ar.

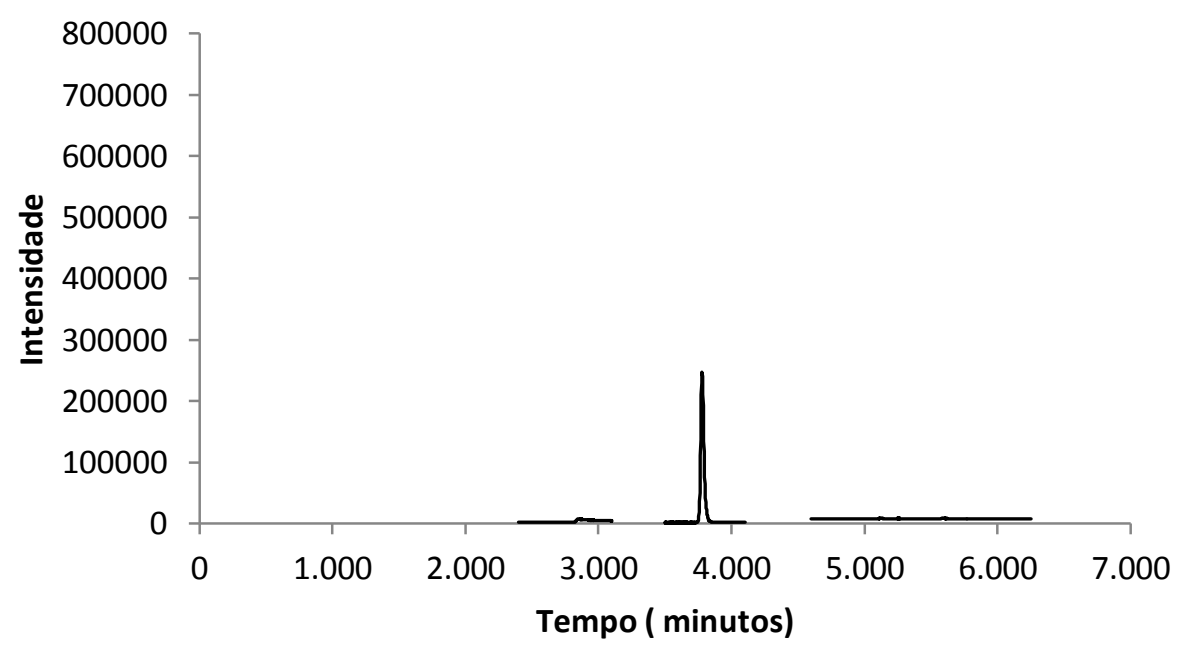


Na Tabela 9, observar-se os dados obtidos para validação do benzeno, etilbenzeno e o, $m, p$-xilenos.

No caso do contaminante benzeno, foi necessário aplicar a ponderação dos dados, utilizando para isso o fator peso $(w)^{1} / x$, para garantir o ajuste adequado durante a faixa linear estudada. $^{66}$

Tabela 9: Valores obtidos na validação do método de HS-SPME para determinação de BTEX em solo por GC-MS

\begin{tabular}{|c|c|c|c|c|c|c|}
\hline \multirow{2}{*}{ Composto } & \multirow{2}{*}{$\begin{array}{c}\text { Faixa } \\
\text { linear } \\
\left(\mu \mathrm{g} \mathrm{kg}^{-1}\right)\end{array}$} & \multirow{2}{*}{$\begin{array}{c}\text { Curva } \\
\text { Analítica } \\
\left(\mathbf{a}, \mathbf{b}, \mathbf{r}^{2}\right)\end{array}$} & \multirow{2}{*}{$\begin{array}{c}\text { LD } \\
\left(\mu \mathrm{g} \mathrm{kg}^{-1}\right)\end{array}$} & \multirow{2}{*}{$\begin{array}{c}\text { LQ } \\
\left(\mu \mathrm{g} \mathrm{kg}^{-1}\right)\end{array}$} & \multicolumn{2}{|c|}{ Precisão Intra-dia } \\
\hline & & & & & Nível & $\operatorname{DPR}(\%)$ \\
\hline \multirow{3}{*}{ Benzeno } & \multirow{3}{*}{$10-260$} & 0.0038 & \multirow{3}{*}{5} & \multirow{3}{*}{10} & Baixo & 4,8 \\
\hline & & -0.0101 & & & Médio & 4,2 \\
\hline & & 0,9810 & & & Alto & 5,8 \\
\hline \multirow{3}{*}{ Etilbenzeno } & \multirow{3}{*}{$10-260$} & 0,0058 & \multirow{3}{*}{5} & \multirow{3}{*}{10} & Baixo & 1,3 \\
\hline & & $-0,0325$ & & & Médio & 1,6 \\
\hline & & 0,9888 & & & Alto & 1,1 \\
\hline \multirow{3}{*}{$m, p$-Xileno } & \multirow{3}{*}{$10-260$} & 0,0053 & \multirow{3}{*}{5} & \multirow{3}{*}{10} & Baixo & 1,9 \\
\hline & & $-0,023$ & & & Médio & 1,2 \\
\hline & & 0,9861 & & & Alto & 0,7 \\
\hline \multirow{3}{*}{$o$-Xileno } & \multirow{3}{*}{$20-260$} & 0,0024 & \multirow{3}{*}{10} & \multirow{3}{*}{20} & Baixo & 2,6 \\
\hline & & $-0,0208$ & & & Médio & 1,0 \\
\hline & & 0,9882 & & & Alto & 0,1 \\
\hline
\end{tabular}

Os valores obtidos para LD e LQ são satisfatórios, visto que de acordo com EPA (1996), o valor de quantificação para um método analítico para analitos voláteis, que incluem os BTEX, deve ser no mínimo $10 \mu \mathrm{g} \mathrm{kg}^{-1}$.

De acordo com a Tabela 1, que apresenta os valores estabelecidos pela CETESB, observa-se que os valores de prevenção estão dentro da faixa linear proposta pelo método, exceto para o o-xileno que tem limites bem superiores. No entanto, o valor médio encontrado no solo para estes compostos está em torno de $1200 \mu \mathrm{g} \mathrm{kg}^{-1},{ }^{69}$ valor utilizado como base para os experimentos de remediação por SFE. 


\subsection{Otimização da SFE}

A extração por fluido supercrítico tem por finalidade a remediação de solos contaminados por BTEX.

Inicialmente, um experimento foi realizado utilizando apenas metade da capacidade da cela de extração, ou seja, 5,0 g de amostra. No entanto, ao se realizar o planejamento experimental $2^{4-1}$, nenhuma variável mostrou-se significativa para o processo, fato que pode ser explicado pela presença de espaço intersticial na cela diminuindo, assim, o contato do fluido com a amostra contaminada. Para avaliar esse efeito, um segundo planejamento experimental $2^{4-1}$, sob as mesmas condições que o primeiro, foi realizado utilizando a capacidade máxima da cela de extração, aproximadamente $11,0 \mathrm{~g}$ de amostra.

Os resultados obtidos, expressos em porcentagem de remoção, estão apresentados na Tabela 10. É possível observar que há uma elevada taxa de remoção, em todos os experimentos e para todos os contaminantes, especialmente para o benzeno e etilbenzeno. Já para os isômeros do xileno, nota-se uma variação maior na eficiência de extração, apresentando os melhores resultados quando a extração ocorre nas condições críticas do $\mathrm{CO}_{2}$.

Com os dados apresentados, foi possível avaliar os efeitos significativos, como demonstrados nos gráficos de Pareto para as quatro variáveis respostas (Figura 17). Para a extração do benzeno nenhuma variável mostrou-se significativa, talvez por este ser o composto mais volátil, quando comparado aos outros quatro.

No entanto, para os outros 3 compostos, a variável pressão torna-se significativa, com efeito positivo, significando que quanto maior a pressão, melhor a remoção dos analitos. Por se tratar de um planejamento fatorial fracionário, não há cálculo para os efeitos das interações entre variáveis (Figura 17).

Outra informação importante presente nos gráficos de Pareto são os baixos valores de efeito para as variáveis razão de tempo de extração estático/dinâmico e tempo total de extração.

Resultados semelhantes foram encontrados por Gonçalves e colaboradores (2006) ${ }^{70}$ quando otimizaram a extração de resíduos de pesticidas em solo por SFE. Após a realização de um planejamento composto central, observaram que as variáveis mais significativas para a eficiência do processo foram pressão e temperatura, sendo o tempo total de extração o menos importante. 
Tabela 10: Resultados referente ao planejamento fatorial fracionário $2^{4-1}$ para os analitos benzeno, etilbenzeno, $m, p$-xileno e $o$-xileno, expresso em eficiência de extração.

\begin{tabular}{ccccccccc}
\hline & \multicolumn{3}{c}{ Variáveis Independentes } & \multicolumn{3}{c}{ Eficiência de extração (\%) } \\
\cline { 2 - 9 } Ensaios & $\boldsymbol{x}_{\mathbf{1}}$ & $\boldsymbol{x}_{\mathbf{2}}$ & $\boldsymbol{x}_{\mathbf{3}}$ & $\boldsymbol{x}_{\mathbf{4}}$ & Benz. & Etil. & $\begin{array}{c}m, p- \\
\text { Xilenos }\end{array}$ & $\begin{array}{c}\text { Xilenos } \\
\end{array}$ \\
\hline $\mathbf{1}$ & -1 & -1 & -1 & -1 & 99,09 & 99,34 & 89,81 & 84,65 \\
$\mathbf{2}$ & 1 & -1 & -1 & 1 & 98,81 & 99,53 & 92,71 & 88,04 \\
$\mathbf{3}$ & -1 & 1 & -1 & 1 & 99,10 & 99,88 & 98,64 & 97,03 \\
$\mathbf{4}$ & 1 & 1 & -1 & -1 & 99,10 & 99,87 & 98,48 & 97,58 \\
$\mathbf{5}$ & -1 & -1 & 1 & 1 & 99,14 & 99,09 & 84,18 & 75,61 \\
$\mathbf{6}$ & 1 & -1 & 1 & -1 & 99,15 & 99,08 & 82,92 & 72,78 \\
$\mathbf{7}$ & -1 & 1 & 1 & -1 & 99,14 & 99,98 & 100,21 & 99,84 \\
$\mathbf{8}$ & 1 & 1 & 1 & 1 & 99,17 & 99,99 & 100,35 & 100,01 \\
\hline
\end{tabular}

Obs.: $x_{1}, x_{2}, x_{3}$ e $x_{4}$ se referem respectivamente as variáveis independentes: razão entre tempo de extração estático/dinâmico, pressão, temperatura e tempo de extração.

Figura 17: Gráfico de Pareto referente ao planejamento fatorial fracionário, $2^{4-1}$, para as várias benzeno, etilbenzeno, m,p-xileno e o-xileno

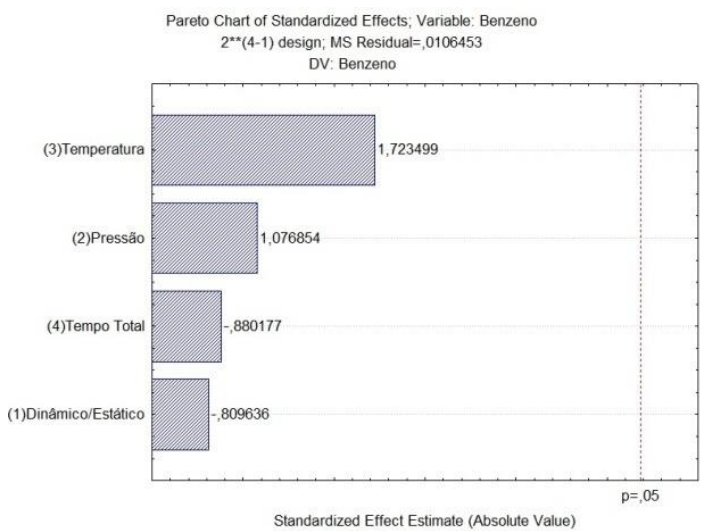

(a)

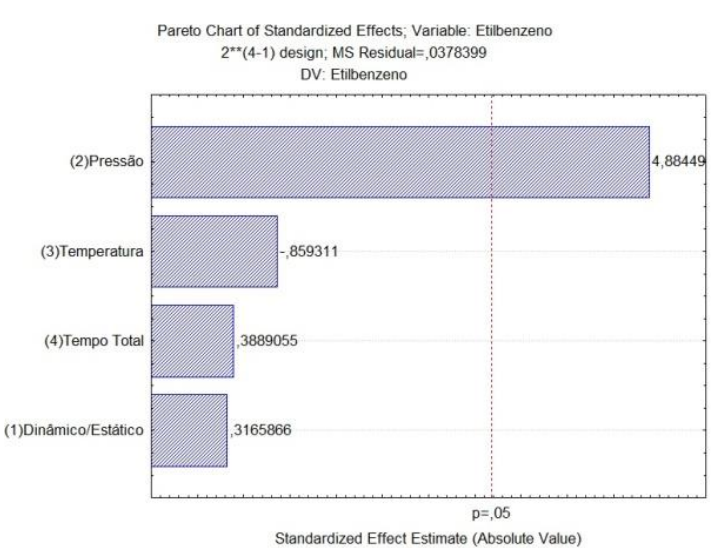

(b) 


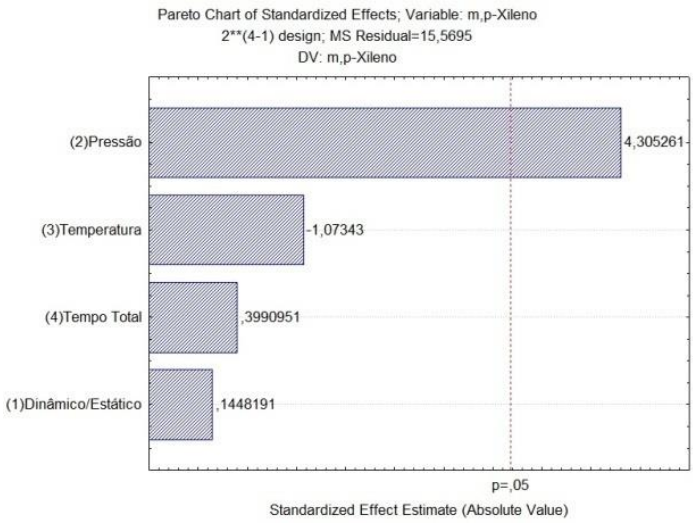

(c)

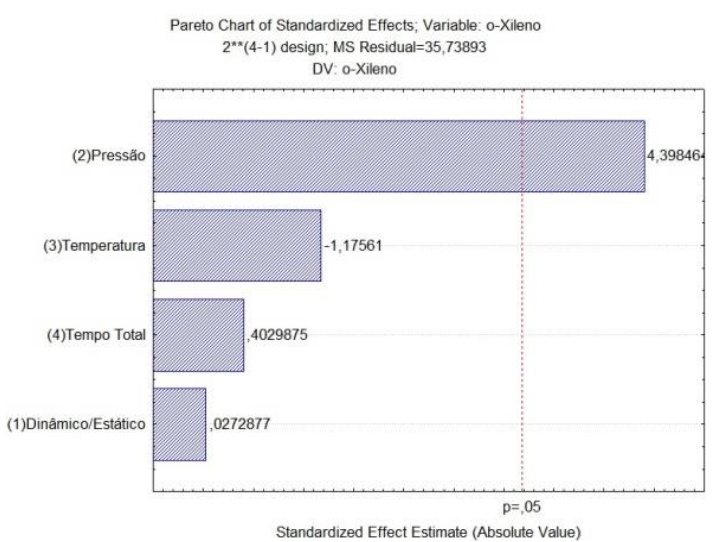

(c)

Associados a máxima eficiência de extração às condições obtidas com $\mathrm{CO}_{2}$ no estado supercrítico, fez-se uma nova análise estatística dos dados, utilizando apenas as variáveis independentes pressão e temperatura, obtendo-se, portanto, um planejamento fatorial $2^{2}$ realizado em duplicata, de acordo com a Tabela 11.

Novamente, foram elaborados os gráficos de Pareto para as variáveis dependentes. No entanto, por se tratar agora de um planejamento fatorial completo, pode-se analisar o efeito da interação entre pressão e temperatura, conforme apresentado na Figura 18.

Tabela 11: Planejamento fatorial $2^{2}$ avaliando o efeito da pressão e temperatura, obtido em duplicata.

\begin{tabular}{ccccccc}
\hline \multirow{2}{*}{ Ensaios } & \multicolumn{2}{c}{$\begin{array}{c}\text { Variáveis } \\
\text { Independentes }\end{array}$} & \multicolumn{4}{c}{ Eficiência de Remoção $(\%)$} \\
\cline { 2 - 7 } & $\boldsymbol{x}_{\mathbf{2}}$ & $\boldsymbol{x}_{\mathbf{3}}$ & Benz. & Etil. & $\begin{array}{c}m, p- \\
\text { Xilenos }\end{array}$ & $o$ - Xilenos \\
\hline $\mathbf{1 . 1}$ & -1 & -1 & 99,09 & 99,34 & 89,81 & 84,65 \\
$\mathbf{1 . 2}$ & -1 & -1 & 98,81 & 99,53 & 92,71 & 88,04 \\
$\mathbf{2 . 1}$ & 1 & -1 & 99,10 & 99,88 & 98,64 & 97,03 \\
$\mathbf{2 . 2}$ & 1 & -1 & 99,10 & 99,87 & 98,48 & 97,58 \\
$\mathbf{3 . 1}$ & -1 & 1 & 99,14 & 99,09 & 84,18 & 75,61 \\
$\mathbf{3 . 2}$ & -1 & 1 & 99,15 & 99,08 & 82,92 & 72,78 \\
$\mathbf{4 . 2}$ & 1 & 1 & 99,14 & 99,98 & 100,21 & 99,84 \\
$\mathbf{4 . 2}$ & 1 & 1 & 99,17 & 99,99 & 100,35 & 100,01 \\
\hline
\end{tabular}


Figura 18: Gráficos de Pareto referente ao planejamento fatorial $2^{2}$, avaliando o efeito das variáveis pressão e temperatura, bem como o efeito da interação entre elas.

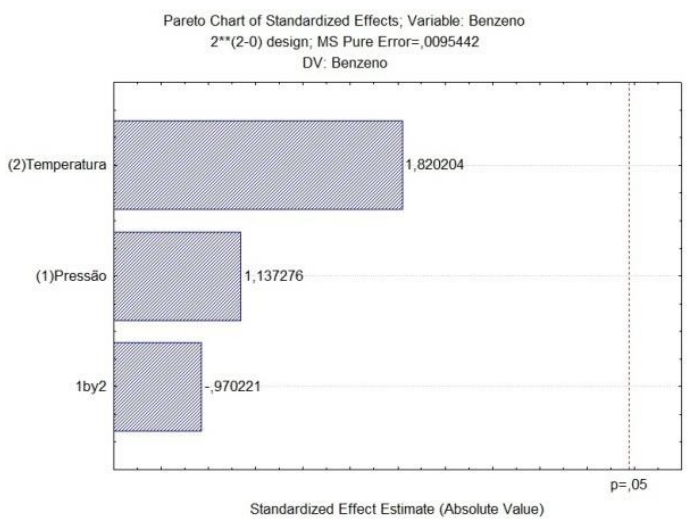

(a)

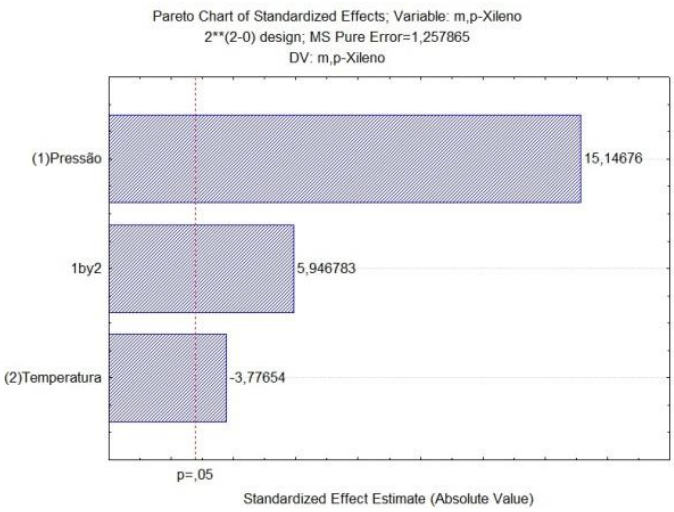

(c)

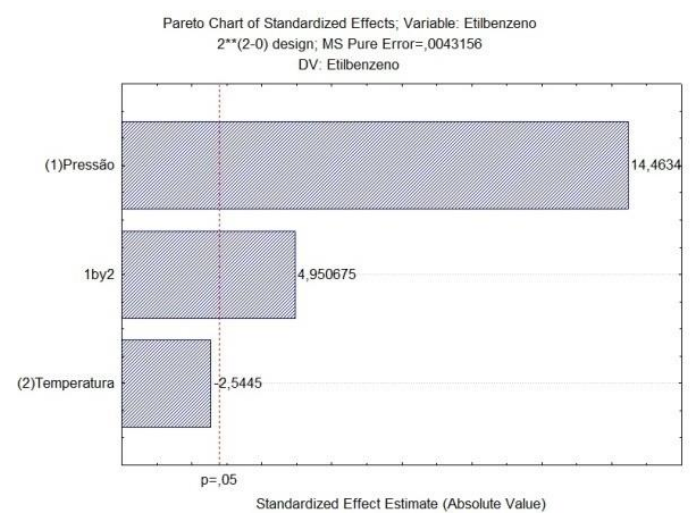

(b)

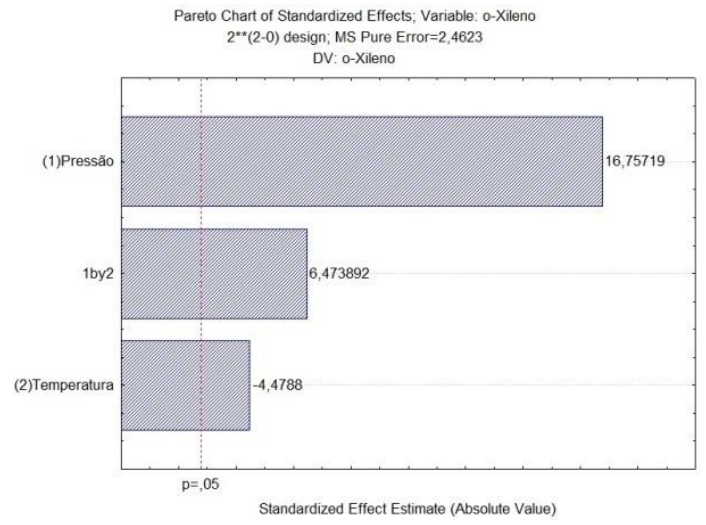

(d)

O comportamento observado para o benzeno continua o mesmo, fato esperado devido às constantes taxas de remoção em todos os experimentos. Porém, para o etilbenzeno, a interação entre pressão e temperatura se torna significativa, assim como ocorre para os isômeros do xileno. Para esses, a variável temperatura também é significante para a eficiência do processo.

Embora a temperatura tenha apresentado um efeito negativo, a interação entre pressão e temperatura tem efeito positivo e maior que o efeito causado pela temperatura isolado, significando que com o aumento da temperatura e pressão, a remoção destes compostos é favorecida, ou seja, pelo $\mathrm{CO}_{2}$ no estado supercrítico.

Em baixas pressões $(\mathrm{P}<150$ bar $)$ o $\mathrm{CO}_{2}$ tem menor força de solvente com o aumento da temperatura, provavelmente devido à drástica diminuição da densidade do $\mathrm{CO}_{2}$ nesta condição. Assim, a solubilidade de alguns analitos no $\mathrm{CO}_{2}$ pode diminuir, fato que compromete 
a eficiência de extração, o que explica o porquê do efeito negativo que a temperatura exerce na extração dos isômeros do xileno. ${ }^{19}$

O R${ }^{2}$, obtido por meio da Análise de Variância (ANOVA), mostrou o ajuste do modelo, o qual foi maior que 0,98 para todas as variáveis, exceto para o benzeno, o qual apresentou um $\mathrm{R}^{2}$ de 0,58 , visto que não foi possível elaborar um modelo para este composto.

Devido às elevadas taxas de remoção, não foram realizados novos experimentos em outras faixas de valores; à pressão de 90 bar e temperatura a $45^{\circ} \mathrm{C}$ foi possível alcançar $100 \%$ de eficiência.

Estes resultados podem ter sido influenciado por uma série de fatores como, por exemplo, o fluxo de $\mathrm{CO}_{2}$ no modo dinâmico de extração. Por se tratar de um sistema de extração lab-made, o controle do fluxo não é muito preciso, fato que o excluiu do planejamento experimental, visto que seria difícil a variação em 3 níveis diferentes de valores.

O fluxo ideal para extração com fluido supercrítico deve compreender de 1,0 a 4,0 mL $\min ^{-1}{ }^{19}$ valores muito abaixo do obtido com este tipo de sistema, devido às suas características construtivas e de operação, o qual tem por fluxo médio $400 \mathrm{~mL} \mathrm{~min}{ }^{-1}$.

\subsection{Aplicação do método de remediação e avaliação da eficiência por HS-SPME/GC-MS}

Para aplicação do método de remediação utilizando $\mathrm{CO}_{2}$ no estado supercrítico, duas amostras de solo foram utilizadas. A primeira foi retirada de uma região de postos de combustíveis destinada à lavagem de veículos, visto que, nesse procedimento, elevadas quantidades de óleo são derramadas no solo ou direcionadas para rede de esgoto. A outra amostra foi retirada próximo ao tanque subterrâneo de armazenamento de combustível, que, se identificada a presença desses compostos, poderia evidenciar vazamentos.

As duas amostras, homogeneizadas a 2,0 mm, foram submetidas a avaliação por HSSPME/GC-MS assim que coletadas, evidenciando a presença de muitos outros compostos contendo a mesma relação $\mathrm{m} / \mathrm{z}$ monitorada no modo SIM, além dos compostos de interesse. A concentração não foi estimada visto que, benzeno, etilbenzeno e isômeros do xileno estão acima do limite superior de quantificação do método de HS-SPME.

Após submetido a remediação por $\mathrm{CO}_{2}$ no estado supercrítico o solo foi, novamente, avaliado e o que se observou foi o total desaparecimento dos picos cromatográficos. Esse fato 
evidenciou uma provável descontaminação total do solo, visto que após a remediação os contaminantes se apresentaram abaixo do limite inferior de quantificação/detecção.

\section{Conclusão do capítulo 2}

O método analítico proposto para a determinação dos BTEX em solo segue a tendência atual de preparo de amostras, que tem por finalidade o uso de pequeno ou nenhum consumo de solvente orgânico tanto na etapa de extração quanto na de dessorção (química verde).

A validação da extração por HS-SPME mostrou que o método é eficaz para o objetivo proposto, alcançando os limites de quantificação propostos tanto por órgãos internacionais (EPA) quanto nacionais (CETESB), com faixa linear de $10-260 \mu \mathrm{g} \mathrm{kg}^{-1}$ para maioria dos analitos, com $\mathrm{R}^{2}>0,98$.

A utilização de SFE para descontaminação de solos contaminados se mostrou uma alternativa viável, visto que se obteve uma eficiência de $100 \%$ para os analitos avaliados.

Pode-se observar que a influência da temperatura e pressão varia de acordo com os analitos, tornando-se mais proeminente para os analitos de maior massa molecular. Para o benzeno, analito mais volátil entre os avaliados, somente a pressão foi necessária para a remoção total, sem a necessidade do uso de temperaturas elevadas. 



\section{Capítulo 3}

Desenvolvimento, otimização e validação de um método para determinação de sulfonamidas em lodo de esgoto por QuEChERS e LC-ESI-TOF 



\section{Introdução}

A presença de fármacos no meio ambiente é constantemente relatada, principalmente em águas residuais, devido ao descarte impróprio ou pela excreção após a ingestão dos mesmos. Os fármacos, após lançados no esgoto, podem retornar ao meio ambiente devido à falta de sistema de tratamento adequado ou, alternativamente, podem ser direcionados a uma ETE. No entanto, as estações de tratamento de esgoto muitas vezes não possuem um sistema de degradação eficiente para esses compostos, fazendo com que eles sejam parcialmente degradados ou que retornem na sua forma intacta para o meio ambiente.

O sistema de degradação por lodo ativado é a forma de degradação biológica mais comum, porém, a eficiência de remoção de fármacos do ambiente nem sempre está relacionada a degradação dos mesmos, podendo ocorrer também a adsorção no lodo.

Dessa forma, o desenvolvimento de metodologias que sejam capazes de determinar fármacos em lodo de esgoto é extremamente importante, visto que esses podem ser reutilizados como fertilizantes em lavouras. Uma classe de fármacos importantes para ser avaliada é a das sulfonamidas, classe de antibiótico bastante empregada tanto na medicina humana quanto animal.

Essa é uma tarefa difícil, uma vez que a matriz é complexa apresentando uma mistura de inúmeros compostos, e os fármacos se encontram presentes em concentrações muito baixas. A escolha da técnica a ser empregada no preparo de amostra é, neste caso, fundamental para o sucesso da análise. Após a extração é necessário desenvolver um método robusto de separação dos fármacos de interesse dos demais contaminantes extraídos da amostra de lodo. A seguir os analitos de interesse devem ter sua identidade confirmada por uma técnica adequada, e sua quantificação realizada.

A estratégia escolhida para a determinação de sulfonamidas em amostra de lodo esgoto foi a seguinte: (a) extração empregando QuEChERS; (b) separação dos analitos presentes no extrato por HPLC; (c) confirmação da identidade e análise de quantificação por espectrometria de massas de alta resolução.

A escolha do QuEChERS para a etapa de extração deveu-se às suas características conforme a sigla indica: rápido, barato, eficiente, robusto e simples de ser operado. Deve-se ainda destacar a grande diversidade de fases sólidas que podem ser empregadas na etapa de d- 
SPE. A técnica selecionada para a separação dos compostos extraídos do lodo pelo QuEChERS foi a cromatografia liquida de alta eficiência (HPLC), adequado para esse tipo de separação. Essa técnica foi acoplada a espectrometria de massas de alta resolução com analisador do tipo ToF (Time of Fligth ou tempo de voo), empregando eletrospray (ESI) como fonte de ionização. Esse conjunto é denominado LC-ESI-ToF.

\section{Objetivo}

O objetivo desse trabalho foi desenvolver uma metodologia analítica para a determinação de possíveis resíduos de sulfonamidas em lodo de esgoto utilizando um método rápido para a extração desses compostos, baseado no método QuEChERS seguido por LC-ESIToF.

Para melhor adaptação do método à matriz e aos analitos escolhidos, fez-se uso da ferramenta estatística de planejamento de experimentos para otimização do mesmo. A separação e detecção das sulfonamidas foram realizadas por LC-MS. Para finalizar, o método foi validado de acordo com as diretrizes da norma RE no 899 da ANVISA (2003). ${ }^{64}$

\section{Materiais e Métodos}

\subsection{Padrões e Reagentes}

Os padrões analíticos para as 9 sulfonamidas estudadas (Tabela 12) foram adquiridos de Sigma-Aldrich. Soluções estoques (SE) foram preparadas em acetonitrila em concentração de $400 \mathrm{mg} \mathrm{L}^{-1}$ e acondicionadas a $4{ }^{\circ} \mathrm{C}$ durante todo o estudo. Soluções intermediárias (SI) foram preparadas a fim de se preservar a integridade da SE, assim, as soluções de trabalho utilizadas durante o desenvolvimento do procedimento analítico foram adquiridas a partir da SI na concentração de interesse. Como padrão interno, utilizou-se a sulfametoxazol deuterada, também adquirida de Sigma-Aldrich.

Acetonitrila de elevado grau de pureza (grau HPLC, Tedia) foi utilizada tanto como fase móvel para separação cromatográfica quanto para a preparação das soluções padrões. A água utilizada foi purificada por um sistema Milli-Q (Millipore).

Os reagentes ácido-fórmico 98\% de pureza (Tedia), hidróxido de amônio 30\% de pureza (Synth), $\mathrm{NaCl}$ (Mallinckrodt) e MgSO4 (Sigma-Aldrich). 
Tabela 12: Estrutura química, massa molar e pka de todas as sulfonamidas estudadas.

\begin{tabular}{llll}
\hline & & Massa & \\
Composto & Estrutura & molar & pKa \\
& & g/mol &
\end{tabular}

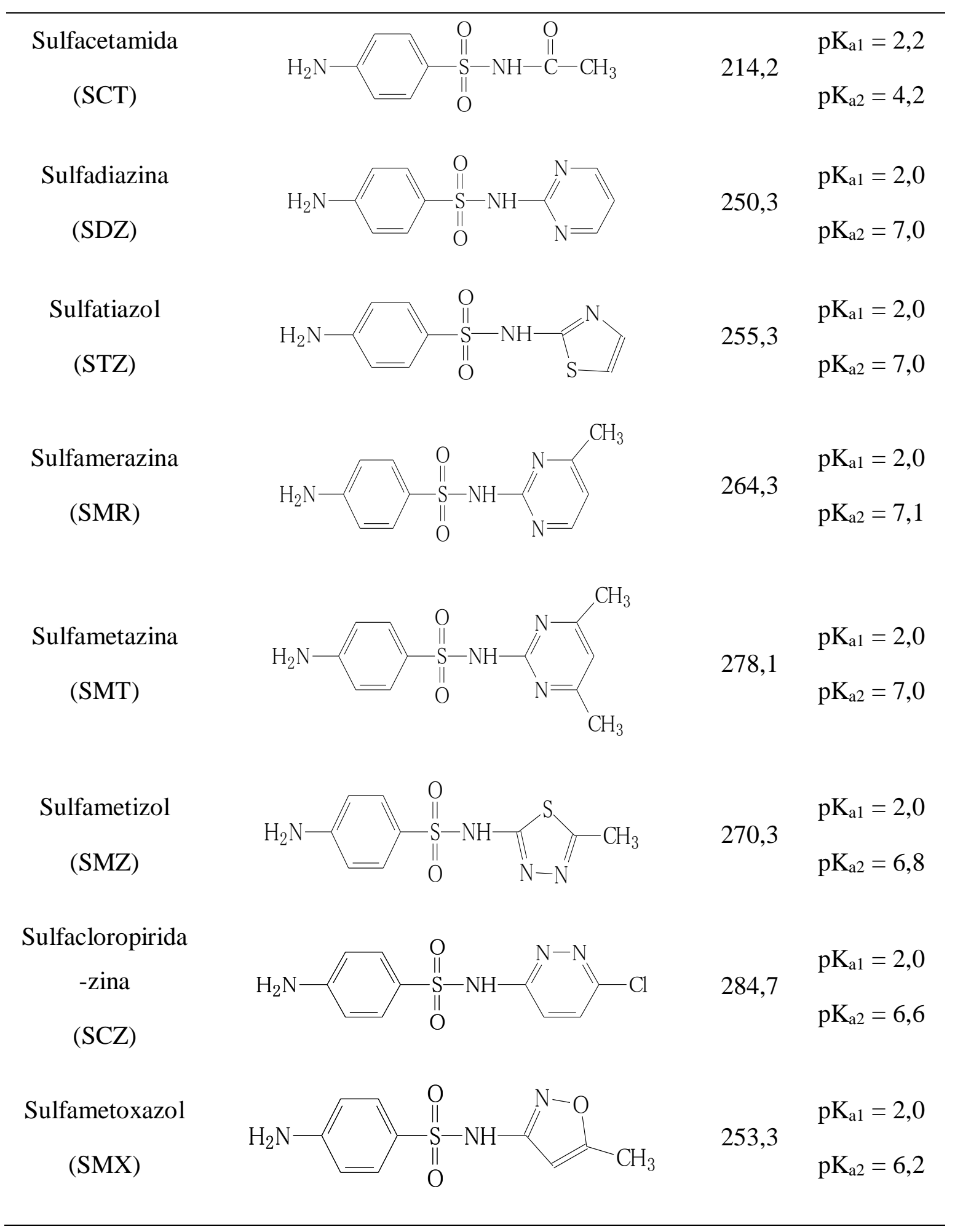




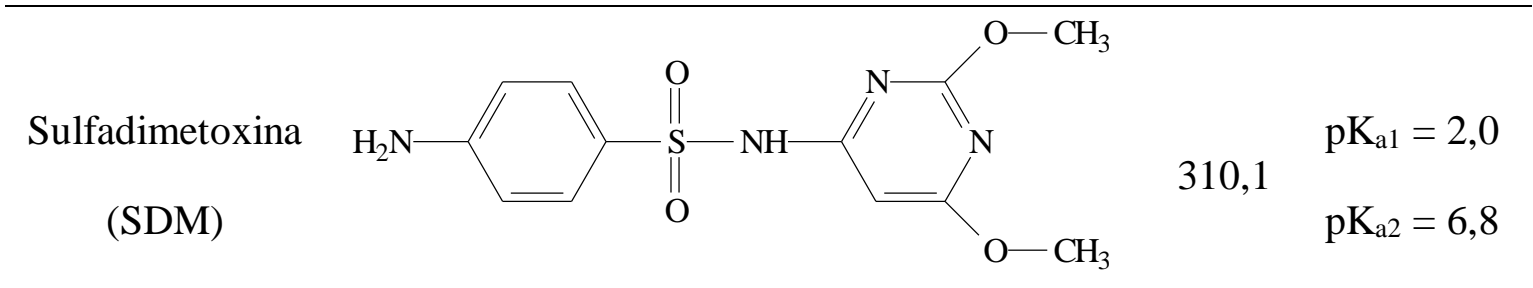

\subsection{Separação e detecção analítica}

Para a separação analítica, fez-se uso de um HPLC série Prominence 20AD da Shimadzu, coluna cromatográfica Agilent C18 (2,1 mm x 100 mm x 2,7 $\mu \mathrm{m})$, volume de injeção $5,0 \mu \mathrm{L}$, temperatura do forno $40^{\circ} \mathrm{C}$, vazão $0,25 \mathrm{~mL} \mathrm{~min}^{-1}$ e fase móvel composta por $\mathrm{ACN}$ e $\mathrm{H}_{2} \mathrm{O}$ ambos a 0,1\% de ácido fórmico, com gradiente de acordo com a Figura 19.

Figura 19: Programa do gradiente da fase móvel utilizado para separação das sulfonamidas.

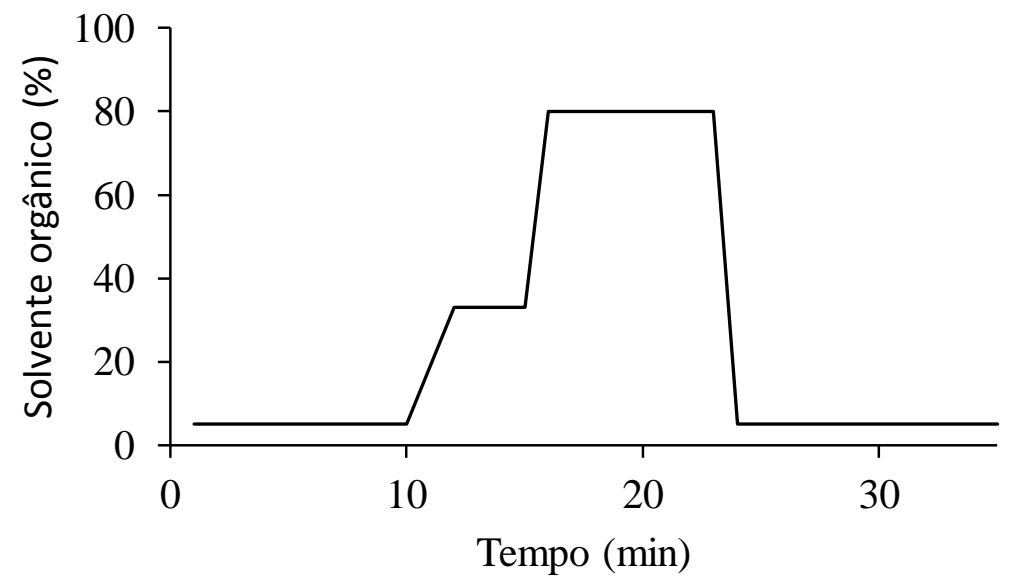

A detecção foi feita por um espectrômetro de massas híbrido (QqTOF), Bruker, modelo micrOTOF-Q II, funcionando no modo full MS. Apesar desse sistema apresentar dois analisadores de massas em tandem, quadrupolo e ToF (sendo o último de alta resolução), o quadrupolo ficou em "by-pass", sendo o eluente da coluna de HPLC direcionado diretamente para o ESI e depois para ToF. A fonte de electrospray operou no modo positivo de ionização, voltagem do capilar de $3,5 \mathrm{kV}$, pressão do nebulizador de 4,0 bar, vazão do gás secante de 8,0 $\mathrm{L} \min ^{-1}$ e temperatura da fonte $200{ }^{\circ} \mathrm{C}$.

As massas utilizadas foram: sulfacetamida $(215,00 \pm 0,05)$, sulfadiazina $(251,05 \pm 0,02)$, sulfatiazol $(256,02 \pm 0,02)$, sulfamerazina $(265,07 \pm 0,05)$, sulfametazina $(279,09 \pm 0,05)$, sulfametizol $(251,02 \pm 0,05)$, sulfacloropiridazina $(285,00 \pm 0,05)$, sulfametoxazol $(254,05 \pm 0,05)$ e suldimetoxina $(311,07 \pm 0,05)$. 


\subsection{Preparação do lodo}

O lodo utilizado foi gentilmente cedido pelo Laboratório de Processos Biológicos (LPB) da Escola de Engenharia de São Carlos (Universidade de São Paulo).

Em nosso laboratório (CROMA) foi mantido refrigerado a $4,0{ }^{\circ} \mathrm{C}$. Para a extração, o excesso de água presente no lodo foi retirado com auxílio da filtração a vácuo utilizando funil de Büchner.

A contaminação, à concentração desejada $\left(0,5 \mathrm{mg} \mathrm{kg}^{-1}\right)$, foi feita em alíquotas de lodo de 4,0 g separadas em tubos Falcon de $50 \mathrm{~mL}$. Após a contaminação, os tubos foram mantidos abertos para evaporação da ACN utilizada na preparação dos padrões analíticos e, em seguida, fechados e mantidos refrigerados $-4,0^{\circ} \mathrm{C}$ por $48 \mathrm{~h}$.

\subsection{Otimização do método}

Para otimização do método, fez-se uso da ferramenta estatística planejamento de experimentos, pois com ela foi possível avaliar o efeito individual dos parâmetros estudados, bem como o efeito da interação entre eles.

Para o QuEChERS essa proposta também é válida. No trabalho de Li et al. (2014), ${ }^{71}$ foi empregado primeiramente um planejamento P-B (Plackett and Burman) para triagem de seis variáveis independentes, entre as quais o volume de água adicionado, volume de ácido acético e quantidade de PSA para extração de pesticidas em solo. Selecionadas as mais importantes, o ponto ótimo de extração foi determinado por planejamento composto central.

Para esse trabalho algumas variáveis foram analisadas individualmente como, por exemplo, o efeito da composição da fase extratora, e a quantidade de lodo utilizada (estabelecido em 4,0 g por ser uma quantidade de amostra muito próxima a utilizada nos métodos originais).

As quantidades utilizadas das variáveis independentes clássicas empregadas no QuEChERS foram avaliadas por meio da realização de planejamento de experimentos fatorial fracionário $2^{4-1}$, totalizando a realização de 8 experimentos, de acordo com os valores apresentados na Tabela 13. 
Tabela 13: Valores estudados no planejamento fatorial fracionário $2^{4-1}$ utilizado para otimização do QuEChERS.

\begin{tabular}{lccc}
\hline \multicolumn{1}{c}{ Variáveis } & \multicolumn{3}{c}{ Níveis avaliados } \\
\cline { 2 - 4 } Independentes & $\mathbf{+ 1}$ & $\mathbf{0}$ & $\mathbf{- 1}$ \\
\hline Proporção do Solvente & 2 & 2,5 & 3 \\
$\mathrm{ACN} / \mathrm{H}_{2} \mathrm{O}$ & $2: 1$ & $3: 1$ & $4: 1$ \\
$\mathrm{NaCl}(\%)$ & 10 & 20 & 30 \\
$\mathrm{MgSO}_{4}(\mathrm{mg})$ & 40 & 60 & 80 \\
\hline
\end{tabular}

\subsection{Validação do Método}

Avaliou-se, durante a validação desse método os parâmetros linearidade, limite de detecção, limite de quantificação, precisão, exatidão, recuperação, efeito matriz e eficiência do método.

Os limites de detecção e quantificação foram determinados como sendo a concentração que apresentou a intensidade do sinal 3 e 10 vezes superior à do ruído obtido, respectivamente.

A curva analítica foi obtida pela fortificação da matriz isenta em 6 níveis crescentes de concentração dos analitos, sendo feito em quintuplicata os níveis baixo, médio e alto, e nos demais em duplicata. Plotou-se a razão de área obtida pela divisão da área do analito pela área padrão interno versus a concentração adicionada à amostra.

O efeito matriz $(M E)$, recuperação $(R E)$ e eficiência do método $(E M)$ foram calculados de acordo com as seguintes expressões:

$$
\begin{gathered}
M E(\%)=B /_{A} \times 100 \\
R E(\%)=C /_{B} \times 100 \\
E M(\%)=(M E \times R E) / 100
\end{gathered}
$$

onde, A é referente a solução padrão, B a matriz contaminada após a extração e C a matriz contaminada antes de se iniciar o procedimento de extração, de acordo com metodologia proposta por Matuszewski et al. (2003). ${ }^{72}$ 


\section{Resultados e Discussão}

\subsection{Otimização do método QuEChERS de extração}

A matriz escolhida para esse trabalho apresenta uma complexidade enorme, visto que inúmeros interferentes podem ser nela encontrados. Outro motivo que pode interferir negativamente nos processos analítico é a composição do lodo utilizado, já que, mesmo sendo uma amostra sólida, é composta por aproximadamente $90 \%$ de água (dado obtido secando-se a amostra a $100{ }^{\circ} \mathrm{C}$ e comparando-se a diferença de peso). Após essa averiguação, fixou-se a porcentagem de água em $20 \%$, a fim de se manter a homogeneidade da amostra e testou-se diferentes solventes orgânicos, variando-se o pH do meio.

O efeito da extração pelo procedimento QuEChERS foi avaliado com os solventes acetonitrila e acetato de etila, devido a diferença de polaridade de ambos. Os resultados são apresentados na Figura 20. Observa-se que para a maioria dos compostos, ACN apresenta os melhores resultados. No entanto, ao se observar os compostos mais polares (sulfacetamida e sulfadiazina), os resultados obtidos com $\mathrm{ACN} 0,1 \%$ ácido fórmico são bastante expressivos e, essa mesma composição, apresenta pouca diferença em relação a ACN pura para os outros analitos. Assim, conclui-se que adicionando $0,1 \%$ ácido fórmico à acetonitrila foi a melhor opção para a extração de sulfonamidas do lodo de esgoto.

Figura 20: Avaliação do efeito da extração da sulfonamidas pelo método QuEChERS utilizando solventes de diferentes polaridades.

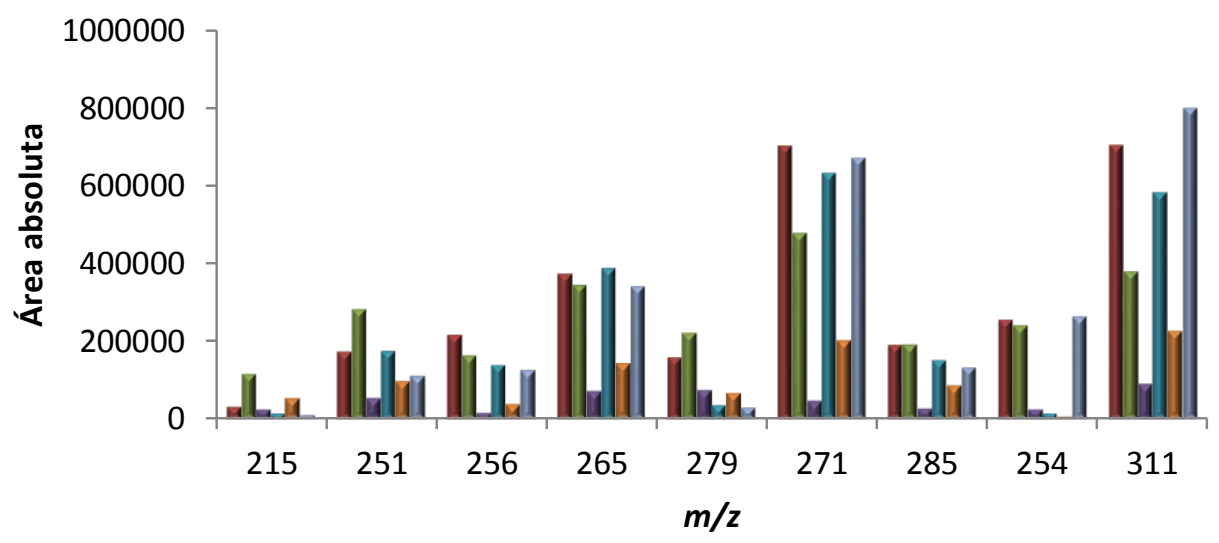




\subsubsection{Otimização por planejamento fatorial fracionário $2^{4-1}$}

Após a definição da fase extratora, iniciou-se os estudos para verificar os efeitos gerados por cada etapa utilizada no método. Para isso, fez-se uso da ferramenta estatística de planejamento de experimentos, optando por utilizar o planejamento fatorial fracionário $2^{4-1}$ visto que, com ele, é possível realizar uma triagem das variáveis independes significativas para o processo de extração.

A composição da fase extratora (proporção de ACN acidificada e água), volume utilizado, efeito salting-out e a quantidade de $\mathrm{MgSO}_{4}$ adicionada foram os parâmetros avaliados, de acordo com os valores citados na Tabela 13.

Foram realizados oito experimentos referentes ao planejamento fatorial fracionário, com adição de dois experimentos no ponto central permitindo assim, a obtenção do erro puro.

Com os dados obtidos com o planejamento $2^{4-1}$ (Tabela 14) foi possível verificar o efeito de cada variável na resposta avaliada, por meio da elaboração dos diagramas de Pareto. Observa-se que entre as 4 variáveis avaliadas a que apresenta menor efeito sobre a área absoluta dos picos é a porcentagem de $\mathrm{NaCl}$. Assim, para se estimar o efeito também das interações entre as variáveis, um novo tratamento estatístico foi realizado considerando somente as três variáveis de maior efeito, obtendo um planejamento fatorial $2^{3}$.

Com os diagramas de Pareto resultantes dessa etapa estatística, foi possível observar os efeitos gerados sob a variável resposta referentes a interação entre as 3 variáveis analisadas no processo de otimização. Com clareza é possível observar a importância desse estudo, visto que, para cerca de $90 \%$ das sulfonamidas estudadas, as interações entre as variáveis apresentam os maiores valores de efeitos para o processo de extração (Figura 21).

Observa-se que o efeito individual da variável referente à proporção de volume de solvente extrator tem sinal negativo, indicando que quanto menor, maior será a extração dos analitos, o que pode ser facilmente entendido devido a maior concentração do mesmos encontrada após a extração. Porém, o nível mínimo estudado se refere a um volume 2 vezes maior que o total de massa utilizado, ou seja, 8,0 mL. Volume abaixo desse valor prejudicaria a separação das fases, tornando-se difícil retirar uma alíquota da porção de acetonitrila. Por esse motivo, fixou-se o volume em $8,0 \mathrm{~mL}$ para a etapa posterior. 
Tabela 14: Resultados, expressos em área absoluta, obtidos com o planejamento fatorial fracionário.

\begin{tabular}{llllllllll}
\hline \multirow{2}{*}{ Experimentos } & \multicolumn{7}{c}{ Respostas (área absoluta dos picos cromatográficos) } \\
\cline { 2 - 8 } & Cetamida & Diazina & Tiazol & Merazina & Metazina & Metizol & Cloropirida & Metoxazol & Dimetoxina \\
\hline $\mathbf{1}$ & 120040 & 297252 & 159845 & 470317 & 634552 & 206055 & 188593 & 271391 & 396252 \\
$\mathbf{2}$ & 98056 & 240850 & 117328 & 360756 & 467247 & 143834 & 133846 & 195905 & 303151 \\
$\mathbf{3}$ & 107548 & 263474 & 145265 & 375164 & 486548 & 185621 & 160750 & 236618 & 377418 \\
$\mathbf{4}$ & 76019 & 170618 & 85640 & 242295 & 296829 & 101636 & 92254 & 135079 & 221144 \\
$\mathbf{5}$ & 73544 & 140587 & 49479 & 187863 & 233293 & 58396 & 72580 & 120712 & 175746 \\
$\mathbf{6}$ & 104533 & 246619 & 150899 & 363818 & 478708 & 187869 & 162470 & 225374 & 345194 \\
$\mathbf{7}$ & 148872 & 382577 & 256748 & 559955 & 782309 & 327828 & 265405 & 383385 & 570147 \\
$\mathbf{8}$ & 88599 & 199363 & 115213 & 284003 & 354174 & 146219 & 132712 & 192554 & 330732 \\
$\mathbf{P C}$ & 98865 & 220096 & 103968 & 309442 & 385520 & 114157 & 116255 & 183481 & 257552 \\
$\mathbf{P C}$ & 96250 & 213047 & 110443 & 302789 & 385416 & 127293 & 126153 & 195313 & 278727 \\
\hline
\end{tabular}

PC: Ponto central 
Figura 21: Diagramas de Pareto para todas as sulfonamidas estudadas, obtidos pela realização do planejamento $2^{4-1}$
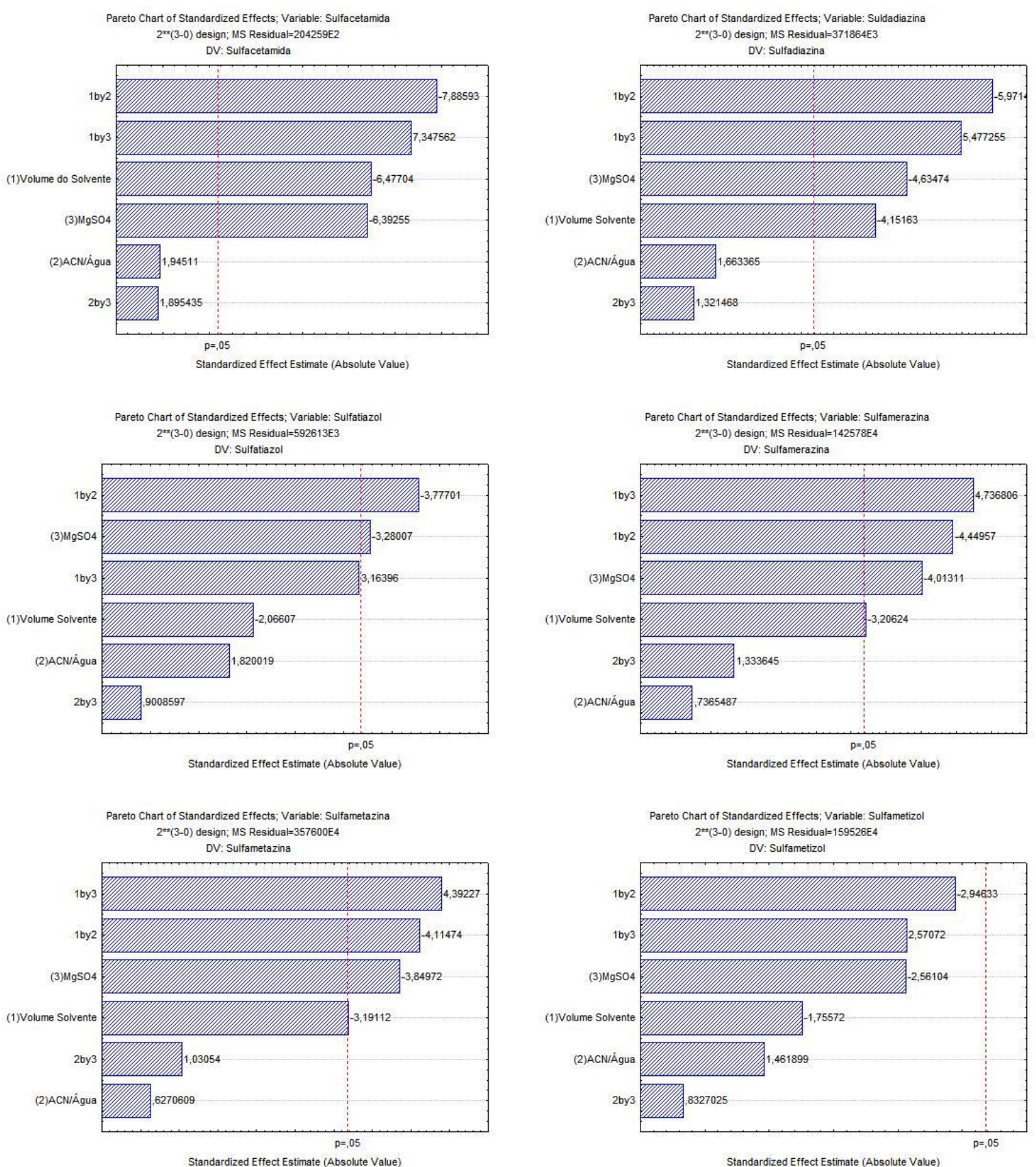

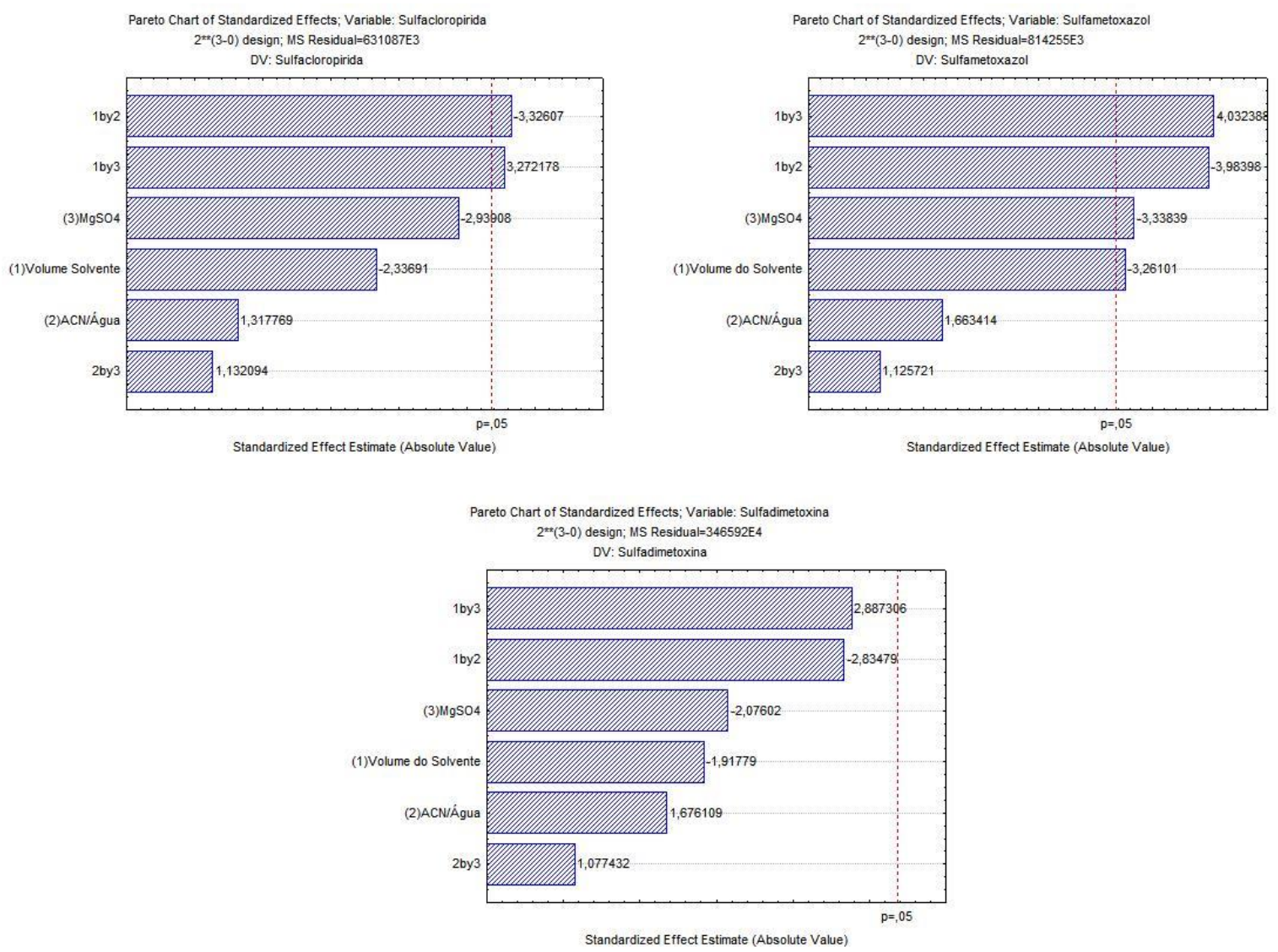

Sendo assim, um planejamento composto central foi elaborado considerando-se somente a composição da fase extratora e a quantidade de $\mathrm{MgSO}_{4}$ utilizadas, a fim de se estimar uma melhor condição de extração. Esse planejamento permite o estudo em 5 níveis distintos, totalizando o número de experimentos pela expressão: $2^{\text {n }}\left(2^{2}=4\right.$ pontos fatoriais $)+2 n(2 \times 2$ $=4$ pontos axiais) +4 (pontos centrais com três réplicas). As réplicas no ponto central têm como finalidade verificar a variância da resposta prevista e fornecer uma medida do erro puro.

Os 5 níveis avaliados são apresentados na Tabela 15, enquanto que todos os resultados obtidos com os 12 experimentos, realizados de forma aleatória, estão apresentados na Tabela 16.

A partir desses resultados, foi possível então estimar a melhor condição de extração com auxílio dos gráficos denominados de superfície de resposta. Facilmente é notado que os maiores valores absolutos de áreas de cada pico cromatográfico são encontradas próximo ao ponto central de extração (Figura 22). Assim, este ponto foi escolhido para dar continuidade aos ensaios. 
Tabela 15: Valores reais e codificados utilizados para a elaboração do planejamento composto central

\begin{tabular}{cccccc}
\hline Variáveis & \multicolumn{5}{c}{ Níveis Codificados } \\
\cline { 2 - 6 } independentes & $-1,41$ & $-1,0$ & 0 & 1,0 & 1,41 \\
\hline ACN/Água & $2,59: 1$ & $3: 1$ & $4: 1$ & $5: 1$ & $5,41: 1$ \\
MgSO $_{4}(\mathrm{~g})$ & 25,9 & 30 & 40 & 50 & 54,1 \\
\hline
\end{tabular}

\subsubsection{Otimização do clen-up por d-SPE}

A etapa empregando a extração em fase sólida dispersiva (d-SPE) é amplamente utilizada com o procedimento QuEChERS, visando a remoção de possíveis interferentes presentes na matriz que podem, de alguma forma, interferir no processo de extração.

No entanto, é relatado que, juntamente com os interferentes podem ser removidos também os analitos de interesse diminuindo, assim, a eficiência do processo. Com o intuito de se evitar esse efeito, três materiais sorbentes foram avaliados nessa etapa: PSA (remoção de ácidos e açucares), grafite (remoção de pigmentos) e C18 (remoção de lipídios e compostos apolares). A resposta avaliada foi a relação entre o sinal do analito e o ruído $(S / N)$, visto que, a diminuição dos interferentes presentes na matriz pode acarretar a diminuição do ruído presente, favorecendo assim, a detecção dos analitos. Um experimento controle, sem adição da d-SPE foi executado a fim de comparação

Com a Figura 23 observa-se que não houve grandes variações na relação $S / N$ para a maioria dos compostos quando adicionado a etapa de d-SPE, exceto para os compostos sulfametizol $(\mathrm{m} / \mathrm{z}, 271)$ e sulfametoxazol $(\mathrm{m} / \mathrm{z}, 254)$, para os quais a adição de grafite e PSA, respectivamente, aumentaram consideravelmente a relação $\mathrm{S} / \mathrm{N}$. Para a sulfadimentoxina $(\mathrm{m} / z$ 311) não observou-se aumento na relação $S / N$ com a d-SPE, obtendo uma relação de 3500 nos resultados obtidos para a extração controle.

Contudo, a adição dessa etapa não trouxe grandes benefícios para o método em geral, adicionando custo ao processo e aumentando o tempo total de extração. Por esses motivos, optou-se por não utilizá-la para validação do mesmo. Resultados semelhantes foram encontrados ao se extrair fármacos de matrizes ambientais, como lodo, em que a adição da etapa de clean-up aumentou a recuperação das fluoroquinolonas e sulfonamidas em apenas 10-15\%, 73 já para tetraciclinas, o resultado não foi muito diferente do encontrado sem adição da d-SPE, levando os autores a abandonar essa etapa. 
Tabela 16: Resultados obtidos para planejamento composto central, considerando como variável resposta a área absoluta dos picos cromatográficos.

\begin{tabular}{|c|c|c|c|c|c|c|c|c|c|c|c|}
\hline \multirow{2}{*}{ Exp. } & \multicolumn{3}{|c|}{ Variáveis } & \multicolumn{8}{|c|}{ Resposta (área absoluta dos picos cromatográficos) } \\
\hline & $\overline{A^{a}}$ & $\mathbf{B}^{\mathbf{b}}$ & $\overline{\text { SCT }}$ & $\overline{\text { SDZ }}$ & $\overline{\text { STZ }}$ & $\overline{\text { SMR }}$ & $\overline{\text { SMT }}$ & $\overline{\text { STZ }}$ & $\overline{\mathrm{SCZ}}$ & SMX & $\overline{\text { SDM }}$ \\
\hline $\mathbf{P C}$ & 0,00 & 0,00 & 136310,5 & 296941,5 & 148352,0 & 334342,0 & 373969,5 & 128262,5 & 120751,5 & 168318,5 & 229143,0 \\
\hline 8 & 0,00 & 1,41 & 138985,5 & 304967,5 & 155258,0 & 364517,0 & 406452,5 & 134209,0 & 138468,0 & 188990,5 & 257252,0 \\
\hline 3 & 1,00 & $-1,00$ & 95983,5 & 208873,5 & 104612,5 & 269167,5 & 303241,5 & 85369,5 & 100602,0 & 141556,5 & 217339,0 \\
\hline 2 & $-1,00$ & 1,00 & 87094,5 & 155115,5 & 62532,0 & 191696,0 & 217752,0 & 43601,5 & 66273,5 & 105576,0 & 175942,0 \\
\hline 5 & $-1,41$ & 0,00 & 141387,0 & 300831,0 & 134599,0 & 360804,0 & 388967,5 & 121831,0 & 134541,0 & 182042,5 & 274172,5 \\
\hline PC & 0,000 & 0,00 & 139824,0 & 298616,5 & 146124,5 & 353358,0 & 368471,0 & 110393,0 & 130812,0 & 192436,0 & 274079,0 \\
\hline
\end{tabular}

PC: Experimentos referentes ao ponto central

a variável independente referente a proporção de acetonitrila e água presente no solvente extrator

${ }^{\mathrm{b}}$ variável independente referente a quantidade de $\mathrm{MgSO}_{4}$ utilizada. 
Figura 22: Gráficos de superfície obtidos com auxílio do planejamento composto central, utilizados para determinar a melhor condição de extração.
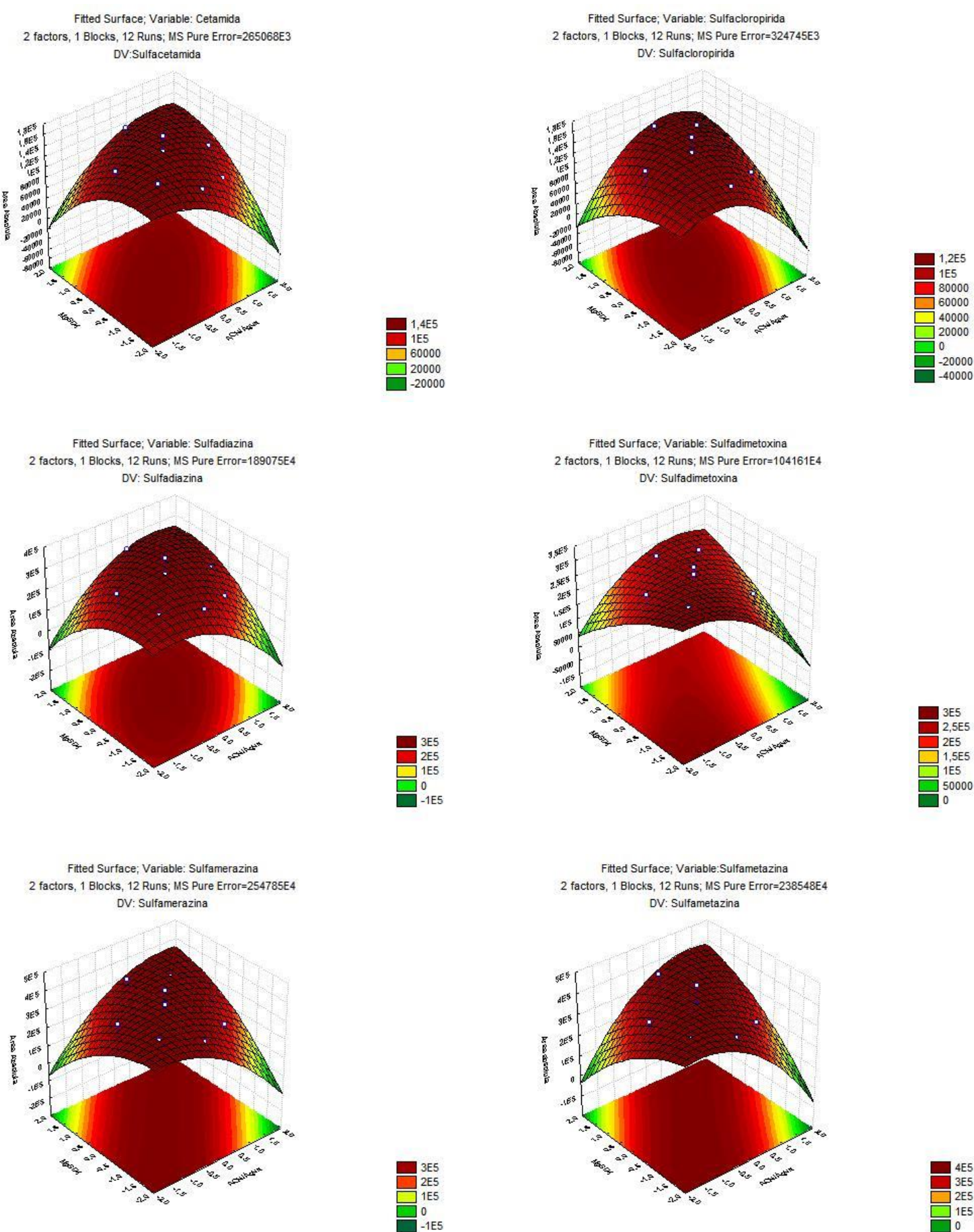

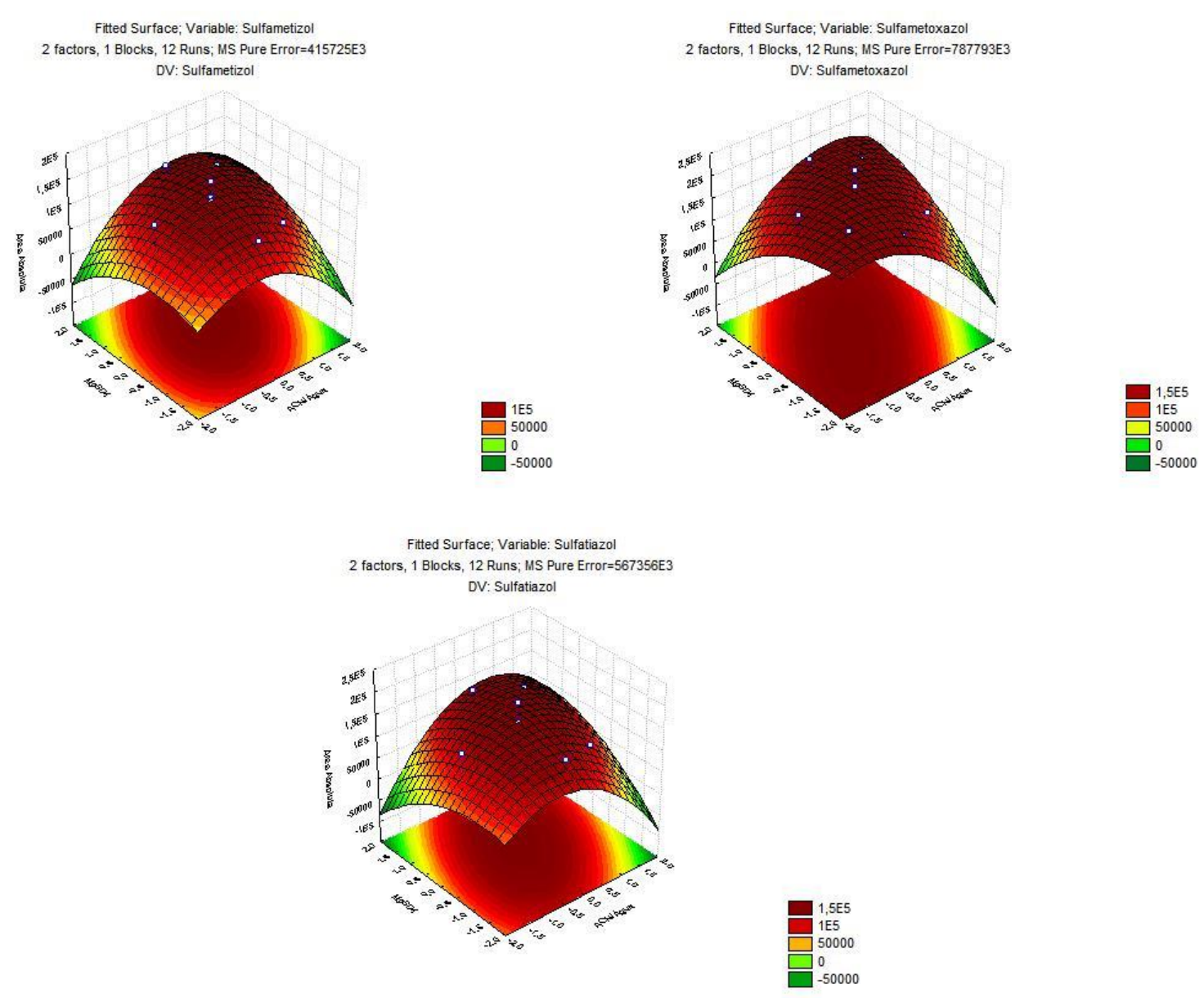

Figura 23: Resultados referentes aos diferentes tipos de sorbentes utilizados na d-SPE.

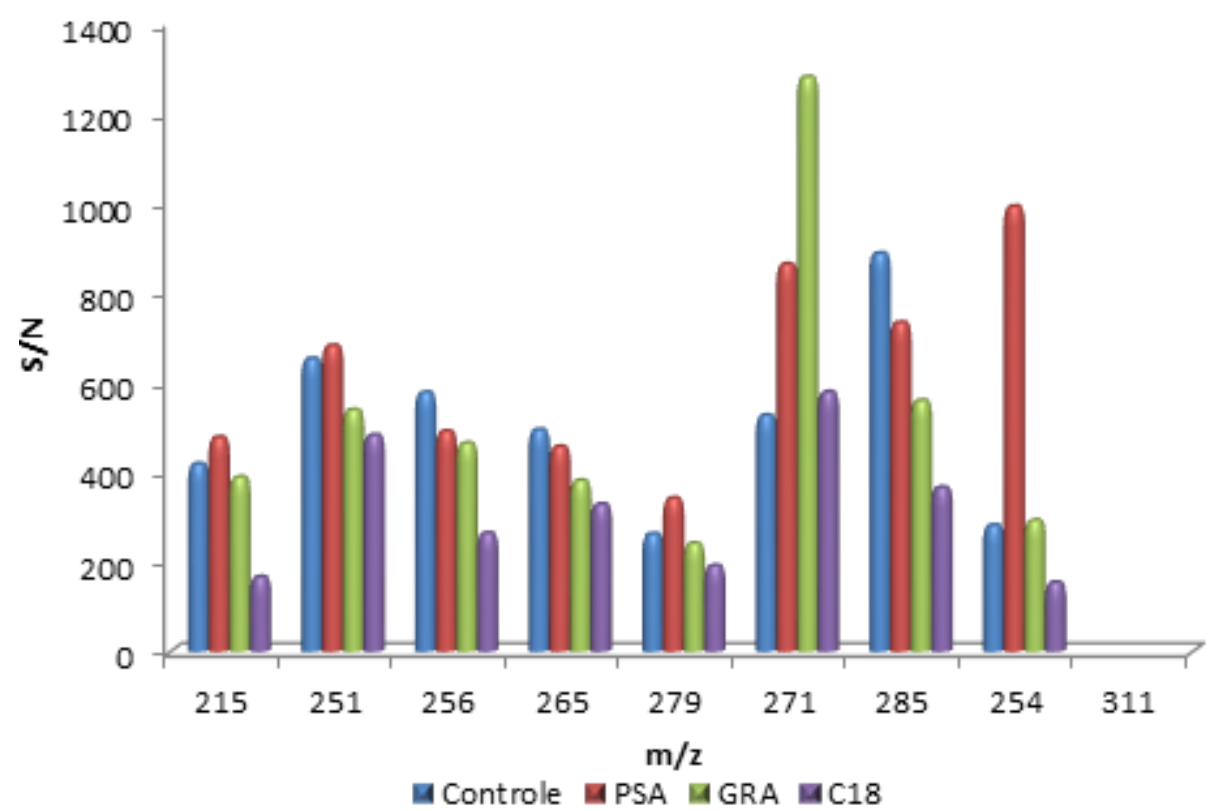




\subsection{Validação do método}

\subsubsection{Linearidade}

A linearidade é a figura de mérito que avalia a capacidade do método analítico em fornecer resultados diretamente proporcionais à concentração dos compostos de interesse. Normalmente, espera-se que os dados se comportem de maneira homocedástica ao longo da faixa linear, apresentando a mesma variância para todos os níveis.

De acordo com o teste $F$, para todos os analitos avaliados nesse trabalho, o valor obtido para $F_{E x p}$ foi maior que o respectivo $F_{T a b}$ exigindo, assim, melhor adequação dos dados ao modelo, ou seja, o uso de ponderação utilizando o fato peso. $\mathrm{Na}$ Tabela 17 , observa-se claramente que com a ponderação da regressão linear, há alteração tanto no coeficiente de correlação quanto na soma dos resíduos possibilitando, assim, melhor ajuste dos dados.

Estabelecido o melhor tipo de regressão para cada sulfonamida estudada, foi possível estabelecer os valores dos coeficientes de regressão. A Tabela 18 apresenta os resultados referentes à faixa linear obtida, LD e LQ.

Os valores obtidos são totalmente satisfatórios, e, embora ainda não exista um valor para limite máximo de concentração permitido em lodo de esgoto, a faixa linear compreendida e os valores de quantificação abrangem os valores encontrados em trabalhos atuais. ${ }^{38}$

\subsubsection{Precisão e Exatidão}

O estudo para precisão intradias foi expresso em desvio padrão relativo (DPR, \%), obtendo valores abaixo de $20 \%$ para os LQs e abaixo dos $15 \%$ para os demais níveis. O estudo de exatidão apresentou resultados insatisfatórios para alguns compostos como, exemplo, a sulfametazina cuja exatidão se mostrou próximo a $75 \%$ para os três níveis avaliados (Tabela 19). No entanto, para a maioria das SAs o resultado esteve dentro do esperado para os três níveis, abrangendo valores na faixa de $80-120 \%$. Estes valores são satisfatórios, visto que estão dentro dos limites de referência utilizados pela maioria das agências regulamentadoras, como ANVISA. 
Tabela 17: Valores de $\mathrm{R}^{2}$ e da soma dos resíduos para todas as $\mathrm{SAs}$ estudadas, utilizando diferentes tipos de ponderação.

\begin{tabular}{|c|c|c|c|c|c|c|c|c|c|c|}
\hline \multirow{2}{*}{ Ponderação } & \multirow{2}{*}{$\begin{array}{c}\text { Parâmetros } \\
\text { Avaliados }\end{array}$} & \multicolumn{9}{|c|}{ Compostos $(m / z)$} \\
\hline & & 215 & 251 & 256 & 265 & 279 & 271 & 285 & 254 & 311 \\
\hline \multirow{2}{*}{1} & $\mathrm{R}^{2}$ & 0,9807 & 0,9881 & 0,9767 & 0,9903 & 0,9750 & 0,9819 & 0,9884 & 0,9892 & 0,9895 \\
\hline & $\Sigma$ Resíduos & 86,71 & 100,77 & 211,51 & 169,54 & 297,87 & 300,74 & 75,33 & $-32,23$ & 357,58 \\
\hline \multirow{2}{*}{$1 / x^{2}$} & $\overline{\mathrm{R}^{2}}$ & 0,9117 & 0,9694 & 0,9806 & 0,9769 & 0,9553 & 0,9853 & 0,9909 & 0,9896 & 0,9643 \\
\hline & $\Sigma$ Resíduos & 9,80 & 0,52 & 0,68 & 2,11 & 0,01 & 0,76 & 0,37 & $-0,79$ & $-0,75$ \\
\hline $1 / x$ & $\overline{\mathrm{R}^{2}}$ & 0,9692 & 0,9811 & 0,9847 & 0,9889 & 0,9800 & 0,9883 & 0,9925 & 0,9920 & 0,9856 \\
\hline $1 / x^{0,5}$ & $\Sigma$ Resíduos & $-2,64$ & 25,49 & 83,83 & 81,26 & 93,88 & 108,30 & 12,65 & $-35,36$ & 145,30 \\
\hline \multirow{2}{*}{$1 / y$} & $\overline{\mathrm{R}^{2}}$ & 0,9766 & 0,9836 & 0,9843 & 0,9887 & 0,9802 & 0,9875 & 0,9925 & 0,9921 & 0,9863 \\
\hline & $\Sigma$ Resíduos & $-65,25$ & $-39,96$ & $-48,37$ & $-56,7622$ & $-91,36$ & $-32,55$ & $-14,47$ & $-15,47$ & $-78,01$ \\
\hline $1 / y^{2}$ & $\overline{\mathrm{R}^{2}}$ & 0,9467 & 0,9729 & 0,9728 & 0,9683 & 0,9426 & 0,9819 & 0,9894 & 0,9880 & 0,9560 \\
\hline
\end{tabular}


Tabela 18: Figuras de mérito utilizadas para validação do método QuEChERS na extração das sulfonamidas em lodo de esgoto.

\begin{tabular}{|c|c|c|c|c|c|}
\hline $\begin{array}{c}\text { Composto } \\
(m / z)\end{array}$ & $\begin{array}{c}\text { Faixa } \\
\text { Linear } \\
\text { ng g }^{-1}\end{array}$ & $\begin{array}{c}\text { Equação de } \\
\text { calibração } \\
\left(\mathbf{a}, \mathbf{b}, \mathbf{R}^{2}\right)\end{array}$ & $\begin{array}{c}\text { LQ } \\
\text { ng g }^{-1}\end{array}$ & $\begin{array}{c}\text { LD } \\
\text { ng g }^{-1}\end{array}$ & $\begin{array}{c}\text { Tipo de } \\
\text { Ponderação }\end{array}$ \\
\hline 215 & $25-800$ & $\begin{array}{l}0,0020 \\
0,1078 \\
0,9812\end{array}$ & 25 & 9 & $1 / y^{0,5}$ \\
\hline 251 & $25-600$ & $\begin{array}{l}0,0078 \\
0,1639 \\
0,9866\end{array}$ & 25 & 9 & $1 / y^{0,5}$ \\
\hline 256 & $15-800$ & $\begin{array}{c}0,0053 \\
-0,0223 \\
0,9806\end{array}$ & 15 & 5 & $1 / x^{2}$ \\
\hline 265 & $15-600$ & $\begin{array}{l}0,0120 \\
0,0029 \\
0,9909 \\
\end{array}$ & 15 & 5 & $1 / y^{0,5}$ \\
\hline 279 & $15-800$ & $\begin{array}{l}0,0130 \\
0,0576 \\
0,9800\end{array}$ & 15 & 5 & $1 / x$ \\
\hline 271 & $15-800$ & $\begin{array}{c}0,0068 \\
-0,0316 \\
0,9853\end{array}$ & 15 & 5 & $1 / x^{2}$ \\
\hline 285 & $15-800$ & $\begin{array}{c}0,0045 \\
-0,0161 \\
0,9909\end{array}$ & 15 & 5 & $1 / x^{2}$ \\
\hline 254 & $25-800$ & $\begin{array}{c}0,0061 \\
-0,0612 \\
0,9920\end{array}$ & 25 & 9 & $1 / x$ \\
\hline 311 & $10-800$ & $\begin{array}{c}0,0097 \\
-0,0067 \\
0,9928\end{array}$ & 10 & 4 & $1 / x$ \\
\hline
\end{tabular}

Obs.: considerando-se a equação de calibração com regressão do tipo $y=a x+b$ 
Tabela 19: Estudo sobre exatidão e precisão interdias necessários para validação do método QuEChERS.

\begin{tabular}{|c|c|c|c|}
\hline $\begin{array}{c}\text { Compostos } \\
(m / z)\end{array}$ & Níveis & $\begin{array}{c}\text { Intradias } \\
\text { (DPR, \%) } \\
\quad \text { n = 5 }\end{array}$ & $\begin{array}{c}\text { Exatidão } \\
(\mathbf{n}=\mathbf{3})\end{array}$ \\
\hline \multirow{3}{*}{215} & Baixo & 12,45 & 80,92 \\
\hline & Médio & 8,67 & 91,50 \\
\hline & Alto & 6,79 & 82,60 \\
\hline \multirow{3}{*}{251} & Baixo & 5,61 & 77,23 \\
\hline & Médio & 5,31 & 98,91 \\
\hline & Alto & 10,20 & 86,79 \\
\hline \multirow{3}{*}{256} & Baixo & 20,05 & 75,01 \\
\hline & Médio & 1,96 & 87,95 \\
\hline & Alto & 10,54 & 81,79 \\
\hline \multirow{3}{*}{265} & Baixo & 17,54 & 79,68 \\
\hline & Médio & 3,23 & 99,31 \\
\hline & Alto & 7,82 & 93,72 \\
\hline \multirow{3}{*}{279} & Baixo & 22.49 & 81,83 \\
\hline & Médio & 4,60 & 93,31 \\
\hline & Alto & 6,95 & 89,37 \\
\hline \multirow{3}{*}{271} & Baixo & 10,44 & 78,45 \\
\hline & Médio & 3,43 & 86,20 \\
\hline & Alto & 10,22 & 86,67 \\
\hline \multirow{3}{*}{285} & Baixo & 11,99 & 97,71 \\
\hline & Médio & 4,12 & 87,64 \\
\hline & Alto & 7,60 & 96,53 \\
\hline \multirow{3}{*}{254} & Baixo & 9,67 & 102,62 \\
\hline & Médio & 2,47 & 95,91 \\
\hline & Alto & 4,36 & 104,22 \\
\hline \multirow{3}{*}{311} & Baixo & 20,01 & 93,35 \\
\hline & Médio & 3,19 & 101,40 \\
\hline & Alto & 8,24 & 96,90 \\
\hline
\end{tabular}

\subsubsection{Recuperação, Efeito Matriz e Eficiência do Método}

O acoplamento da cromatografia liquida com a espectrometria de massas utilizando ionização a pressão atmosférica trouxe um grande avanço para analises de resíduos de fármacos no meio ambiente. Porém, é constatado que, mesmo com a boa seletividade alcançada por LCMS ou LC-MS/MS, a presença de interferentes endógenos da matriz ainda é um problema. 
Esses compostos, quando não isolados adequadamente no processo de preparo de amostra, podem prejudicar a eficiência da ionização dos analitos, causando tanto a supressão do sinal obtido quanto o aumento do mesmo, efeito conhecido como efeito matriz (ME - do inglês Matrix Effect). ${ }^{74}$ Uma das várias teorias envolvidas nesses processos sugere uma competição entre analito e interferentes não voláteis pela transferência de elétrons do capilar para a solução e a separação de cargas na superfície das gotículas que darão origem aos íons em fase gasosa. ${ }^{75}$ Sendo assim, estimar a dimensão do ME se torna um passo crucial no desenvolvimento de um método analítico, visto que interfere diretamente na avaliação do processo.

Os valores de recuperação e efeito matriz apresentam um comportamento relativamente particular, visto que, quanto maior o efeito matriz, maior é a recuperação do método. Esse efeito foi evidenciado para os maiores níveis de concentração, justificado, talvez, pelo fato de que a interação dos analitos com a matriz pode ser tão forte que, em situações que se tem maior quantidade de analito presente na amostra este, ao ser extraído, pode carregar consigo contaminantes da matriz, fazendo com que o efeito matriz nessas condições aumente (Tabela 20).

No trabalho desenvolvido por Herrero e colaborados $(2014)^{76}$ utilizando o método QuEChERS para extração de benzotriazol, benzoltiazol e benzenosulfonamida, o efeito matriz estimado não foi tão alto quando comparado com os obtidos nesse trabalho. Porém, a comparação é dificultada visto que não é mencionado em qual nível de concentração é estimado o efeito matriz, inviabilizando a visualização do comportamento do efeito matriz em diferentes concentrações.

O mesmo problema é encontrado ao fazer a comparação dos dados com os obtidos por Peysson et al. (2013), ${ }^{50}$ ao desenvolverem o método QuEChERS para análise multiresíduo de fármacos em lodo de esgoto. Os resultados do efeito matriz encontrados para as sulfonamidas avaliadas (sulfadiazina, sulfadimetoxina, sulfametoxazol e sulfapiridina) não foram tão elevados, variando em $20 \%$ em torno do ideal. Porém, os dados também não foram apresentados referentes a cada concentração avaliada.

Com os valores obtidos para recuperação e efeito matriz, a eficiência calculada para o método (valor considerando o efeito matriz observado e a recuperação alcançada) variou de 1,51 - 25,84\% que, embora distante dos valores desejado (próximo a 100\%) foi possível 
alcançar os níveis de quantificação e detecção necessários para a determinação de sulfonamidas em lodo.

Tabela 20: Valores obtidos com os ensaios de recuperação, efeito matriz e eficiência do método QuEChERS.

\begin{tabular}{|c|c|c|c|c|}
\hline $\begin{array}{c}\text { Compostos } \\
(\mathrm{m} / \mathrm{z})\end{array}$ & Níveis & $\begin{array}{c}\text { Recuperação } \\
(\%)\end{array}$ & $\begin{array}{c}\text { Efeito Matriz } \\
(\%)\end{array}$ & $\begin{array}{l}\text { Eficiência do } \\
\text { método }\end{array}$ \\
\hline \multirow{3}{*}{215} & Baixo & 32,50 & 79,50 & 25,84 \\
\hline & Médio & 36,91 & 29,46 & 10,87 \\
\hline & Alto & 59,71 & 19,73 & 11,78 \\
\hline \multirow{3}{*}{251} & Baixo & 23,99 & 96,45 & 23,14 \\
\hline & Médio & 35,74 & 33,22 & 11,87 \\
\hline & Alto & 61,80 & 22,11 & 13,66 \\
\hline \multirow{3}{*}{256} & Baixo & 13,32 & 87,60 & 11,67 \\
\hline & Médio & 20,20 & 33,02 & 6,67 \\
\hline & Alto & 39,78 & 23,67 & 9,42 \\
\hline \multirow{3}{*}{265} & Baixo & 22,45 & 93,75 & 21,05 \\
\hline & Médio & 31,11 & 40,81 & 12,70 \\
\hline & Alto & 62,92 & 25,77 & 16,22 \\
\hline \multirow{3}{*}{279} & Baixo & 24,84 & 79,34 & 19,71 \\
\hline & Médio & 30,36 & 35,44 & 10,76 \\
\hline & Alto & 52,72 & 24,22 & 12,77 \\
\hline \multirow{3}{*}{271} & Baixo & 18,80 & 66,28 & 12,46 \\
\hline & Médio & 23,59 & 29,73 & 7,01 \\
\hline & Alto & 43,24 & 22,53 & 9,74 \\
\hline \multirow{3}{*}{285} & Baixo & 16,62 & 49,21 & 8,18 \\
\hline & Médio & 16,52 & 25,63 & 4,23 \\
\hline & Alto & 32,88 & 20,11 & 6,61 \\
\hline \multirow{3}{*}{254} & Baixo & 11,36 & 46,65 & 5,30 \\
\hline & Médio & 11,48 & 23,41 & 2,69 \\
\hline & Alto & 7,89 & 19,08 & 1,51 \\
\hline \multirow{3}{*}{311} & Baixo & 12,07 & 58,19 & 7,02 \\
\hline & Médio & 18,20 & 27,81 & 5,06 \\
\hline & Alto & 34,84 & 19,91 & 6,94 \\
\hline
\end{tabular}

\section{Conclusão do capítulo 3}

O desenvolvimento e otimização do método QuEChERS para análise de sulfonamidas presentes em lodo de esgoto apresentou algumas vantagens e limitações.

Dentro da necessidade atual de se desenvolver metodologias rápidas e compatíveis com o conceito de "green chemistry", a aplicação do QuEChERS se torna adequada. Quando comparada com as técnicas clássicas de preparo de amostra, observa-se considerável redução 
no volume de solvente orgânico utilizado, porém, com as atuais técnicas miniaturizadas, como a SPME, o volume de solvente empregado nessa técnica ainda é um pouco elevado $(6,0 \mathrm{~mL}$ de ACN por amostra, enquanto a SPME esse valor pode ser reduzido a escala de $\mu \mathrm{L}$ ). Porém, ao se considerar que esse trabalho foi desenvolvido para amostras sólidas, o volume utilizado se torna reduzido, visto que não são muitas as opções disponíveis para o preparo desse tipo de amostra, se reduzindo basicamente a ASE, SFE, Líquido-Sólido e a tradicional Soxhlet.

Embora os valores obtidos para a recuperação do método não tenham atingido os valores normalmente sugeridos pelas agencias regulamentadoras (que varia de 80-120\%) os valores obtidos para LQ $\left(10\right.$ - $\left.25 \mathrm{ng} \mathrm{g}^{-1}\right)$ e LD $\left(4-9 \mathrm{ng} \mathrm{g}^{-1}\right)$ foram satisfatórios para análise.

O $M E$ apresentou um comportamento atípico, exercendo maior efeito para as concentrações mais elevadas indicando, possivelmente, que o clean-up da amostra não foi satisfatório. Modificações no método QuEChERS poderiam ser avaliadas, porém, tal procedimento poderia afetar a filosofia do método, acarretando maiores tempos de análise.

Contudo, pode-se concluir que o método proposto tem potencialidade para a aplicação sugerida, fornecendo bons limites de quantificação e faixa linear, visto que a concentração de sulfonamidas em lodo de esgoto não possui um valor constante. 


\section{Capítulo 4}

Desenvolvimento de um sistema online para extração e clean-up de sulfonamidas provenientes de matriz complexa 



\section{Introdução}

Esse capítulo descreve o desenvolvimento de um sistema on-line de clean-up da amostra com posterior concentração dos analitos em sistema de cromatografia liquida capilar.

A intenção é promover a extração dos analitos de interesse, presentes em amostras complexas, após a etapa de extração do tipo líquido-líquido ou líquido-sólido, visto que, após está o extrato obtido geralmente é constituído por $100 \%$ de solvente orgânico como, por exemplo, acetonitrila.

Na prática, a injeção direta desse extrato nem sempre é viável, visto que, dependendo da quantidade de solvente utilizado, pode ocorrer a diluição dos analitos o que gerará concentrações muito inferiores aos limites de detecção instrumental. Ao se obter um baixo volume de extrato final, como na utilização de técnicas miniaturizadas de preparo de amostra, uma saída encontrada para contornar esse problema é a diluição do extrato final em água, formando solução contento cerca de 5,0\% de solvente orgânico. Após essa etapa, o extrato pode ser submetido a uma etapa de concentração utilizando métodos como a SPE, ou injeção direta no sistema cromatográfico, com a desvantagem de diluir a amostra.

A alternativa mais empregada é a evaporação total do solvente orgânico sob baixo fluxo de nitrogênio, com posterior reconstituição dos analitos em um solvente apropriado para injeção (exemplo, água) em menor volume aumentando, assim, o fator de concentração do método. Porém, além de somar uma etapa ao método, esse procedimento pode ser fonte adicional de erros.

Ao se utilizar fases trocadoras de íons como sorbente, a concentração de analitos presentes em extratos constituídos de $100 \%$ solvente orgânico pode ser realizada, devido a interação iônica entre analito-sorbente. Trabalhos recentes relatam o uso de fases trocadoras catiônicas para a extração de sulfonamidas presentes em amostras de mel, obtendo resultados satisfatórios e concordantes com a legislação vigente. ${ }^{77}$

Porém, no caso de amostras mais complexas, o emprego desse tipo de sorbente pode não ser apropriado, devido a possível saturação dos sítios de ligação frente a competição entre os analitos e interferentes. Dessa forma, uma etapa de clean-up se faz necessária, visando à máxima remoção dos interferentes, acarretando uma etapa a mais no processo de preparo de amostras. 
A SPE online tem como objetivos a diminuição do tempo de extração e menor manipulação da amostra pelo analista permitindo maior reprodutibilidade dos resultados. ${ }^{78}$ No entanto, na maioria dos casos, a SPE on-line é realizada em uma única coluna de extração que, por mudanças na direção da vazão e composição da fase móvel, permite a retenção e eluição dos analitos.

Como forma de promover o clean-up da amostra pode-se acoplar uma coluna, antes da coluna de extração no sistema de SPE online, com a finalidade de reter os interferentes presentes na amostra favorecendo, assim, a retenção dos compostos de interesse na coluna principal de extração, sendo essa, a proposta desse capitulo.

A seleção dos sorbentes utilizados em ambas colunas deve ser cautelosa, visto que para a primeira coluna, o sorbente deve ter pouca ou nenhuma interação com os analitos, enquanto que na segunda coluna, a interação sorbente-analito deverá ser suficiente para promover a extração dos mesmos.

\section{Objetivo}

\subsection{Objetivo Geral}

Este trabalho tem como objetivo principal o desenvolvimento de um sistema capilar de clean-up e extração de sulfonamidas presentes em extratos constituídos de $100 \%$ solvente orgânico, proveniente de matrizes complexas.

\subsection{Objetivos Específicos}

A proposta visa avaliar o acoplamento de três colunas, sendo a primeira utilizada para o clean-up, a segunda para a extração dos analitos e a terceira coluna utilizada para a separação cromatográfica, todas ligadas em um sistema cromatográfico capilar totalmente automatizado. Para isso, utilizou-se fases estacionárias distintas nas colunas, e fases móveis alcalinizadas para a extração e acidificada para a separação cromatográfica. 


\section{Parte Experimental}

\subsection{Reagente e Materiais}

Acetonitrila de elevado grau de pureza (grau HPLC, Tedia) foi utilizada tanto como fase móvel para separação cromatográfica quanto para a preparação das soluções padrões. A água utilizada foi purificada por um sistema Milli-Q (Millipore).

Os reagentes utilizados foram ácido-fórmico 98\% de pureza (Tedia), hidróxido de amônio 30\% de pureza (Synth). As sulfonamidas foram as mesmas apresentadas na Tabela 12.

Os sorbentes avaliados para a realização da SPE online, foram Strata-x, Oasis MAX e WAX, com estrutura e fornecedores descritos na Tabela 21.

Tabela 21: Fases poliméricas empregadas na etapa de clean-up da amostra e extração dos analitos

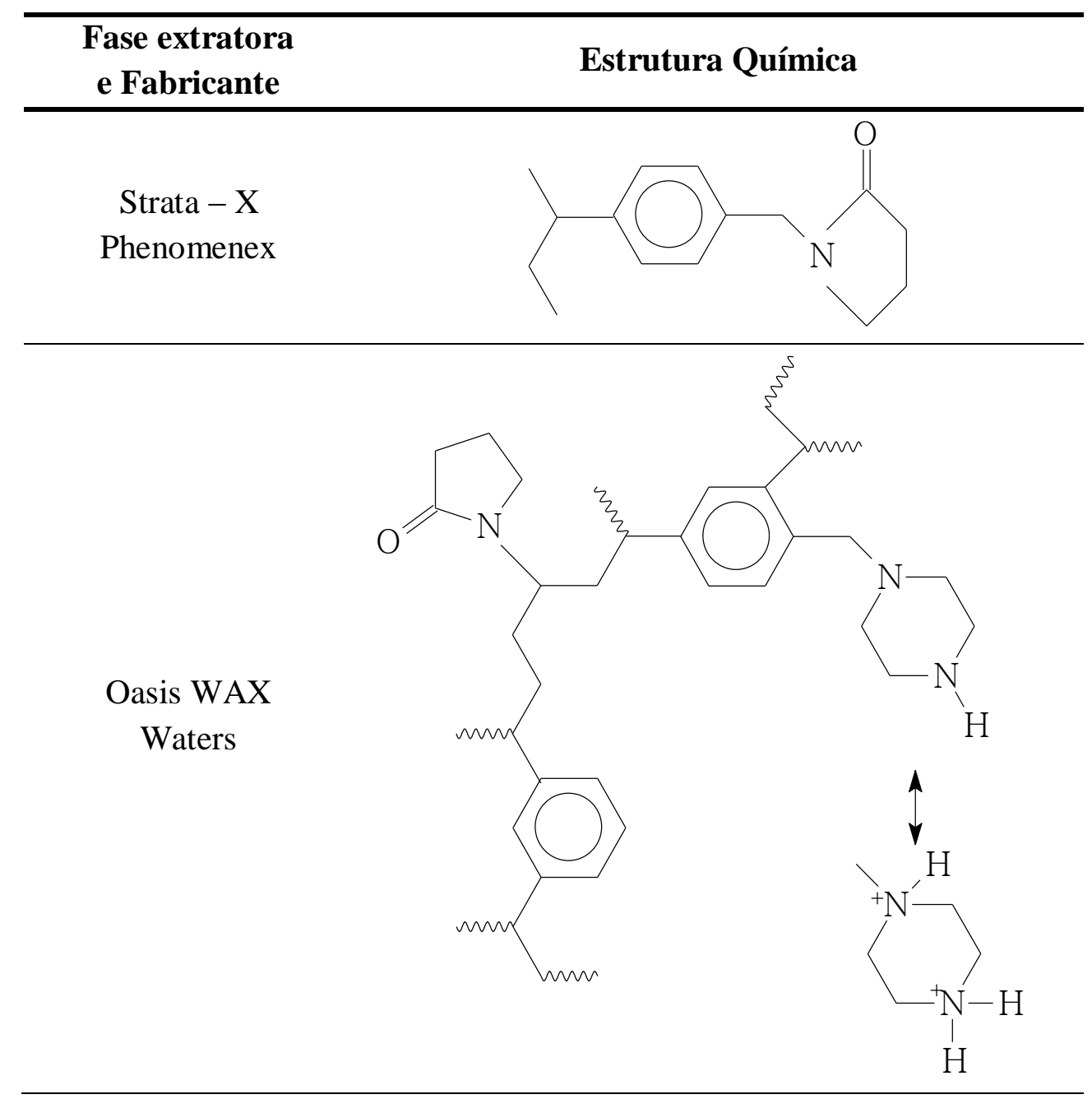




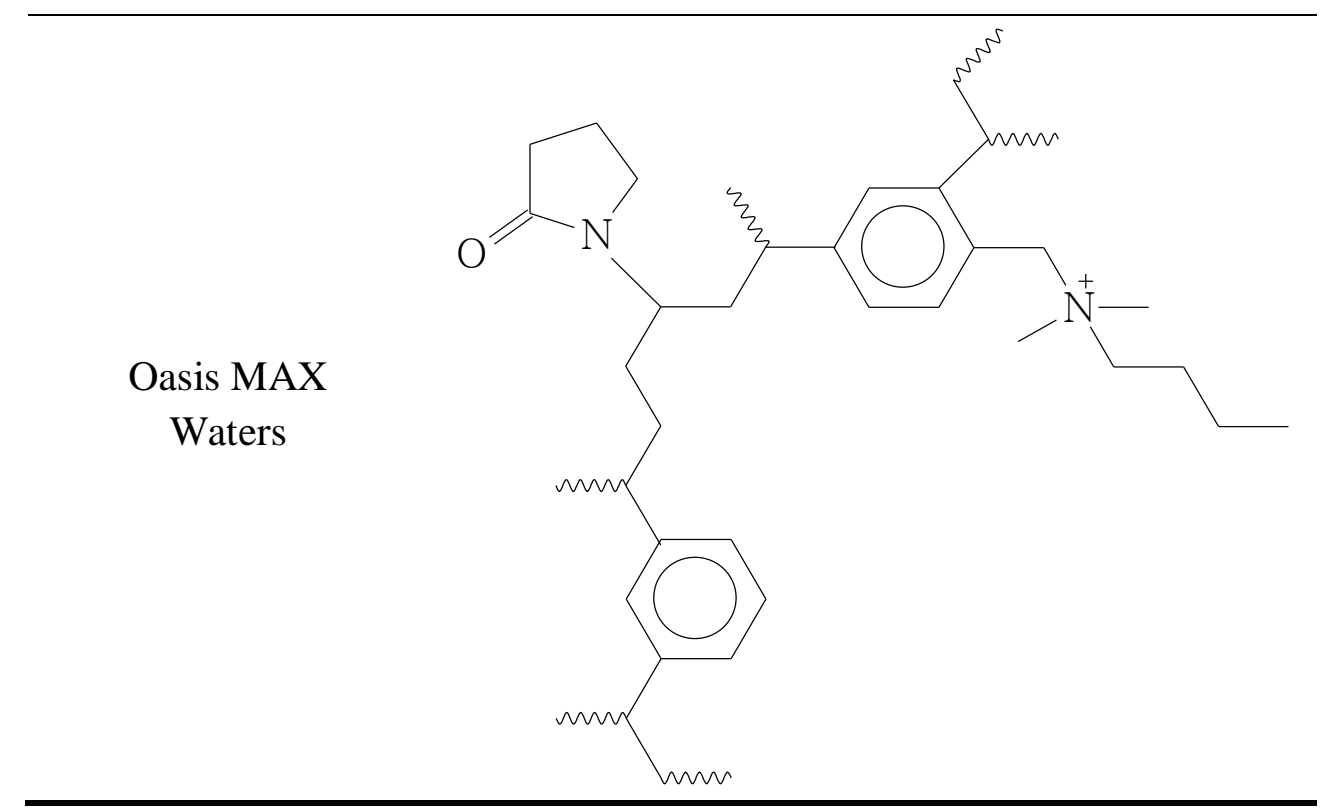

\subsection{Sistema Cromatográfico}

Os procedimentos de SPE online e separação analítica foram realizados no equipamento Dionex RSLC Ultimate ${ }^{\circledR}$ 3000. Trata-se de um cromatógrafo que opera suportando pressões de até 800 bar (11.600 psi) e vazão da ordem de cromatografia capilar a nano proporcionando, assim, a flexibilidade necessária para desenvolver os diversos procedimentos para a SPE online sugeridos nesse projeto.

Utilizou-se para separação analítica uma coluna Acclaim ${ }^{\circledR}$ PepMap RSLC C18 $(0,3 \times 150 \mathrm{~mm} ; 2,0 \mu \mathrm{m})$, com vazão de $10 \mu \mathrm{L} \mathrm{min}^{-1}$ e forno a $40^{\circ} \mathrm{C}$. A fase móvel foi composta por acetonitrila e $\mathrm{H}_{2} \mathrm{O}$ ambos com $0,2 \%$ de ácido fórmico (v/v). $\mathrm{O}$ carregamento da amostra foi realizado por outra bomba operando com porcentagens distintas de $\mathrm{ACN} / \mathrm{H}_{2} \mathrm{O}$, ambos com $1,0 \% \mathrm{NH}_{4} \mathrm{OH}(\mathrm{v} / \mathrm{v})$.

O sistema de injeção pode ser operado em três modos distintos:

- Full loop: utilizado quando todo volume contido na alça de injeção é transferido para o sistema.

- Partial loop: apenas parte da amostra é utilizada, sendo normalmente injetado um volume menor ou igual à metade do volume total da alça de injeção.

- Microliter pick-up: uma quantidade especifica de amostra é enviada a alça de injeção, sendo intercalada com um solvente apropriado, aspirado antes e depois da amostra. Todo o volume de amostra aspirado é utilizado na injeção. Trata-se de uma forma de 
injeção bastante interessante quando se tem quantidade de amostra reduzida, porém a introdução do solvente pode ocasionar dispersão da banda cromatográfica.

Inicialmente o método de injeção microliter pick-up foi escolhido devido à maior economia de amostra. Utilizou-se um loop de $125 \mu \mathrm{L}$, possibilitando a injeção de $40 \mu \mathrm{L}$ amostra.

\subsection{Condições de detecção por espectrometria de massas}

Os testes referentes aos estudos do modo de eluição dos compostos e do método de remoção da amônia residual foram realizados utilizado um espectrômetro de massas do Micromass (Waters) equipado com uma fonte de ionização do tipo electrospray (ESI), operando com voltagem do capilar a $3,5 \mathrm{kV}$ e cone $20-30 \mathrm{~V}$, temperatura da fonte $110^{\circ} \mathrm{C}$, no modo SIM, monitorando o íon $M+1$ de cada analito.

Para os demais estudos, a detecção foi feita por um espectrômetro de massas híbrido (QqTOF), Bruker, modelo micrOTOF-Q II, funcionando no modo full MS. A fonte de electrospray operou no modo positivo de ionização, voltagem do capilar de $3,5 \mathrm{kV}$, pressão do nebulizador de 0,4 bar, vazão do gás secante de 5,0 $\mathrm{L} \mathrm{min}^{-1}$ e temperatura da fonte $200{ }^{\circ} \mathrm{C}$.

\subsection{SPE online capilar}

Para a etapa de SPE online foram confeccionadas 2 colunas de aço inox com dimensões de $500 \mu \mathrm{m}$ de diâmetro interno e $6,0 \mathrm{~cm}$ de comprimento, utilizando telas de proteção de 1/16" de diâmetro interno com $10 \mu \mathrm{m}$ de tamanho de poro (Figura 24), todos adquiridos da VALCO.

Figura 24: Esquema representativo das colunas capilares $(500 \mu \mathrm{m} \times 6,0 \mathrm{~cm})$ utilizadas na etapa de SPE (clean-up e concentração dos analitos)

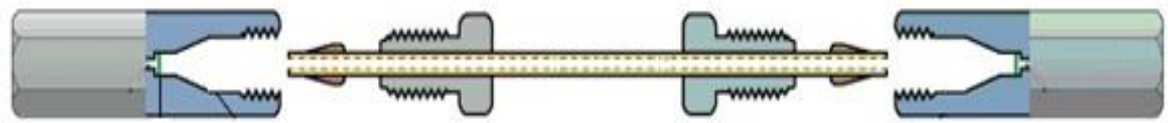

As colunas foram empacotadas pelo método slurry packing com auxílio de uma bomba Shimadzu Proeminence 10 A, empregando uma solução aquosa contendo $10 \%$ de metanol(v/v) para a suspensão da fase estacionária. 
Os testes iniciais visaram a utilização de 2 colunas de dimensões idênticas (Figura 21) porém com fases distintas, acopladas em série. A primeira coluna foi utilizada com a finalidade de promover o clean-up da amostra, retendo preferencialmente os interferentes presentes na amostra. Para isso, foi empacotada com a fase polimérica Strata-X. Essa fase foi escolhida devido à experiência adquirida pelo grupo em analises de sulfonamidas em matrizes ambientais tanto por SPE off-line quanto por online.$^{79}$ Assim, é sabido que com uso da Strata-X é possível promover um bom clean-up da amostra e, em condições específicas, não reter os compostos de interesse no caso, as sulfonamidas (SA).

Na segunda coluna deverá então ocorrer a retenção das SA. Essa coluna possui dimensões idênticas da coluna 1 , porém, foi empacotada com as fases poliméricas aniônicas que operam em modo misto, ou seja, tanto em fase reversa (com balanço hidrofílico-lipofílico - HLB) como trocadora aniônica. Assim, as sulfonamidas que passam pela primeira coluna podem ficar retidas na fase aniônica, desde que se estejam desprotonadas (ou seja, na forma aniônica).

\subsubsection{Etapa de carregamento da amostra}

O extrato obtido com a extração líquido-sólido do lodo de esgoto foi filtrado em uma membrana $0,22 \mu \mathrm{m}$ e o $\mathrm{pH}$ corrigido com $1,0 \%$ de $\mathrm{NH}_{4} \mathrm{OH}(\mathrm{v} / \mathrm{v})$.

A amostra foi injetada no sistema online com auxílio de uma Loading Pump - LP (ThermoFisher Scientific $®$ ) operando em vazão de $50 \mu \mathrm{L} \mathrm{min}^{-1}$, com fase móvel composta por $\mathrm{ACN}$ e $\mathrm{H}_{2} \mathrm{O}$. Tanto na fase orgânica quanto na fase aquosa adicionou-se $\mathrm{NH}_{4} \mathrm{OH}$ na proporção de $1,0 \%(\mathrm{v} / \mathrm{v})$.

As colunas (clean-up e extração) foram conectadas em série permitindo, assim, que a amostra impulsionada pela fase móvel alcalinizada passasse sequencialmente por ambas colunas, com configuração das válvula permitindo que compostos eventualmente não retidos fossem direcionado para o descarte.

Para esse sistema, foi utilizado uma válvula de 6 e uma de 10 pórticos, de acordo com a Figura 25, com as duas válvulas operando na posição A. No momento de carregamento da amostra, a coluna analítica é condicionada com a fase móvel composta por $\mathrm{ACN}$ e $\mathrm{H}_{2} \mathrm{O}$ com $0,2 \%$ de ácido fórmico a $10 \mu \mathrm{L} \mathrm{min}{ }^{-1}$ utilizando a NC pump (ThermoFisher Scientific $\left.{ }^{\circledR}\right)$. Essa mesma bomba é responsável por impulsionar a fase móvel durante a etapa de dessorção dos analitos. 
Figura 25: Representação esquemática das válvulas de 6 e 10 pórticos utilizadas para o desenvolvimento da SPE online com duas colunas acopladas em série, com configuração de eluição no modo backflush.

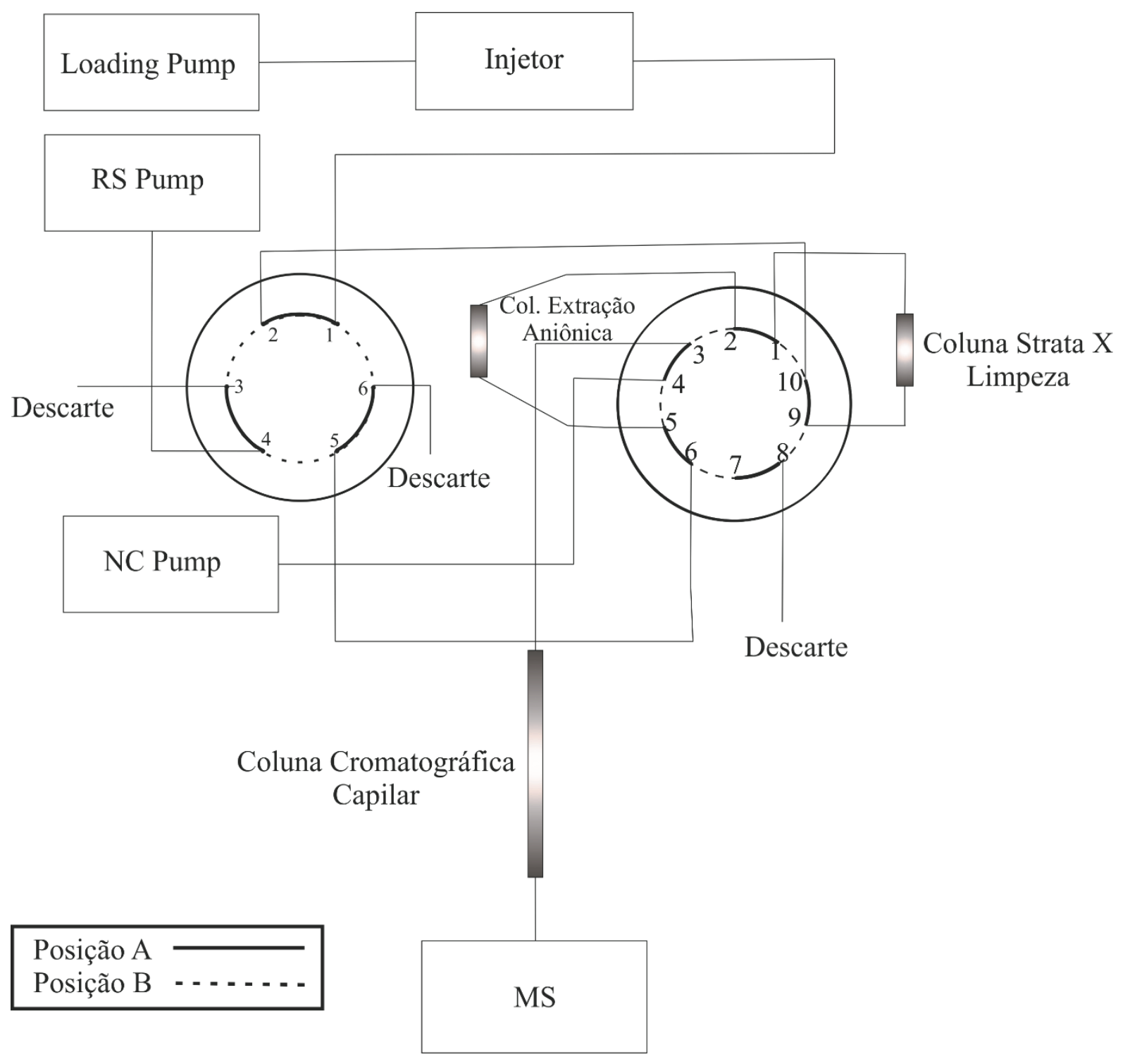

\subsubsection{Etapa de Eluição da amostra}

Após um tempo de carregamento da amostra, otimizado experimentalmente, ocorre o giro das válvulas de comutação de 10 pórticos para a posição B (Figura 25) possibilitando, assim, que a fase móvel composta por $\mathrm{ACN}$ e $\mathrm{H}_{2} \mathrm{O}$ acidificados passe simultaneamente pela coluna de extração e a analítica fazendo com os analitos, então protonados, sejam eluídos no sentido contrário ao utilizado durante a etapa de carregamento da amostra (modo de eluição backflush) e direcionados para a etapa de separação. Quando a configuração das válvulas segue o demonstrado na Figura 26, os analitos também são eluídos da coluna de extração e 
direcionados para a coluna analítica, porém, a eluição ocorre no mesmo sentido do fluxo utilizado na etapa de carregamento (modo de eluição forward flush).

Nessa etapa, a válvula de 6 pórticos permanece na posição A permitindo a limpeza (em modo backflush) da coluna utilizada para o clean-up da amostra, utilizando a LP com fase móvel composta por $100 \%$ ACN alcalinizada. Dessa forma, evita-se a saturação da mesma após injeções consecutivas. Após esse tempo, a coluna de clean-up é novamente condicionada com a proporção de fase móvel que será utilizada na próxima injeção.

A utilização de elevadas quantidade de hidróxido de amônio na fase móvel utilizada para o carregamento da amostra, pode danificar a coluna de separação cromatográfica, visto que pode ocorrer a solubilização da sílica utilizada como suporte para a cadeia octadecil, utilizada na coluna Acclaim® PepMap RSLC C18.

Como forma de minimizar esse efeito, testou-se duas configurações distintas para o sistema cromatográfico. A primeira consiste em remover a elevada concentração de hidróxido de amônio residual utilizando água, antes da eluição dos analitos. A segunda tentativa consiste na utilização da infusão em $\mathrm{T}$ de fase aquosa acidificada na entrada da coluna analítica promovendo, assim, a diluição da fase móvel com elevada concentração de hidróxido de amônio. 
Figura 26: Representação esquemática das válvulas de 6 e 10 pórticos utilizadas para o desenvolvimento da SPE online com duas colunas acopladas em série, com configuração de eluição no modo forward flush.

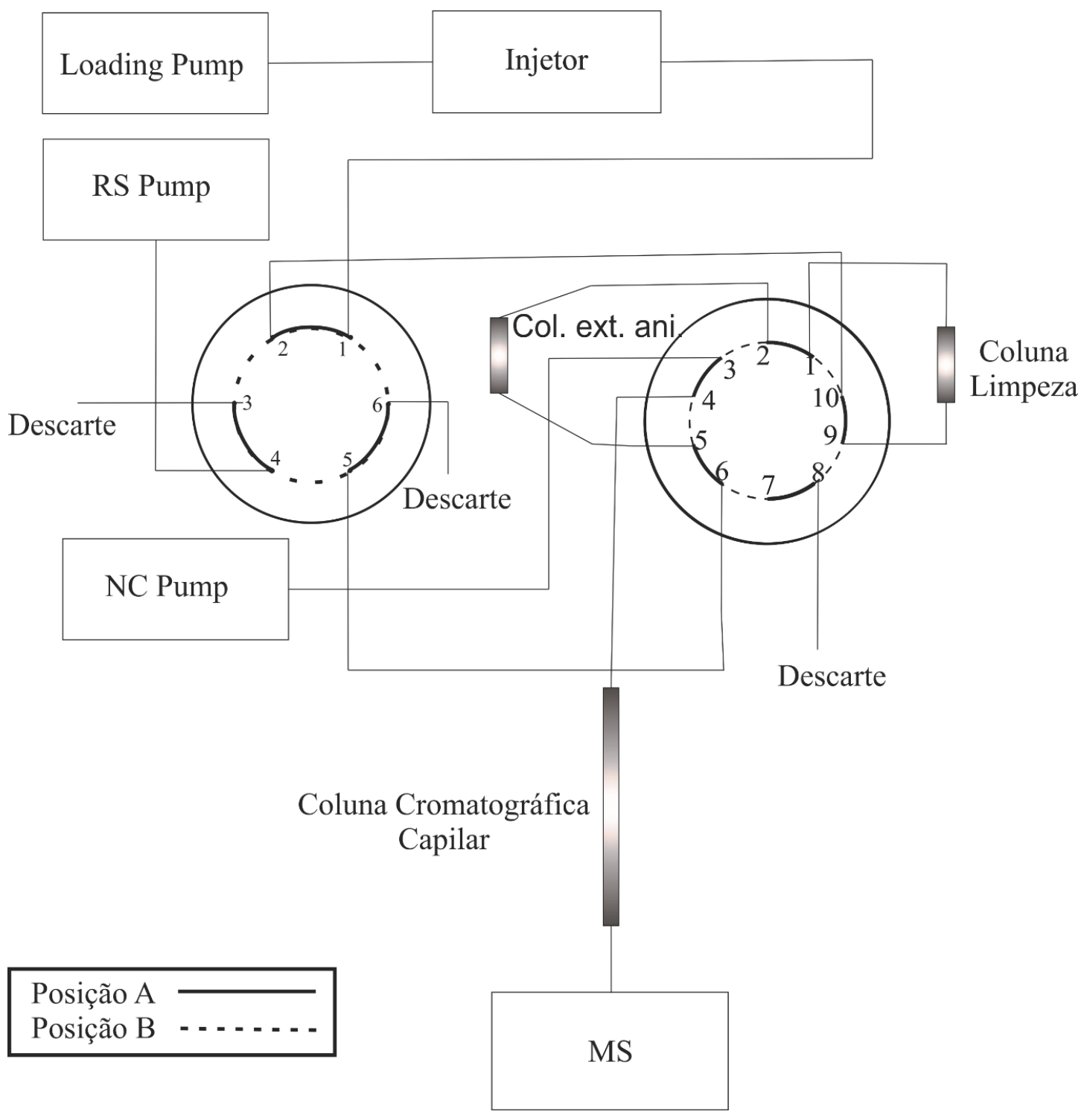

\section{Resultados e Discussão}

\subsection{Desenvolvimento do sistema SPE capilar online}

Ao se trabalhar com sistemas analíticos empregando mais de uma coluna conectadas em série, é necessário que se faça um estudo inicial verificando se nas condições estudadas o objetivo individual de cada coluna é atingido. 
Para isso, tanto a coluna de clean-up quanto a coluna de extração foram conectadas diretamente e individualmente ao detector de massas híbrido QqTOF. O padrão analítico contendo todas as SAs estudadas na concentração de $0,5 \mathrm{mg} \mathrm{L}^{-1}$ em $\mathrm{ACN}\left(1,0 \% \mathrm{NH}_{4} \mathrm{OH}\right)$ foi impulsionado por $\mathrm{ACN} 1,0 \% \mathrm{NH}_{4} \mathrm{OH}$ com auxílio da $L P$ operando no modo isocrático.

Nos ensaios referentes a retenção das sulfonamidas, o conector 2 (utilizado para fazer a conexão entre a tubulação utilizada) da Figura 27 foi substituído pela coluna de extração (preenchida com Oasis MAX). Após o tempo de carregamento da amostra, a válvula de 10 pórticos passa a operar na posição $\mathrm{B}$, permitindo que a fase móvel composta por $\mathrm{ACN} / \mathrm{H}_{2} \mathrm{O} 0,2$ $\%$ ácido fórmico, impulsionada pela NC pump, percole por essa coluna promovendo a dessorção das SAs e detecção direta no QqTOF.

Figura 27: Representação gráfica das configuração das válvulas de 6 e 10 pórticos utilizadas para o estudo da interação das SA com a fase aniônica OASIS, na ausência da coluna analítica.

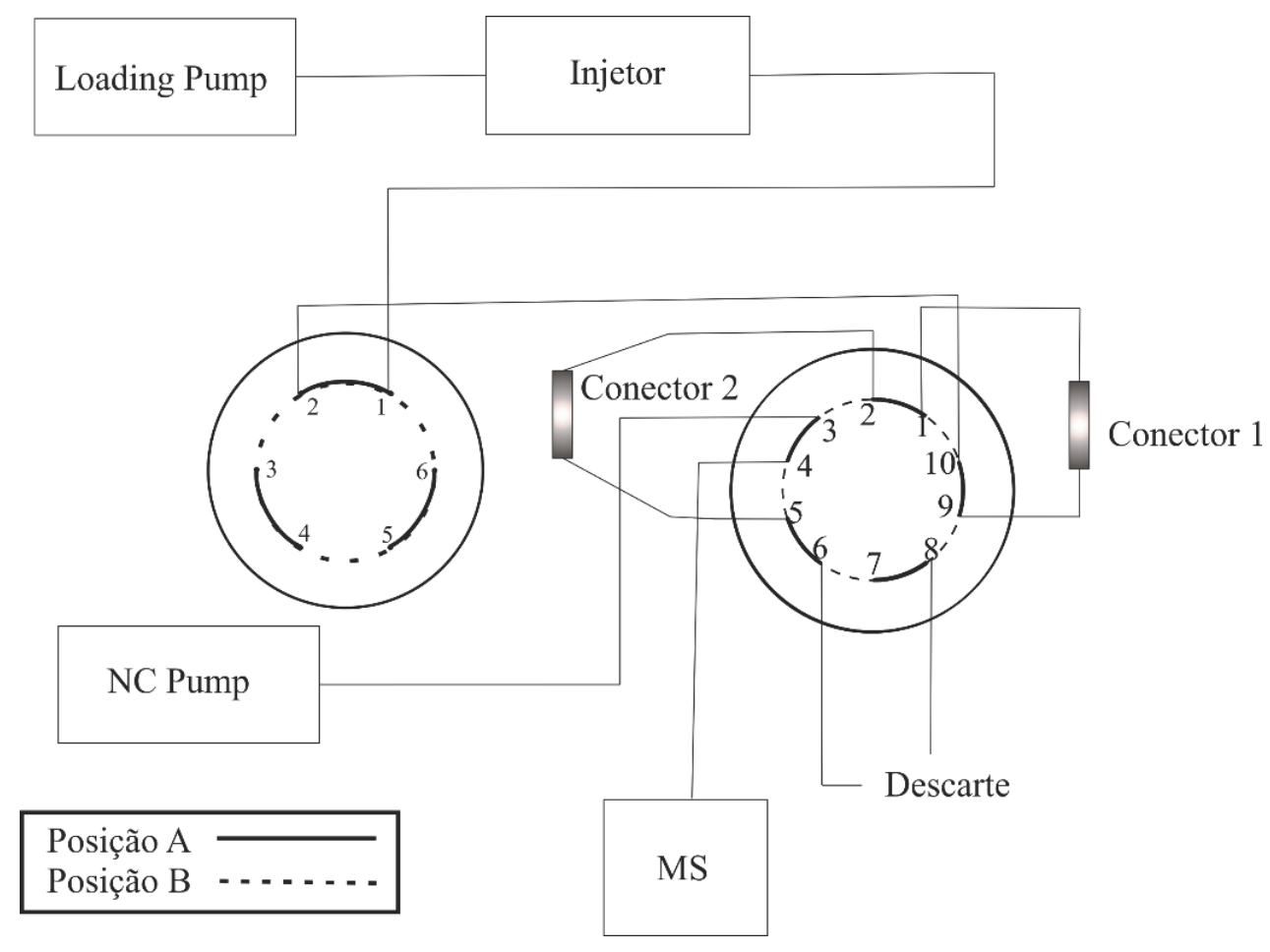

Na Figura 28 pode-se observar os picos referentes a todas sulfonamidas estudadas, próximo a 8,0 minutos de extração, indicando que todas foram adequadamente retidas pela coluna de troca aniônica e dessorvidas com a fase móvel utilizada, ressaltando que a falta de simetria e deformação dos picos se deve ao fato de não haver a focalização na coluna analítica. 
Figura 28: Cromatogramas de íons extraídos (EIC) obtidos com o estudo na coluna de extração (Oasis MAX) para os compostos de $m / z$ (a) 251 (b) 279 (c) 271 (d) 265 (e) 254 (f) 256 (g) 311 (h) 285 e (i) 215.
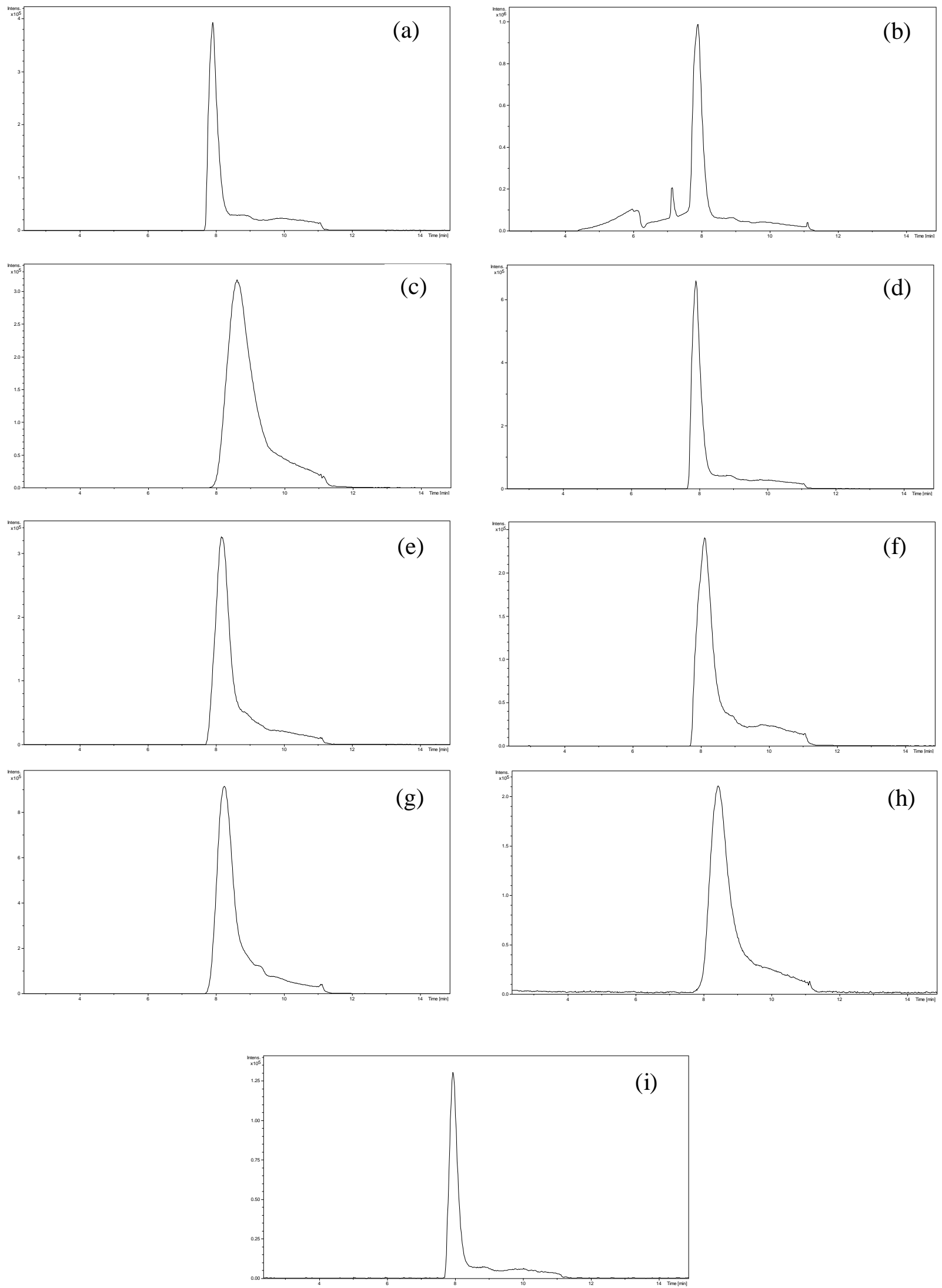
Como a coluna preenchida com a fase polimérica Strata-X tem a finalidade de reter possíveis interferentes presentes na matriz, espera-se que no momento de carregamento da amostra todos os analitos sejam detectados pelo espectrômetro de massas. A configuração das válvulas para esse experimento pode ser visualizada na Figura 29, onde o conector 1 foi substituído pela coluna de clean-up ocorrendo, assim, a detecção das SAs pelo MS no momento de carregamento da amostra.

Figura 29: Representação gráfica das configuração das válvulas de 6 e 10 pórticos utilizadas para o estudo da interação das SA com a fase polimérica Strata-X, na ausência da coluna analítica.

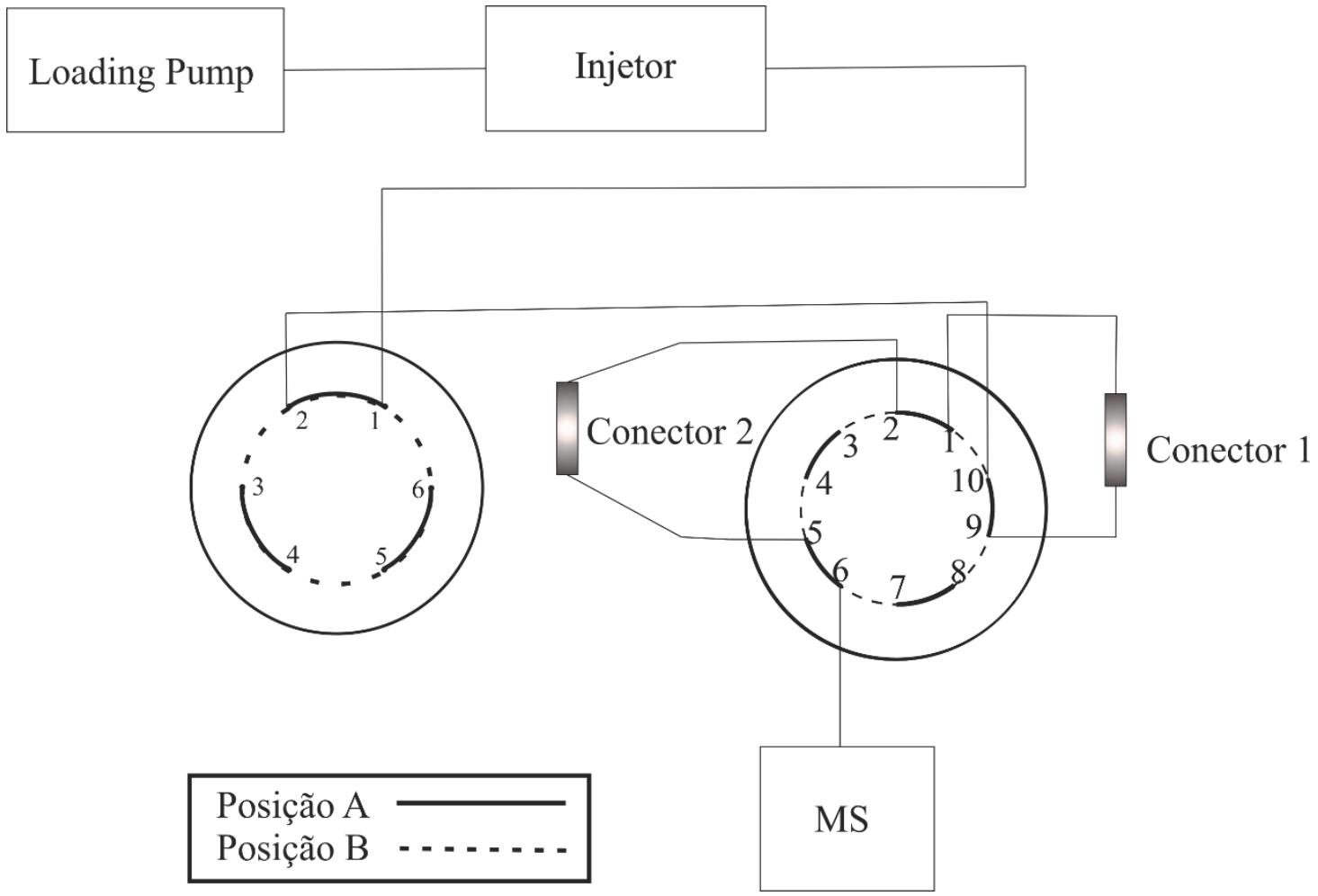

Na Figura 30, a presença de "bandas" referentes às massas das sulfonamidas estudadas até o tempo de 5 minutos, indica que durante a etapa de carregamento, e sob as condições avaliadas, ou seja, $100 \%$ de $\mathrm{ACN}$ na $L P$ as SAs não sofreram interação com a fase Strata X. 
Figura 30: Cromatogramas (EIC) obtidos com o estudo na coluna de clean-up (Strata-X) para os compostos de $\mathrm{m} / z$ (a) 251 (b) 279 (c) 271 (d) 265 (e) 254 (f) 256 (g) 311 (h) 285 e (i) 215
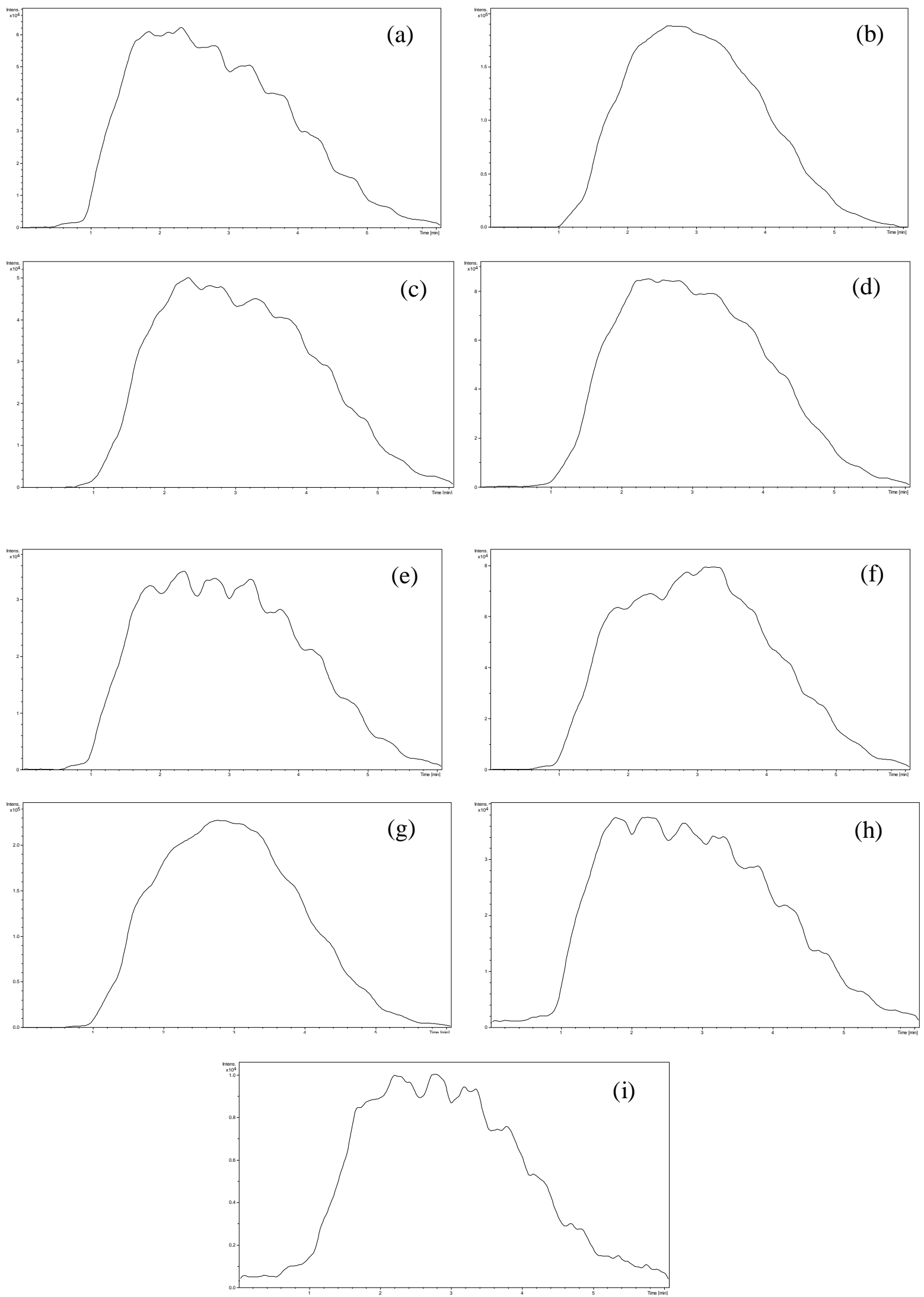


\subsection{Seleção do tipo de fase extratora aniônica}

As fases trocadoras de ânions podem ser classificadas em trocadores fracas (WAX) ou fortes (SAX). Muitas vezes, ao se utilizar trocadoras iônicas fortes pode ocorrer a ligação irreversível entre o composto de interesse e a fase extratora. Entretanto, a trocadora aniônica fraca, pode não ter força de ligação suficiente para reter os compostos aniônicos.

Por tal fato, duas fases trocadoras de íons provenientes do mesmo fabricante foram avaliadas, a fim de se verificar o fator de retenção em ambas. A maioria dos compostos não foram retidos na fase Oasis WAX. Para os compostos de $m / z$ 215, 251e 256 a fase OASIS MAX (trocadora aniônica forte) apresentou retenção incontestavelmente superior a OASIS WAX sendo, então, selecionada para continuidade do trabalho (Figura 31).

Figura 31: Cromatogramas obtidos utilizando fases trocadoras de íons forte $(-)$ e fraca $(-)$ para as sulfonamidas de $m / z$ (a) 256 , (b) 251 e (c) 215
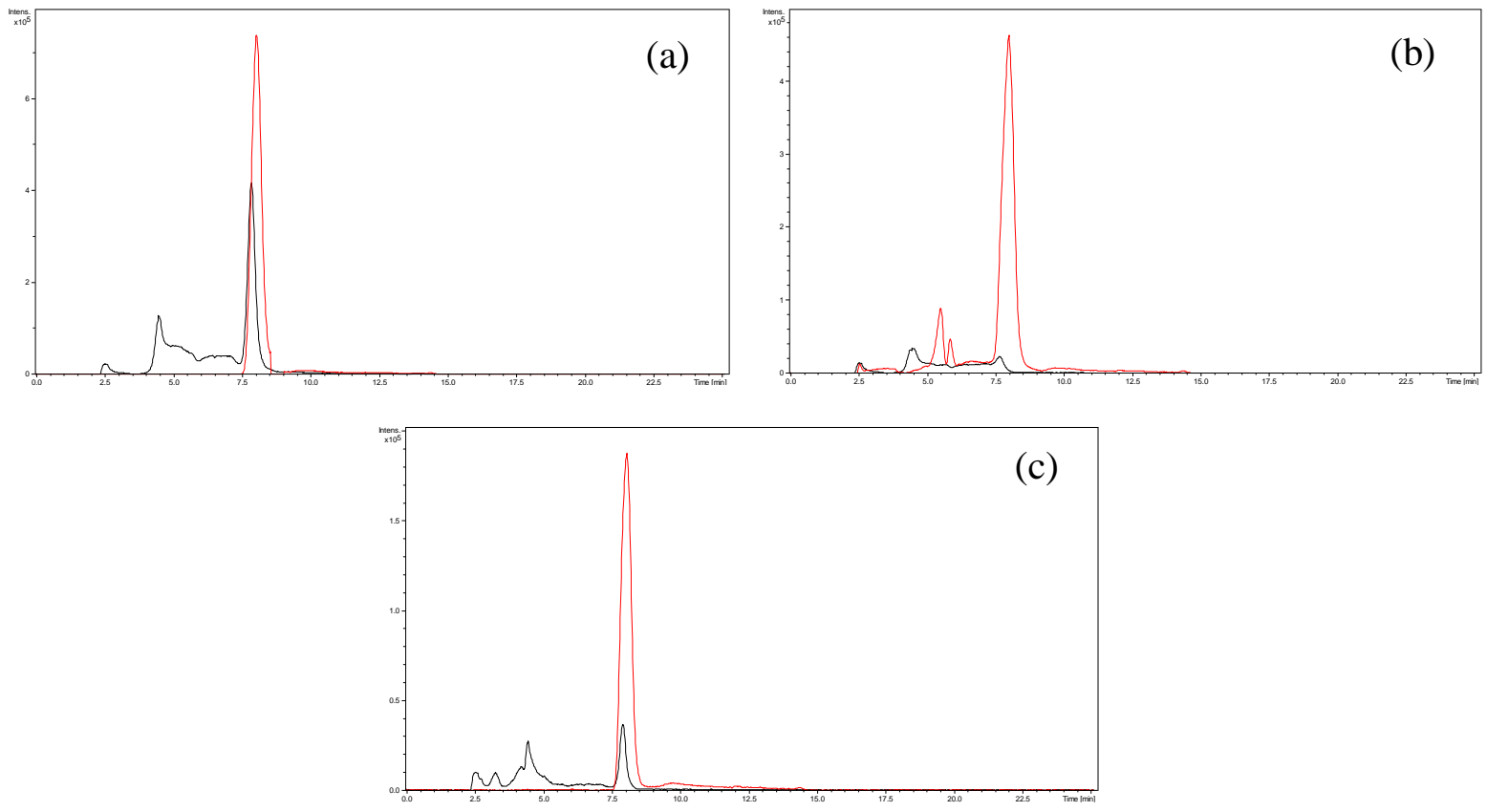

\subsection{Avaliação do tempo de carregamento da amostra}

Ao se fazer o carregamento da amostra no sistema online de extração, é imprescindível avaliar o tempo dedicado a essa etapa, pois tempos muito curtos podem ser insuficientes para que toda amostra seja introduzida no sistema, e tempos longos podem ocasionar perda do analitos, visto que o solvente utilizado nessa etapa fica continuamente passando pela coluna de extração. 
Para esse estudo, avaliou-se o carregamento em 3,0-7,0 minutos, com a $L P$ operando com $50 \%$ de $\mathrm{ACN}$ com 1,0\% $\mathrm{NH}_{4} \mathrm{OH}$. Para esse teste foram utilizados as amostras após a extração do lodo de esgoto.

De acordo com a Figura 32, observa-se que ao aumentar o tempo de carregamento há um aumento no sinal analítico avaliado, após 5 minutos de carregamento, para o composto $\mathrm{m} / \mathrm{z}$ 251. Esse resultado pode ser explicado frente ao efeito matriz. Nessa situação, com o aumento do tempo de carregamento, pode ocorrer a remoção de interferentes da matriz, visto que uma maior quantidade de solvente orgânico é continuamente passado pela coluna de extração, melhorando assim, a ionização desse composto. Porém, acima de 4 minutos de carregamento já não se observa sinal para os compostos de $m / z 215$ e 265, provavelmente por esses serem eluídos pelo excesso de fase móvel. Para os demais compostos, não se observou grandes alterações na resposta com o aumento do tempo de carregamento de 3 para 7 minutos.

Assim, estabeleceu-se o tempo de carregamento em 3,0 minutos por esse tempo permitir a identificação de todos os compostos e com um menor tempo total de análise.

Figura 32: Área absoluta dos picos cromatográficos referentes as SAs estudadas em diferentes tempos de carregamento da amostra para SPE online.

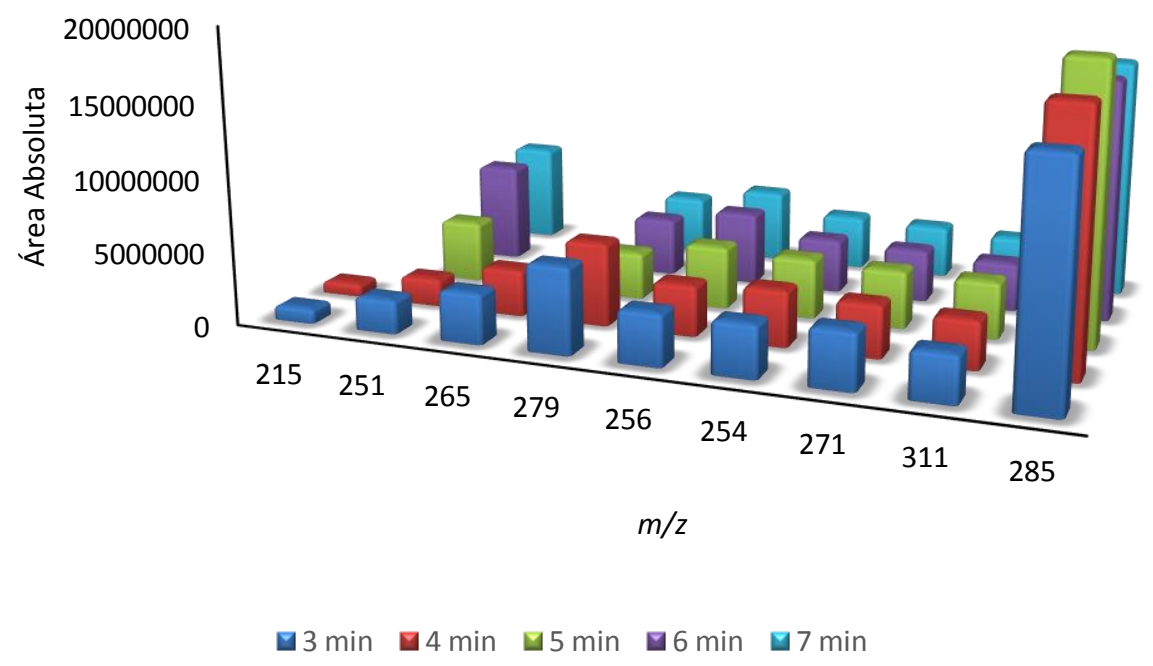

\subsection{Seleção do modo de operação do sistema column swtiching}

Ao se utilizar o método SPE online, a eluição dos compostos de interesse da coluna de concentração pode ser efetuada por dois arranjos instrumentais distintos, denominados de forward flush e backflush. 
Embora a maioria dos trabalhos utilizando column swtiching apresente resultados satisfatórios com os sistemas operando no modo backflush, devido à melhor focalização dos analitos no início da coluna de concentração, neste trabalho foram avaliadas as duas formas.

Na configuração representada na Figura 26, a bomba loading pump $(L P)$ impulsiona os analitos através das colunas de clean-up e de concentração, simultaneamente, enquanto que a bomba NC condiciona a coluna analítica com fase móvel adequada. Com o giro da válvula de 10 pórticos após 3,0 minutos, o solvente contido na bomba $\mathrm{NC}$ é direcionado para a coluna de extração no mesmo sentido de fluxo usado na etapa de carregamento, ocasionando a eluição das SAs e direcionando-as para a coluna de separação. Assim, como não há mudança na direção do fluxo na eluição, esse modo é denominado de forward flush (fluxo direto).

A Figura 25, apresenta a mesma configuração de carregamento da amostra, porém, a configuração instrumental da válvula de 10 pórticos, faz com que, ao ser acionado a mudança de posição da mesma, a eluição ocorra no sentido de fluxo contrário daquele utilizado na etapa de carregamento, sendo assim, denominado de backflush (fluxo inverso).

A desvantagem em se utilizar o método backflush de eluição está no envio indesejado de algum material particulado remanescente no extrato da matriz à coluna analítica diminuindo, assim, sua eficiência e vida útil, caso não tenha a proteção adequada, como filtros e pré-coluna. No modo forward flush, além de atuar como coluna de concentração, essa funcionará como uma proteção adicional a coluna analítica; no entanto, pode-se observar o alargamento do pico cromatográfico de alguns compostos, devido ao maior tempo necessário para a amostra percolar por toda coluna de concentração.

O fator de assimetria dos picos cromatográficos $-F_{S}$, (Figura 33), determinado de acordo a equação 14, pode ser utilizado como ferramenta para avaliar a eficiência do modo de eluição. Picos cromatográficos com $F_{S}>1,2$ apresentam distorção no final do pico, conhecida como cauda, já quando $F_{S}<0,8$, a assimetria é frontal, denominada de fronting. Valores que variam entre 0,8 - 1,2 são considerados satisfatórios, sendo que quanto mais próximo de 1,0, for, melhor será a simetria do pico). 
Figura 33: Medida do fator de assimetria de um pico cromatográfico.

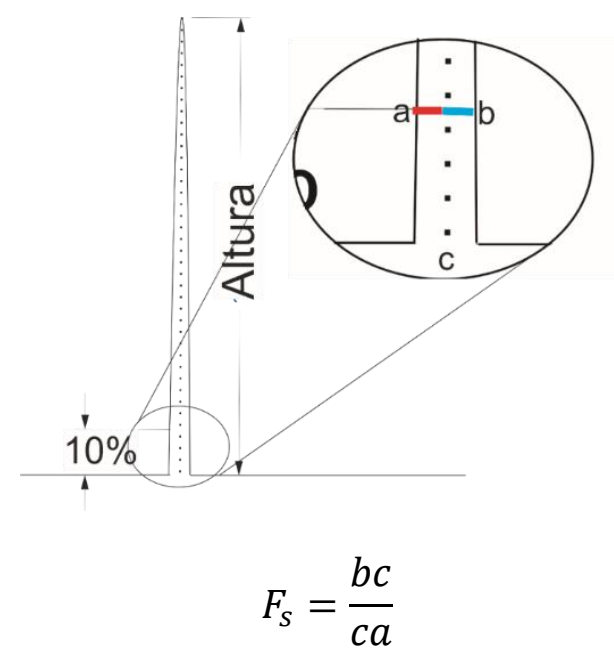

Os resultados obtidos demonstraram que para todas as SAs estudadas a eluição em modo forward flush forneceu picos mais altos e simétricos (Tabela 22), embora não estejam dentro da faixa determinada como satisfatória $(0,8-1,2)$. Esses resultados foram obtidos com a injeção de $40 \mu \mathrm{L}$ de solução das $\mathrm{SAs}$ em $\mathrm{ACN}\left(1,0 \% \mathrm{NH}_{4} \mathrm{OH}\right)$ à concentração de $0,5 \mathrm{mg} \mathrm{L}^{-1}$ e eluição realizada com $\mathrm{ACN}$ e $\mathrm{H}_{2} \mathrm{O}$ ambos com $0,2 \%$ de ácido fórmico na proporção de $\mathrm{ACN}$ inicial de $8,0 \%$ e final de $80 \%$.

Tabela 22: Dados referentes a eluição das SAs estudadas no modo forward flush e backflush

\begin{tabular}{ccc|cc}
\hline \multirow{2}{*}{$\begin{array}{c}\text { Compostos } \\
(\boldsymbol{m} / \boldsymbol{z})\end{array}$} & \multicolumn{3}{c}{ Parâmetros Avaliados } \\
\cline { 2 - 5 } & Forward Flush & Backflush & Forward Flush & Backflush \\
\cline { 2 - 5 } & nd & nd & nd & nd \\
$\mathbf{2 1 5}$ & 1,91 & 2,42 & 1505728 & 903721 \\
$\mathbf{2 6 5}$ & 1,59 & 2,48 & 4077417 & 2230732 \\
$\mathbf{2 7 9}$ & 1,31 & 0,16 & 9768668 & 4638302 \\
$\mathbf{2 5 6}$ & 2,00 & 3,27 & 2581630 & 1989187 \\
$\mathbf{2 5 4}$ & 1,80 & 0,67 & 490459 & 288297 \\
$\mathbf{2 7 1}$ & 1,35 & nd & 1917874 & nd \\
$\mathbf{3 1 1}$ & 1,71 & 3,18 & 11536468 & 6169350 \\
$\mathbf{2 8 5}$ & 1,76 & nd & 682548 & nd \\
\hline
\end{tabular}

nd: não detectado 
O fator de assimetria para a SA m/z 254, obtido no modo backflush foi melhor quando comparado ao obtido no modo forward flush, porém, ao se observar a altura dos picos, nota-se um aumento de $170 \%$ na intensidade do sinal, melhorando assim, a detectabilidade do método. Ademais, ao se observar o cromatograma referente a esse analito com eluição no modo backflush nota-se a distorção do pico cromatográfico (Figura 34).

A sulfonamida de $m / z 215$ (sulfacetamida) não foi identificada em nenhum dos métodos de eluição avaliados. Já para as SAs m/z 271 e 285 foi constatado o aparecimento de picos duplos quanto utilizada a eluição no modo backflush.

Resultados semelhantes foram encontrados ao se analisar quatro estatinas em plasma humano por column swtiching utilizando uma coluna de material de acesso restrito (RAM). Os métodos em forward flush e backflush apresentaram resultados semelhantes quando comparados ao número de pratos, resolução e assimetria dos picos. No entanto, o modo forward flush foi escolhido por proporcionar análises mais rápidas. ${ }^{80}$

Figura 34: Cromatograma referente a eluição da sulfatiazol $(\mathrm{m} / \mathrm{z}, 254)$ no modo forward flush e backflush.

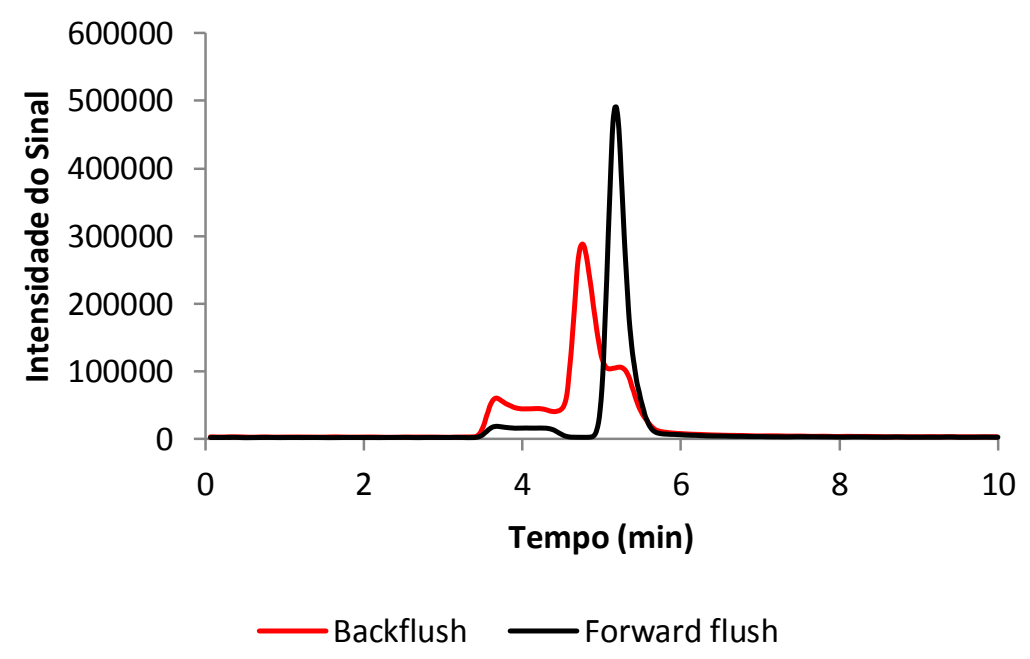

\subsection{Sistema de remoção da amônia residual}

A preocupação inicial em se utilizar um método online de SPE empregando fases aniônicas foi garantir a dissociação dos compostos durante a extração, e a protonação desses para a etapa de eluição. 
Para garantir que todas as sulfonamidas avaliadas estivessem desprotonadas, fez-se uso de acetonitrila e água, ambos com 1,0 \% de $\mathrm{NH}_{4} \mathrm{OH}$, proporcionando valores de $\mathrm{pH}$ na fase aquosa entre $8-9$. No entanto, o volume residual da fase móvel alcalinizada que pode alcançar a coluna analítica não deve ser menosprezado, já que se trata de um sistema capilar. Após injeções consecutivas a eficiência da coluna analítica pode ser prejudicada, visto que a faixa de estabilidade da mesma varia entre valores de $\mathrm{pH}$ de $2-8$.

Tendo em vista essa problemática, dois sistemas foram avaliados a fim de proteger a coluna analítica.

\subsubsection{Sistema A: Remoção da amônia residual utilizada na etapa de carregamento da amostra com água.}

Para garantir que o pH da fase móvel, no momento da eluição dos analitos da coluna de extração, esteja dentro das especificações da coluna analítica, a amônia residual foi removida passando-se água ultrapura por toda coluna aniônica evitando, assim, que a fase móvel alcalinizada remanescente nas tubulações após o carregamento da amostra fosse direcionada para a coluna analítica.

Para essa configuração, uma terceira bomba foi necessária. Trata-se de uma RS Pump (ThermoFisher Scientific ${ }^{\circledR}$ ), operando a uma vazão de $60 \mu \mathrm{L} \mathrm{min}{ }^{-1}$. Como os analitos são aprisionados por uma fase trocadora aniônica forte, a água não tem a força eluente suficiente para removê-los da coluna de extração. De acordo com a Figura 25, essa etapa ocorre mantendose a válvula de 10 pórticos na posição A e alterando a válvula de 6 pórticos para a posição $\mathrm{B}$. Assim, o fluxo de água passará pela coluna de extração no sentido backflush.

Simultaneamente, passa-se pela coluna de clean-up uma maior porcentagem de solvente acetonitrila com 1,0 \% NH $\mathrm{NH}_{4} \mathrm{OH}$, em backflush, para remoção dos interferentes apolares nela retidos.

\subsubsection{Sistema B: Focalização dos analitos na entrada da coluna analítica e ajuste do pH da fase móvel por infusão em $T$.}

Essa configuração teve por objetivo diluir a amônia residual, existente nas conexões da SPE aniônica, na entrada da coluna analítica, com a utilização de uma terceira bomba (bomba RS), operando com $100 \%$ solvente aquoso contendo com $0,2 \%$ ácido fórmico $(v / v)$. Além de 
proporcionar um $\mathrm{pH}$ adequado para a separação analítica, este arranjo visa também a focalização dos analitos no início da coluna, evitando-se a dispersão da banda cromatográfica.

A vazão utilizada na separação cromatográfica foi mantida constante, ou seja, $10 \mu \mathrm{L}$ $\min ^{-1}$, porém, 5,0 $\mu \mathrm{L} \min ^{-1}$ proveniente da bomba NC (com fase móvel composta por ACN e $\mathrm{H}_{2} \mathrm{O} 0,2 \%$ ácido fórmico) e $5,0 \mu \mathrm{L} \mathrm{min}{ }^{-1}$ fornecidos pela bomba $\mathrm{RS}$, de acordo com o sistema representado na Figura 35.

Para as SAs com $m / z$ 271, 311 e 279, o método utilizando a remoção da amônia por lavagem da coluna de extração com água apresentou resultados ligeiramente melhores em relação à área absoluta dos picos cromatográficos, sendo que para as SAs com $m / z 256$ e 251 os resultados obtidos foram muito semelhantes (Figura 36).

Figura 35: Representação gráfica da válvulas de 10 pórticos utilizadas para o desenvolvimento da SPE online com duas colunas acopladas em série e focalização do analitos no início da coluna analítica.

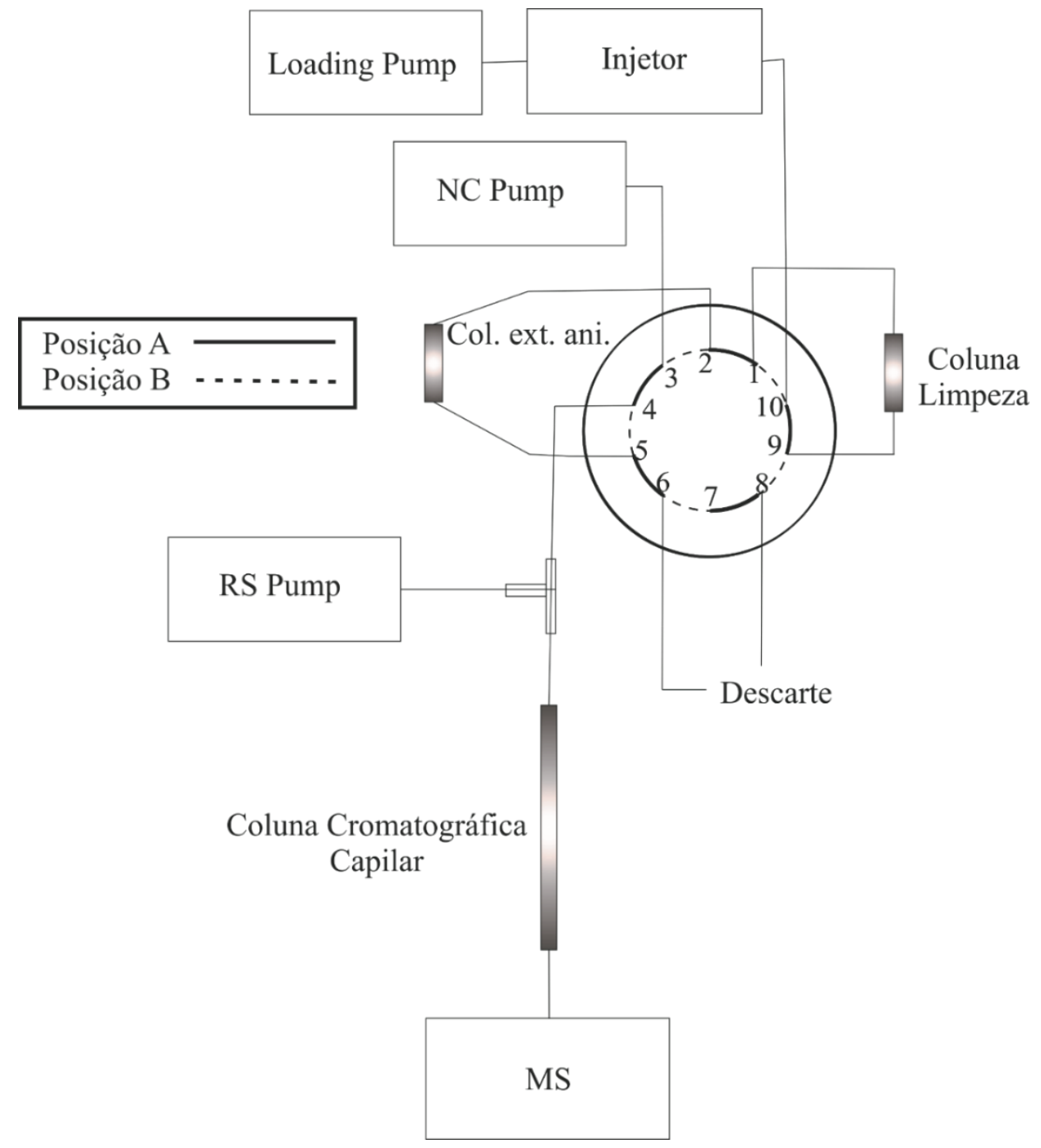


Figura 36: Resultados comparativos entre os dois sistemas utilizados para remoção da fase móvel alcalinizada residual na tubulação do sistema, referentes a área dos picos cromatográficos.

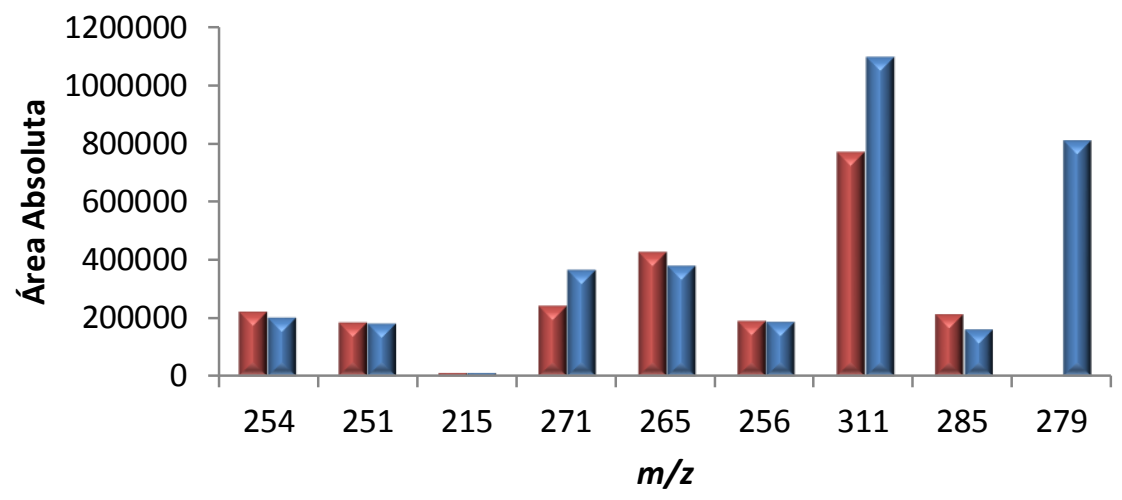

[ Focalização dos analitos na entrada da coluna analítica

回 Remoção com água

No entanto, ao se avaliar a altura dos picos, nota-se que o método com a diluição na entrada da coluna analítica favoreceu a formação de picos mais altos. Muito provavelmente, esses resultados estão correlacionado a focalização dos analitos na entrada da coluna, principalmente para as SAs com $\mathrm{m} / z$ 254, 265, 311 e 285; para as demais, não houve variações muito grandes entre os dois métodos avaliados. A sulfametazina $(\mathrm{m} / z$ 279) não foi adequadamente detectada pelo método utilizando a diluição em $\mathrm{T}$ na entrada na coluna analítica (Figura 37).

Figura 37: Resultados comparativos entre os dois sistemas utilizados para remoção da fase móvel alcalinizada residual na tubulação do sistema, referentes à altura dos picos cromatográficos.

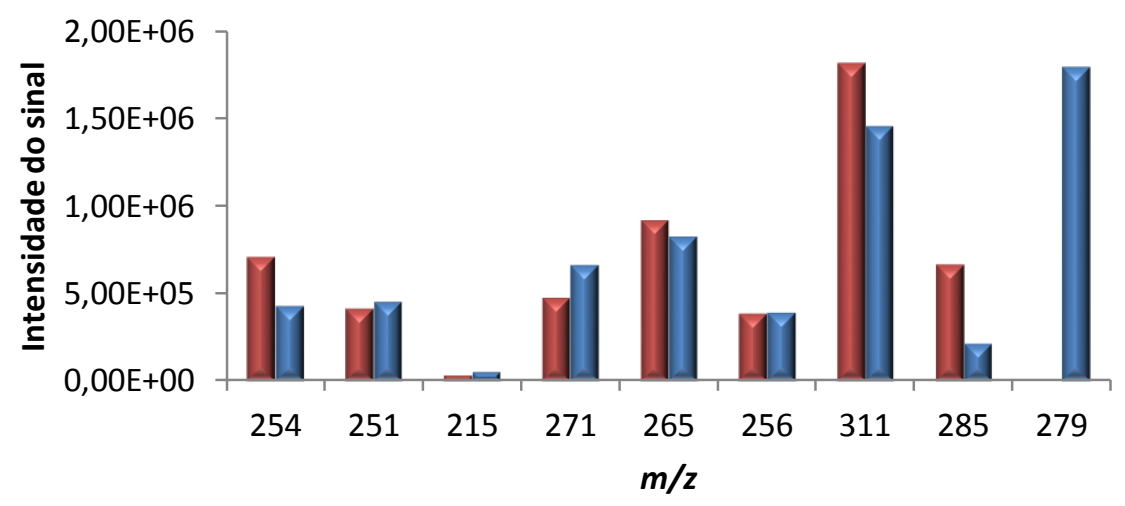

- Focalização dos analitos na entrada da coluna analitica

四emoção com água 
Porém, após várias injeções consecutivas utilizando o método com diluição na entrada da coluna, notou-se perda da reprodutibilidade dos cromatogramas, chegando a casos extremos de nenhuma sulfonamida detectada. Esse fato pode ser atribuído as especificações das bombas utilizadas, visto que, à vazão empregada podem não operar de forma correta, prejudicando a reprodutibilidade do método.

\subsection{Testes de diferentes porcentagens de $\mathrm{ACN}$ utilizada na etapa de carregamento da amostra}

Para garantir a retenção dos interferentes presentes na amostra na primeira coluna é importante que se otimize a porcentagem de acetonitrila utilizada na etapa de carregamento, visto que, a interação dos interferentes nesse solvente pode ser tão grande a ponto de impedir a interação dos mesmos com a fase Strata-X.

Os testes foram realizados fortificando-se a matriz com todas as SA estudadas a 0,5 mg L ${ }^{-1}$, com $\mathrm{pH}$ corrigido com 1,0\% $\mathrm{NH}_{4} \mathrm{OH}$.

A $L P$ foi utilizada mantendo-se na linha b sempre $100 \%$ de $\mathrm{ACN}\left(1,0 \% \mathrm{NH}_{4} \mathrm{OH}\right)$ para promover a limpeza da coluna de Strata-X. As outras linhas foram preenchidas com solução composta por 75,50 e $25 \%$ de $\mathrm{ACN}$ em $\mathrm{H}_{2} \mathrm{O}$ a $1,0 \%$ de $\mathrm{NH}_{4} \mathrm{OH}$.

Os resultados são apresentados na Figura 38, observa-se que o carregamento realizado a $100 \%$ de $\mathrm{ACN}\left(1,0 \% \mathrm{NH}_{4} \mathrm{OH}\right)$ não permite a identificação de alguns compostos (sulfacetamida, sulfadiazina e sulfamerazina). Isso leva a concluir que na presença da matriz esses compostos ou não são retidos na OASIS MAX, devido à saturação dos sítios aniônicos, ou que há a supressão de ionização desses compostos ao alcançar o detector, devido a presença de interferentes que não ficaram retidos na primeira coluna. De posse desses dados, descartouse a possibilidade de trabalhar com a $L P$ operando no modo isocrático a $100 \%$ de $\mathrm{ACN}$.

Com $75 \%$ de $\mathrm{ACN}$ na $L P$, foi possível analisar as SAs que com $100 \%$ de $\mathrm{ACN}$ não foram detectadas, no entanto, para os compostos com $\mathrm{m} / \mathrm{z} 256,271$ e 285 a área obtida para os respectivos picos cromatográficos foram inferiores às obtidas a $100 \%$ de $\mathrm{ACN}$.

Com a $L P$ operando a $50 \%$ de $\mathrm{ACN}$ houve um aumento na área dos picos cromatográficos de todas as SAs, porém, a $25 \%$ de ACN há a diminuição do sinal e aparecimento de picos cromatográficos distorcidos. 
Outro fator importante observado com esse estudo está relacionado com a reprodutibilidade (precisão) dos métodos. Como observado na Tabela 23, o menor desvio padrão relativo (\% DPR) foi encontrado com a $L P$ operando a $50 \%$ de $\mathrm{ACN} 1,0 \% \mathrm{NH}_{4} \mathrm{OH}$.

Figura 38: Gráfico correlacionando as diferentes porcentagens de ACN alcalinizada utilizada na etapa de carregamento da amostra e as respectivas áreas absolutas de cada analito estudado.

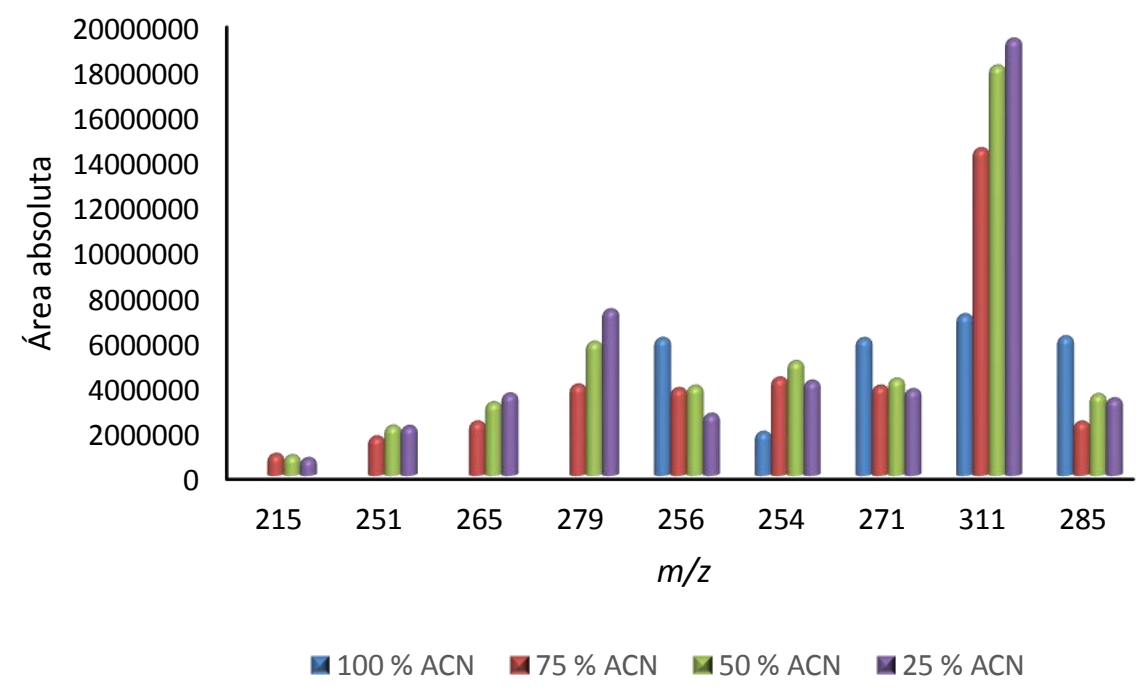

Tabela 23: Desvios padrões relativos (DPR\%) obtidos para as diferentes porcentagens de acetonitrila alcalinizada utilizada na etapa de carregamento da amostra.

\begin{tabular}{|c|c|c|c|c|}
\hline \multirow{2}{*}{$\begin{array}{c}\text { Compostos } \\
(m / z)\end{array}$} & \multicolumn{4}{|c|}{ Desvio Padrão Relativo (\%) para $n=3$} \\
\hline & $100 \% \mathrm{ACN}$ & $75 \% \mathrm{ACN}$ & $50 \% \mathrm{ACN}$ & $25 \% \mathrm{ACN}$ \\
\hline 215 & $\overline{\mathrm{nd}}$ & 7,44 & 1,98 & 6,65 \\
\hline 251 & nd & 9,88 & 2,50 & 0,13 \\
\hline 265 & nd & 9,02 & 1,64 & 6,32 \\
\hline 279 & nd & 4,06 & 2,19 & 4,58 \\
\hline 256 & 13,70 & 8,20 & 0,88 & 42,48 \\
\hline 254 & 66,08 & 1,43 & 4,73 & 19,03 \\
\hline 271 & 13,63 & 0,23 & 1,50 & 14,92 \\
\hline 311 & 70,42 & 5,31 & 0,55 & 2,86 \\
\hline 285 & 17,79 & 10,80 & 2,39 & 2,84 \\
\hline
\end{tabular}

nd: não detectado

Com esses dados foi possível concluir que com o carregamento da amostra realizado a $50 \%$ de ACN permite que a maioria dos interferentes da matriz fique retida na coluna preenchida com Strata-X, permitindo um melhor clean-up da amostra. Assim, as SAs 
desprotonadas podem ser retidas nos sítios ativos da fase aniônica OASIS MAX sendo, posteriormente, eluídas com a $\mathrm{ACN}$ e $\mathrm{H}_{2} \mathrm{O}$ com $0,2 \%$ ácido fórmico.

$\mathrm{O}$ efeito de memória (carry-over) foi avaliado com a injeção de $\mathrm{ACN} 1,0 \% \mathrm{NH}_{4} \mathrm{OH}$, com a intenção de verificar a presença de compostos ainda retidos na coluna de extração. Podese observar, no cromatograma representado na Figura 39, que não há evidências de picos cromatográficos referentes às SAs, com sinal da linha de base na ordem de grandeza de $10^{4}$

Figura 39: Cromatograma referente ao estudo de carry-over utilizando as duas colunas em série, com carregamento da amostra realizado com $50 \% \quad \mathrm{ACN} / \mathrm{H}_{2} \mathrm{O}$ alcalinizada

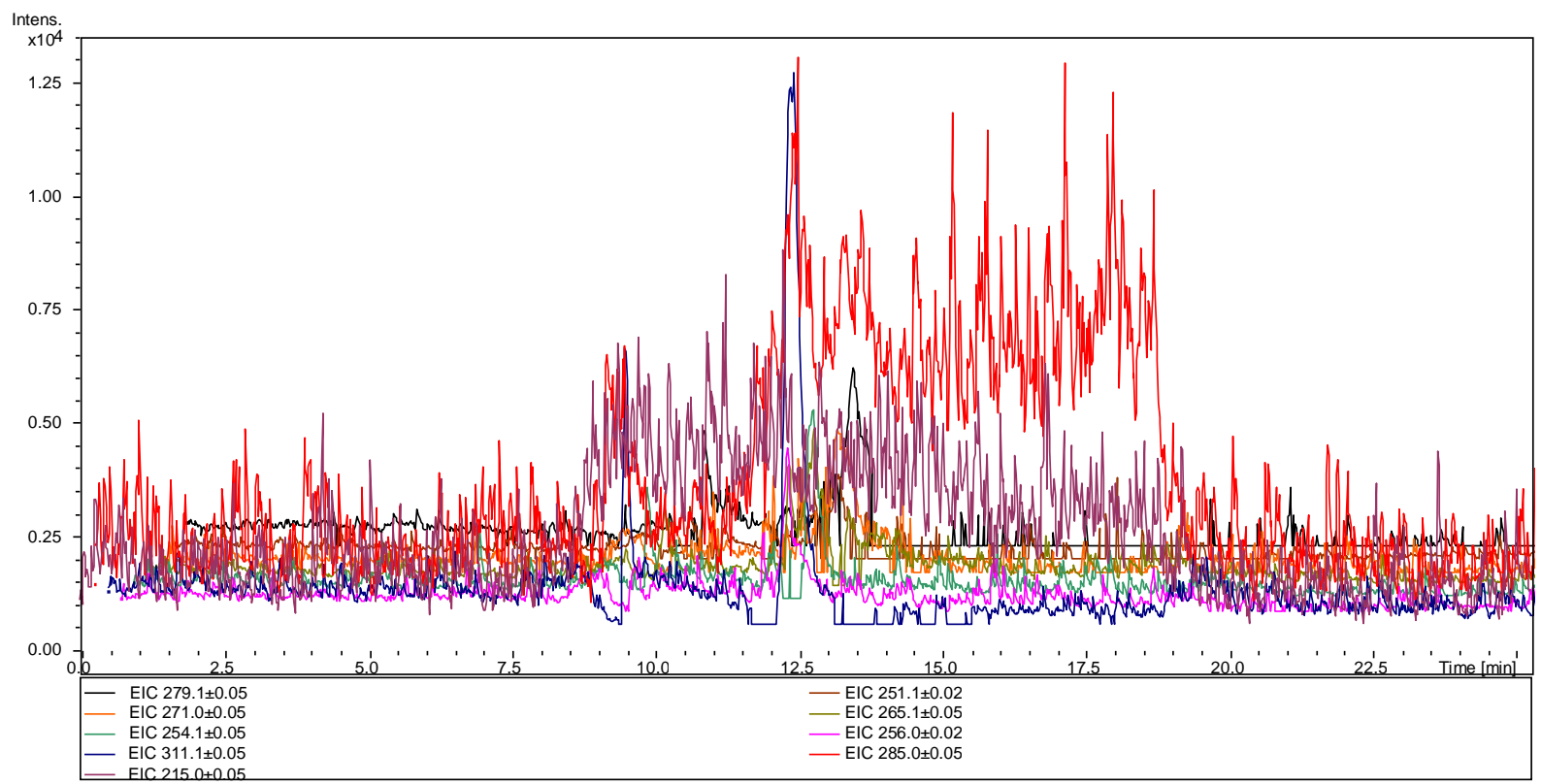

\subsection{Comparação entre resultados obtidos com e sem a presença da coluna Strata-X}

Todos os testes realizados descritos até esse momento foram feitos na presença das duas colunas, a fim de garantir a otimização nas duas dimensões. Porém, com o intuito de se verificar a efetividade da coluna da Strata-X, testes foram realizados na condição otimizada previamente.

Os resultados esperados na ausência da Strata-X relatariam uma menor intensidade do sinal analítico para as sulfonamidas. Isto ocorreria porque uma maior quantidade de interferentes atingiria a coluna preenchida com fase aniônica saturando, assim, os sítios disponíveis para interação com os analitos. Alternativamente, os interferentes podem eluir juntamente com os analitos de interesse causando supressão de ionização dos mesmos. 
Na Figura 40, observa-se que para as sulfametazina, sulfametoxazol e sulfametizol $(\mathrm{m} / \mathrm{z}$ 279, 254 e 271, respectivamente), houve uma diminuição considerável na área absoluta dos picos cromatográficos obtidos na ausência da coluna Strata-X obteve-se valores das áreas absolutas dos picos cromatográficos até $30 \%$ menor do que o valor encontrado na presença da coluna de clean-up preenchida com a fase Strata-X, corroborando assim a hipótese prevista. Para as sulfas cloropiridazina e dimetoxina $(\mathrm{m} / \mathrm{z} 285$ e 311 , respectivamente), os resultados foram menos satisfatórios, atingindo somente $10 \%$ de melhora na presença da coluna de Strata-X.

Para a sulfadiazina, observou-se um aumento de aproximadamente $300 \%$ na área absoluta do pico quando se acoplou as duas colunas em série, ocasionado provavelmente pela forte retenção desse composto na fase polimérica Strata-X. Para os outros analitos não houve alterações significativas nas áreas obtidas.

$\mathrm{Na}$ ausência da coluna de clean-up os picos referentes aos compostos sulfatiazol e sulfamerazina ( $\mathrm{m} / \mathrm{z} 256$ e 265, respectivamente) apresentaram distorções, quando comparados com os picos obtidos na presença da coluna de clean-up (Figura 41). A baixa relação $S / N$ obtida para a sulfacetamida $(\mathrm{m} / \mathrm{z} 215)$ impossibilitou a integração do pico referente a esse composto.

Figura 40: Gráfico de barras referente ao estudo comparativo entre as análises realizadas na presença e ausência da coluna de clean-up em série com uma coluna de extração do tipo trocadora aniônica.

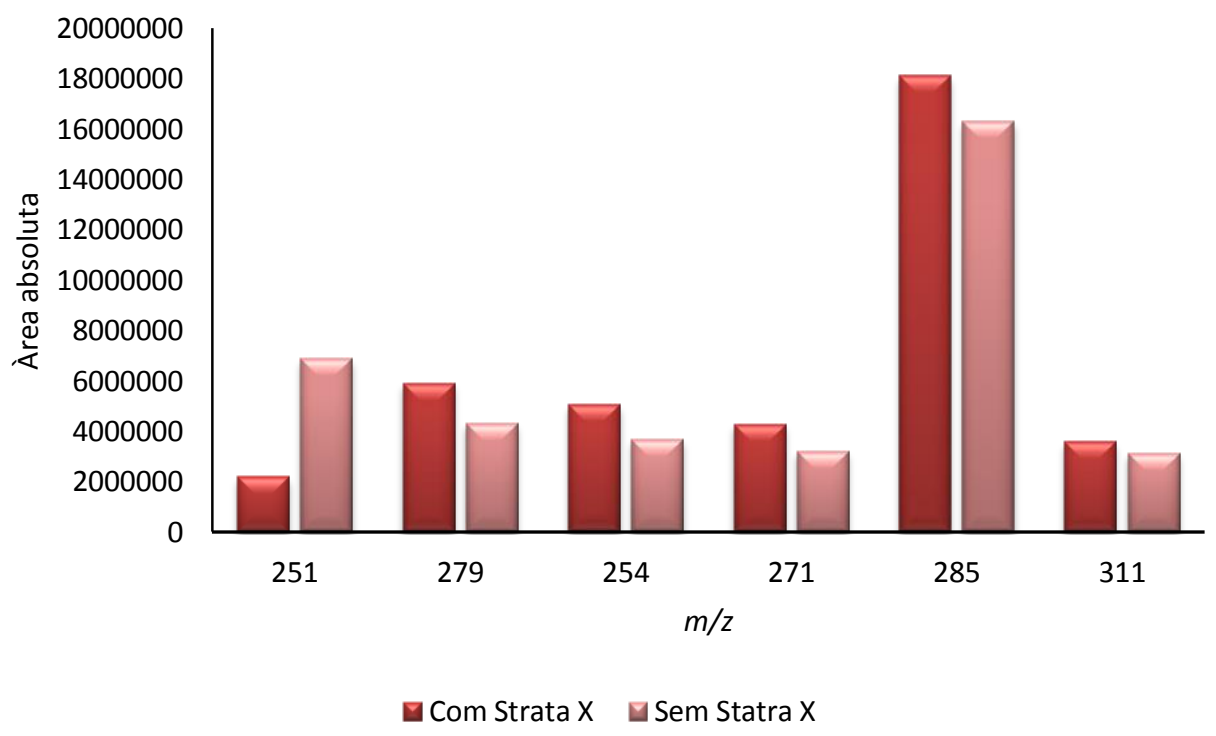


Figura 41: Cromatogramas comparativos entre as extrações realizadas com (- $)$ e sem (- ) a coluna de Strata-X para os compostos com $\mathrm{m} / \mathrm{z}$ (a) 256 e (b) 265
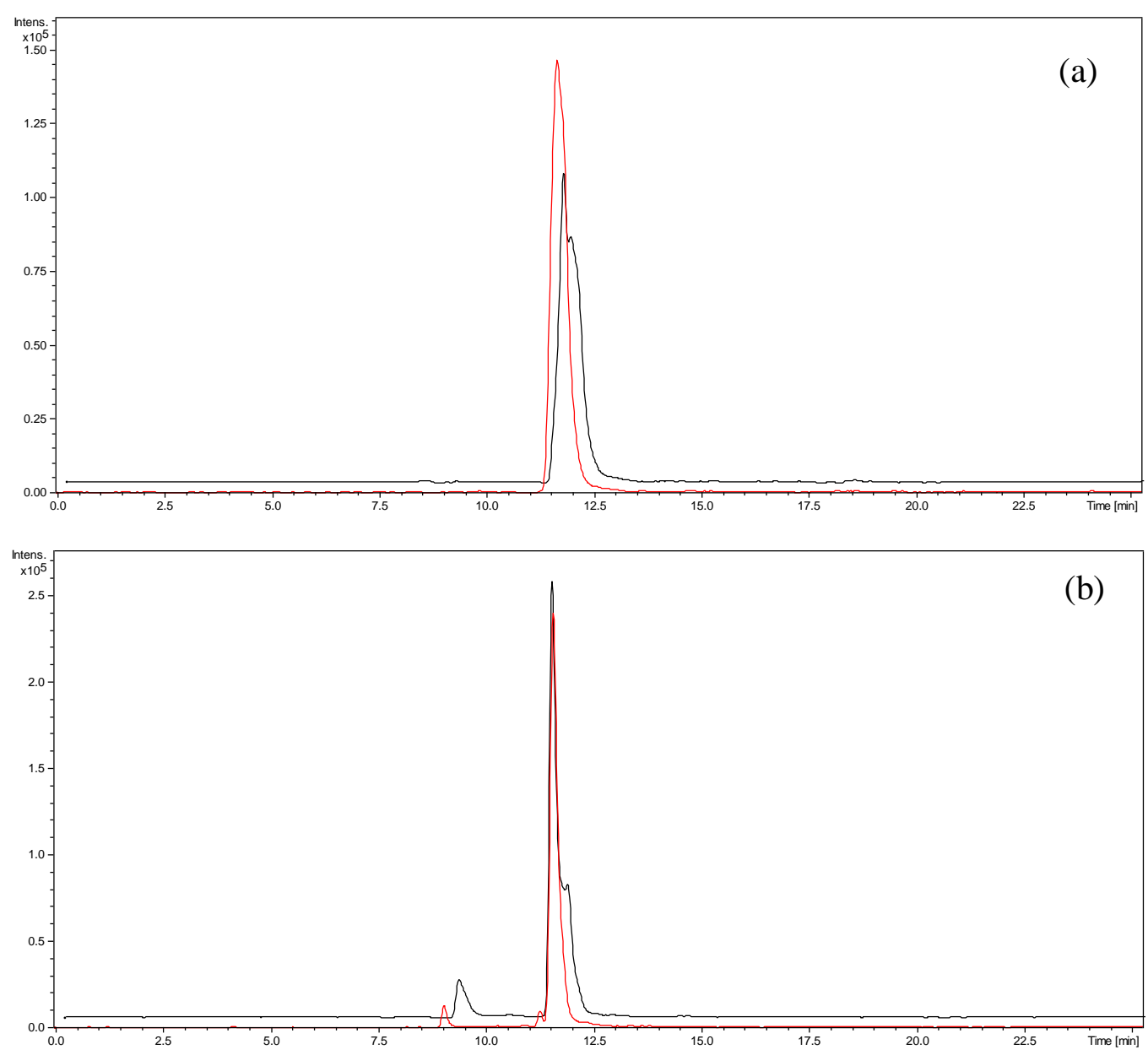

\section{Conclusão do capítulo 4}

Os testes propostos para a elaboração de um sistema online de clean-up e extração de sulfonamidas presentes em extratos constituídos por $100 \%$ solvente orgânico se mostrou uma alternativa promissora, principalmente quando se trata de extratos oriundos de amostras sólidas e complexas.

Normalmente, os procedimentos de preparo de amostras sólidas são lentos e, requerem uma quantidade de solvente orgânico considerável. O sistema online proposto nesse trabalho está acoplado a um cromatógrafo líquido capilar, o que significa menor consumo de solvente orgânico em ambas as etapas (preparo de amostra e análise cromatográfica)

Foi possível verificar boa retenção das SAs estudadas na coluna de extração, constituída por uma fase aniônica forte, Oasis MAX. A utilização de uma coluna acoplada anteriormente a 
de extração, preenchida com a fase polimérica Strata-X, promoveu bom clean-up da amostra, aumentando em até $30 \%$ da área total de algumas sulfonamidas. Porém, ressalta-se a importância do estudo individual dos compostos, visto que, mesmo se tratando da mesma classe, o sistema de clean-up apresentou resultados negativos para algumas sulfonamidas. 



\section{Capítulo 5}

\section{Conclusão geral e perspectivas futuras}





\section{Conclusão geral}

Durante a realização desse trabalho foi possível desenvolver e aplicar metodologias que se enquadram no conceito de química verde, visando sempre, menor consumo de solventes orgânicos e menor impacto ao meio ambiente.

Para a remoção de contaminantes presentes em amostra de solos, foi desenvolvido e aplicado um sistema baseado na extração com fluido supercrítico, utilizando $\mathrm{CO}_{2}$, devido as vantagens inerentes da técnica. No capítulo 2, os resultados referentes a esse trabalho foram apresentados, comprovando a elevada eficiência na remoção de compostos orgânicos monoaromáticos (BTEX) presentes em amostra de solo. A SPME foi utilizada como técnica de preparo de amostra, permitindo assim, obter limites de detecção e quantificação satisfatórios.

O capítulo 3 apresentou um método analítico para extração de sulfonamidas presentes em lodo de esgoto, utilizando o procedimento QuEChERS para o preparo de amostra e LC-ESIToF para separação e detecção dos analitos. Os resultados obtidos com a validação do método foram adequados, com faixa linear variando de 15 a $800 \mathrm{ng} \mathrm{g}^{-1}$. O efeito de matriz observado já era esperado, devido à complexidade da amostra utilizada, fato que pode ser melhorado com uma etapa de clean-up mais eficiente.

O capitulo 4 aborda o desenvolvimento instrumental de um sistema para SPE online capilar, visando o clean-up e extração de analitos presentes em amostras complexas. Para isso, utilizou-se duas colunas capilares acopladas em série, permitindo obter um aumento em até $30 \%$ na extração de algumas sulfonamidas presentes em lodo de esgoto. Com esse sistema, extratos obtidos após extração do tipo liquido-liquido ou liquido-sólido constituído por $100 \%$ solvente orgânicos, podem ser injetados diretamente no sistema online.

\section{Perspectivas futuras}

Os estudos referentes ao desenvolvimento do sistema online de clean-up e concentração de analitos provenientes de amostras complexas se mostrou promissor para a extração de algumas sulfonamidas presentes em lodo de esgoto.

Como se trata de um sistema versátil, o espectro de aplicação é bastante amplo, podendo-se variar tanto a configuração das colunas quanto a fase utilizada como sorbente. Nesse trabalho, outras fases poderiam ter sido utilizadas como preenchimento para coluna de 
clean-up como, por exemplo, fase aniônica fraca (Oasis WAX), favorecendo melhores resultados na extração devido a retenção tanto de compostos apolares como iônicos presentes na matriz.

Após a seleção do melhor tipo de fase extratora utilizada na etapa de clean-up, a validação do método deverá ser realizada, avaliando parâmetros como linearidade, limite de quantificação, fator de concentração e precisão, possibilitando assim, a comparação direta desse sistema com sistemas de SPE online normalmente encontrados. 


\section{Bibliografia}

1 SEMPLE, K. T.; MORRISS, W. J.; PATON, G. I. Bioavailability of hydrophobic organic contaminants in soils : fundamental concepts and techniques for analysis. European Journal of Soil Science, v. 54, n. 12, p. 809-818, 2003.

2 DOU, J.; LIU, X.; HU, Z. Anaerobic BTEX degradation in soil bioaugmented with mixed consortia under nitrate reducing conditions. Journal of environmental sciences (China), $v$. 20, n. 5, p. 585-92, 2008.

3 ESTEVE-TURRILlAS, F. A; ARMENTA, S.; GARRIGUES, S.; PASTOR, A; DE LA GUARDIA, M. Headspace-mass spectrometry determination of benzene, toluene and the mixture of ethylbenzene and xylene isomers in soil samples using chemometrics. Analytica chimica acta, v. 587, n. 1, p. 89-96, 2007.

4 PINEDO, J.; IBÁÑEZ, R.; LIJZEN, J. P. A.; IRABIEN, Á. Assessment of soil pollution based on total petroleum hydrocarbons and individual oil substances. Journal of environmental management, v. 130,n. 1, p. 72-9, 2013.

5 Companhia Ambiental do Estado de São Paulo. Disponível em $\langle$ http://www.cetesb.sp.gov.br/Solo/relatorios/tabela valores 2005.pdf >. Acesso em: 01 mar. 2013.

6 GOMES, H. I.; DIAS-FERREIRA, C.; RIBEIRO, A. B. Overview of in situ and ex situ remediation technologies for PCB-contaminated soils and sediments and obstacles for fullscale application. The Science of the total environment, v. 445-446, n. 1, p. 237-60, 2013.

7 KEMPA, T. et al. In-situ remediation of the contaminated soils in Ostrava city (Czech Republic) by steam curing/vapor. Engineering Geology, v. 154, n. 1, p. 42-55, 2013.

8 CHEN, Z.; MEI, X.; JIN, Y.; KIM, E.-H.; YANG, Z.; TU, Y. Optimisation of supercritical carbon dioxide extraction of essential oil of flowers of tea (Camellia sinensis L.) plants and its antioxidative activity. Journal of the science of food and agriculture, v. 94, n. 2, p. 316-21, 2014.

9 GARCÍA-RODRÍGUEZ, D.; CARRO-DÍAZ, A. M.; LORENZO-FERREIRA, R. A. Supercritical fluid extraction of polyhalogenated pollutants from aquaculture and marine environmental samples: a review. Journal of separation science, v. 31, n. 8, p. 1333-45, 2008.

10 IVANOV, D.; ČOLOVIĆ, R.; BERA, O.; LEVIĆ, J.; SREDANOVIĆ, S. Supercritical fluid extraction as a method for fat content determination and preparative technique for fatty acid analysis in mesh feed for pigs. European Food Research and Technology, v. 233, n. 2, p. 343-350, 2011.

11 BASSETO, F. A.; LANÇAS, F. M. Supercritical fluid extraction followed by gas chromatography-mass spectrometry determination of electrical-grade insulating oil residues from activated bauxite. Scientia Chromatographica, v. 6, n. 1, p. 41-49, 2014. 
12 PINTO, J. S. S.; LANÇAS, F. M. Design, construction and evaluation of a simple pressurized solvent extraction system. Journal of the Brazilian Chemical Society, v. 20, n. 5, p. 913-917, 2009.

13 NOSSACK, A. C.; VILEGAS, J. H. Y.; BAER, D. VON; LANÇAS, F. M. Supercritical fluid extraction and chromatographic analysis (HRGC-FID and HRGC-MS) of Lupinus spp. alkaloids. Journal of the Brazilian Chemical Society, v. 11, n. 5, p. 495-501, 2000.

14 MARASCHIN, M.; SUGUI, J. A.; WOOD, K. V; BONHAM, C.; LANÇAS, F. M.; ARAUJO, P. S.; VERPOORTE, R.; FONTANA, J. D. Supercritical CO 2 extraction of velutinol A from Mandevilla velutina (Apocynaceae ) cultured cells and MALDI-TOF MS analysis. p. 77-82, 2001.

15 BAHIA FILHO, O.; PRADA, P. R.; MENEGHESSO, C.; LANÇAS, F. M. Desvendando a medição nos ensaios químicos: 1 . A curva analítica ou de calibração. Scientia Chromatographica, v. 3, n. 3, p. 251-261, 2011.

16 RIVERO-HUGUET, M.; MARSHALL, W. D. Scaling up a treatment to simultaneously remove persistent organic pollutants and heavy metals from contaminated soils.

Chemosphere, v. 83, p. 668-673, 2011.

17 AMEZCUA-ALLIERI, M. A.; ÁVILA-CHÁVEZ, M. A.; TREJO, A.; MELÉNDEZESTRADA, J. Removal of polycyclic aromatic hydrocarbons from soil: A comparison between bioremoval and supercritical fluids extraction. Chemosphere, v. 86, p. 985-993, 2012.

18 COCERO, M. J.; ALONSO, E.; LUCAS, S. Pilot Plant for Soil Remediation with Supercritical CO 2 under Quasi-Isobaric Conditions. Industrial \& Engineering Chemistry Research, v. 39, n. 12, p. 4597-4602, 2000.

19 TAYLOR, L. T. Supercritical fluid extraction. 1. ed. Canada: John Wiley, 1996s. p. 18.

20 POLLET, P.; DAVEY, E. A.; UREÑA-BENAVIDES, E. E.; ECKERT, C. A.; LIOTTA, C. L. Solvents for sustainable chemical processes. Green Chemistry, v. 16, n. 3, p. 1034, 2014.

21 KOINECKE, A.; KREUZIG, R.; BAHADIR, M. Effects of modifiers, adsorbents and eluents in supercritical fluid extraction of selected pesticides in soil. Journal of Chromatography A, v. 786, n. 1, p. 155-161, 1997.

22 MCBRIDE, M.; WYCKOFF, J. Emerging Liabilities from Pharmaceuticals and Personal Care Products. Environmental Claims Journal, v. 14, n. 2, p. 175-189, 2002.

23 Word Health Organization. Classifications. The Anatomical Therapeutic Chemical Classification System with Defined daily Doses. Oraganização Global. 2013. Disponível em: http://www.imshealth.com/portal/site/imshealth/menuitem.c76283e8bf81e98f53c753c71ad8c 22a/?vgnextoid=4d47d1822e678310VgnVCM10000076192ca2RCRD\&vgnextfmt=default. Acesso em 12 de dez. 2014. 
24 MANZETTI, S.; GHISI, R. The environmental release and fate of antibiotics. Marine pollution bulletin, v. 79, n. 1-2, p. 7-15, 2014.

25 CLARA, M.; KREUZINGER, N.; STRENN, B.; GANS, O.; KROISS, H. The solids retention time-a suitable design parameter to evaluate the capacity of wastewater treatment plants to remove micropollutants. Water research, v. 39, n. 1, p. 97-106, 2005.

26 JOSS, A.; ZABCZYNSKI, S.; GÖBEL, A.; HOFFMANN, B.; LÖFFLER, D.; MCARDELL, C. S.; TERNES, T. A.; THOMSEN, A.; SIEGRIST, H. Biological degradation of pharmaceuticals in municipal wastewater treatment: proposing a classification scheme.

Water research, v. 40, n. 8, p. 1686-96, 2006.

27 KANDA, R.; GRIFFIN, P.; JAMES, H. A.; FOTHERGILL, J. Pharmaceutical and personal care products in sewage treatment works. Journal of Environmental Monitoring, v. 5, n. 5, p. 823, 2003.

28 TAUXE-WUERSCH, A.; DE ALENCASTRO, L. F.; GRANDJEAN, D.;

TARRADELLAS, J. Occurrence of several acidic drugs in sewage treatment plants in Switzerland and risk assessment. Water research, v. 39, n. 9, p. 1761-72, 2005.

29 VIENO, N.; TUHKANEN, T.; KRONBERG, L. Elimination of pharmaceuticals in sewage treatment plants in Finland. Water research, v. 41, n. 5, p. 1001-12, 2007.

30 HERNÁNDEZ, T.; MORENO, J. I.; COSTA, F. Influence of sewage sludge application on crop yields and heavy metal availability. Soil Science and Plant Nutrition, v. 37, n. 2, p. 201-210, 1991.

31 BRASIL. Ministério do Desenvolvimento Urbano e Meio Ambiente. CONAMA. Resolução no 357 de 29 de Agosto de 2006. Diário Oficial da União, Brasilia 02 de março de 2006. Seção I, 32.

32 ARVANITI, O. S.; ASIMAKOPOULOS, A. G.; DASENAKI, M. E.; VENTOURI, E. I.; STASINAKIS, A. S.; THOMAIDIS, N. S. Simultaneous determination of eighteen perfluorinated compounds in dissolved and particulate phases of wastewater, and in sewage sludge by liquid chromatography-tandem mass spectrometry. Analytical Methods, v. 6, n. 5, p. 1341, 2014.

33 YANG, Y.; WU, L. Analysis of endocrine disrupting compounds, pharmaceuticals and personal care products in sewage sludge by gas chromatography-mass spectrometry. Talanta, v. 89, n. 1, p. $258-263,2012$.

34 YANG, S.-F.; LIN, C.-F.; WU, C.-J.; NG, K.-K.; LIN, A. Y.-C.; HONG, P.-K. A. Fate of sulfonamide antibiotics in contact with activated sludge--sorption and biodegradation. Water Research, v. 46, n. 1, p. 1301 - 1308, 2012.

35 BARAN, W.; ADAMEK, E.; ZIEMIAŃSKA, J.; SOBCZAK, A. Effects of the presence of sulfonamides in the environment and their influence on human health. Journal of hazardous materials, v. 196, n. 1, p. 1-15, 2011. 
36 QIANG, Z.; ADAMS, C. Potentiometric determination of acid dissociation constants (pKa) for human and veterinary antibiotics. Water research, v. 38, n. 12, p. 2874-90, 2004.

37 PAMREDDY, A.; HIDALGO, M.; HAVEL, J.; SALVADÓ, V. Determination of antibiotics (tetracyclines and sulfonamides) in biosolids by pressurized liquid extraction and liquid chromatography-tandem mass spectrometry. Journal of chromatography A, v. 1298, n. 1, p. 68-75, 2013.

38 GOBEL, A.; THOMSEN, A.; MCARDELL, C. S.; ALDER, A. C.; GIGER, W.; THEIB, N.; DIRK, L.; TERNES, T. A. Extraction and determination of sulfonamides, macrolides, and trimethoprim in sewage sludge. Journal of Chromatography A, v. 1085,n. 1, p. 179-189, 2005 .

39 MigliORE, L.; CIVITAREALE, C.; BRAMBILLA, G.; DELUPIS, G. D. DI. Toxicity of several important agricultural antibiotics to Artemia. Water Research, v. 31, n. 7, p. 18011806, 1997.

40 SARMAH, A. K.; MEYER, M. T.; BOXALL, A. B. A. A global perspective on the use, sales, exposure pathways, occurrence, fate and effects of veterinary antibiotics (VAs) in the environment. Chemosphere, v. 65, n. 5, p. 725-59, 2006.

41 KATAOKA, H. New trends in sample preparation for clinical and pharmaceutical analysis. TrAC Trends in Analytical Chemistry, v. 22, n. 4, p. 232-244, 2003.

42 ZHANG, Z.; PAWLISZYN, J. Headspace Solid-Phase Microextraction. Analytical Chemistry, v. 65, p. 1843-1852, 1993.

43 ALMEIDA, C.; ROSÁRIO, P.; SERÔDIO, P.; NOGUEIRA, J.M.F. Novas perspectivas na preparação de amostras para análise cromatográfica. Química, v. 95, p. 69-77, 2009.

44 DE FÁTIMA ALPENDURADA, M. Solid-phase microextraction: a promising technique for sample preparation in environmental analysis. Journal of Chromatography A, v. 889, n. 1-2, p. 3-14, 2000.

45 ANASTASSIADES, M.; LEHOTAY, S. J.; ŠTAJNBAHER, D.; SCHENCK, F. J. Fast and easy multiresidue method employing acetonitrile extraction/partitioning and "dispersive solid-phase extraction" for the determination of pesticide residues in produce. Journal of AOAC International, v. 86, n. 2, p. 412-431, 2003.

46 CIEŚLIK, E.; SADOWSKA-ROCIEK, A.; RUIZ, J. M. M.; SURMA-ZADORA, M. Evaluation of QuEChERS method for the determination of organochlorine pesticide residues in selected groups of fruits. Food Chemistry, v. 125, n. 2, p. 773-778, 2011.

47 CERVERA, M. I.; PORTOLÉS, T.; PITARCH, E.; BELTRÁN, J.; HERNÁNDEZ, F. Application of gas chromatography time-of-flight mass spectrometry for target and non-target analysis of pesticide residues in fruits and vegetables. Journal of chromatography. A, v. 1244, n. 1, p. 168-77, 2012.

48 ZHANG, W.; XU, J.; DONG, F.; LIU, X.; ZHANG, Y.; TAO, Y.; WU, X.; ZHENG, Y. Simultaneous determination of three strobilurin fungicide residues in fruits, vegetables and 
soil by a modified quick, easy, cheap, effective, rugged (QuEChERS) method coupled with gas chromatography-tandem mass spectrometry. Analytical Methods, v. 5, n. 24, p. 7102, 2013.

49 PADILLA-SÁNCHEZ, J. A.; PLAZA-BOLAÑOS, P.; ROMERO-GONZÁLEZ, R.; GARRIDO-FRENICH, A.; MARTÍNEZ VIDAL, J. L. Application of a quick, easy, cheap, effective, rugged and safe-based method for the simultaneous extraction of chlorophenols, alkylphenols, nitrophenols and cresols in agricultural soil, analyzed by using gas chromatography-triple quadrupole-mass spectro. Journal of Chromatography A, v. 1217, p. 5724-5731, 2010.

50 PEYSSON, W.; VULLIET, E. Determination of 136 pharmaceuticals and hormones in sewage sludge using quick, easy, cheap, effective, rugged and safe extraction followed by analysis with liquid chromatography-time-of-flight-mass spectrometry. Journal of chromatography. A, v. 1290, p. 46-61, 2013.

51 BUSZEWSKI, B.; SZULTKA, M. Past, Present, and Future of Solid Phase Extraction: A Review. Critical Reviews in Analytical Chemistry, v. 42, n. 3, p. 198-213, 2012.

52 NAZARIO, CARLOS EDUARDO DOMINGUES. Desenvolvimento e caracterização de materiais baseados em sílica com aplicabilidade em extração em fase sólida e cromatografia líquida de alta eficiência. 2013. 225f. Tese (Doutorado em Química Analítica e Inorgânica) - Instituto de Química de São Carlos, Universidade de São Paulo, São Carlos, 2013.

53 FONTANALS, N.; CORMACK, P. A. G.; SHERRINGTON, D. C.; MARCÉ, R. M.; BORRULL, F. Weak anion-exchange hypercrosslinked sorbent in on-line solid-phase extraction-liquid chromatography coupling to achieve automated determination with an effective clean-up. Journal of Chromatography A, v. 1217, p. 2855-2861, 2010.

54 LANÇAS, F. M. Cromatografia Liquida Moderna : HPLC/CLAE. $1^{\circ}$. ed. Campinas: Átomo, 2009. p. 384.

55 SILVA, R. G. DA C.; COLLINS, C. H.; BOTTOLI, C. B. G. Capillary liquid chromatography: state of the art and current applications. Química Nova, v. 34, n. 5, p. 841849, 2011.

56 SWARTZ, M. E. UPLC ${ }^{\mathrm{TM}}$ : An Introduction and Review. Journal of Liquid Chromatography \& Related Technologies, v. 28, n. 7-8, p. 1253-1263, 2005.

57 CHERVET, J. P.; URSEM, M.; SALZMANN, J. P. Instrumental requirements for nanoscale liquid chromatography. Analytical chemistry, v. 68, n. 9, p. 1507-12, 1996.

58 SAITO, Y.; JINNO, K.; GREIBROKK, T. Capillary columns in liquid chromatography: between conventional columns and microchips. Journal of Separation Science, v. 27, n. 17 18, p. 1379-1390, 2004.

59 SZUMSKI, M.; BUSZEWSKI, B. State of the Art in Miniaturized Separation Techniques. Critical Reviews in Analytical Chemistry, v. 32, n. 1, p. 1-46, 2002. 
60 COUTINHO, L. F. M.; LANÇAS, F. M. Cromatografia Líquida Capilar1. Principais Características da Técnica. Scientia Chromatographica, v. 3, n. 2, p. 115-130, 2011.

61 FERREIRA, S. L. C. et al. Box-Behnken design: an alternative for the optimization of analytical methods. Analytica chimica acta, v. 597, n. 2, p. 179-86, 2007.

62 NETO, B. B.; SCARMINIO, I. S.; BRUNS, R. E. Como fazer experimentos. São Paulo: Unicamp, 2007. 480p.

63 BEZERRA, M. A.; SANTELLI, R. E.; OLIVEIRA, E. P.; VILLAR, L. S.; ESCALEIRA, L. A. Response surface methodology (RSM) as a tool for optimization in analytical chemistry. Talanta, v. 76, n. 5, p. 965-77, 2008.

64 BRASIL, AGÊNCIA NACIONAL DE VIGILÂNCIA SANITÁRIA (ANVISA). Guia para métodos analíticos e bioanalíticos, Resolução RE nº 899 ANVISA, 29 de maio de 2003.

65 MULHOLLAND, M.; HIBBERT, D. B. Linearity and the limitations of least squares calibration. Journal of Chromatography A, v. 762, n. 1-2, p. 73-82, 1997.

66 ALMEIDA, A. .; CASTEL-BRANCO, M. .; FALCÃO, A. . Linear regression for calibration lines revisited: weighting schemes for bioanalytical methods. Journal of Chromatography B, v. 774, n. 2, p. 215-222, 2002.

67 MARTENDAL, E.; CARASEK, E. A new approach based on a combination of direct and headspace cold-fiber solid-phase microextraction modes in the same procedure for the determination of polycyclic aromatic hydrocarbons and phthalate esters in soil samples. Journal of chromatography. A, v. 1218, n. 13, p. 1707-14, 2011.

68 SARGENTI, S. R.; LANÇAS, F. M. Design and construction of a simple supercritical fluid extraction system with semi-preparative and preparative capabilities for application to natural products. Journal of Chromatography A, v. 667, p. 213-218, 1994.

69 U. S. ENVIRONMENTAL PROTECTION AGENCY. Volatile/Semivolatile data validation functional guidelines - Part II.Washington, D.C: EPA, 1996. Disponível em: <http://www.epa.gov/region1/oeme/PART2.pdf> Acessado em 20/09/2012.

70 GONÇALVES, C.; CARVALHO, J. J.; AZENHA, M. A; ALPENDURADA, M. F. Optimization of supercritical fluid extraction of pesticide residues in soil by means of central composite design and analysis by gas chromatography-tandem mass spectrometry. Journal of chromatography. A, v. 1110, n. 1-2, p. 6-14, 2006.

71 LI, S.; LIU, X.; ZHU, Y.; DONG, F.; XU, J.; LI, M.; ZHENG, Y. A statistical approach to determine fluxapyroxad and its three metabolites in soils, sediment and sludge based on a combination of chemometric tools and a modified quick, easy, cheap, effective, rugged and safe method. Journal of chromatography. A, v. 1358, p. 46-51, 2014.

72 MATUSZEWSKI, B. K.; CONSTANZER, M. L.; CHAVEZ-ENG, C. M. Strategies for the Assessment of Matrix Effect in Quantitative Bioanalytical Methods Based on HPLC-MS/MS. Analytical Chemistry, v. 75, n. 13, p. 3019-3030, 2003. 
73 BOURDAT-DESCHAMPS, M.; LEANG, S.; BERNET, N.; DAUDIN, J.-J.; NÉLIEU, S. Multi-residue analysis of pharmaceuticals in aqueous environmental samples by online solidphase extraction-ultra-high-performance liquid chromatography-tandem mass spectrometry: Optimisation and matrix effects reduction by quick, easy, cheap, effective, . Journal of chromatography. A, v. 1349, p. 11-23, 2014.

74 TRUFELLI, H.; PALMA, P.; FAMIGLINI, G.; CAPPIELLO, A. An overview of matrix effects in liquid chromatography-mass spectrometry. Mass spectrometry reviews, v. 30, n. 3, p. 491-509, 2010.

75 KING, R.; BONFIGLIO, R.; FERNANDEZ-METZLER, C.; MILLER-STEIN, C.; OLAH, T. Mechanistic investigation of ionization suppression in electrospray ionization. Journal of the American Society for Mass Spectrometry, v. 11, n. 11, p. 942-50, 2000.

76 HERRERO, P.; BORRULL, F.; POCURULL, E.; MARCÉ, R. M. A quick, easy, cheap, effective, rugged and safe extraction method followed by liquid chromatography-(Orbitrap) high resolution mass spectrometry to determine benzotriazole, benzothiazole and benzenesulfonamide derivates in sewage sludge. Journal of chromatography. A, v. 1339, p. 34-41, 2014.

77 DUBREIL-CHÉNEAU, E.; PIROTAIS, Y.; VERDON, E.; HURTAUD-PESSEL, D. Confirmation of 13 sulfonamides in honey by liquid chromatography-tandem mass spectrometry for monitoring plans: validation according to European Union Decision 2002/657/EC. Journal of chromatography. A, v. 1339, p. 128-36, 2014.

78 PAN, J.; ZHANG, C.; ZHANG, Z.; LI, G. Review of online coupling of sample preparation techniques with liquid chromatography. Analytica chimica acta, v. 815, p. 1-15, 2014.

79 CARVALHO, LUCAS SPONTON. Desenvolvimento e validação de métodos analíticos para avaliação de remoção de sulfonamidas no tratamento de águas residuárias em reatores biológicos de leito fixo. 2013.135f. Dissertação (Mestrado em Química Analítica e Inorgânica) - Instituto de Química de São Carlos, Universidade de São Paulo, São Carlos, 2013.

80 FAGUNDES, V. F.; LEITE, C. P.; PIANETTI, G. A.; FERNANDES, C. Rapid and direct analysis of statins in human plasma by column-switching liquid chromatography with restricted-access material. Journal of chromatography. B, Analytical technologies in the biomedical and life sciences, v. 947-948, p. 8-16, 2014. 